\title{
unesp
}

UNIVERSIDADE ESTADUAL PAULISTA

FACULDADE DE ENGENHARIA CAMPUS DE BAURU

\section{Avaliação da suscetibilidade eletromagnética dos cabos metálicos dos sistemas de supervisão, proteção, comunicação e controle de subestações de alta tensão}




\section{unssp \\ UNIVERSIDADE ESTADUAL PAULISTA \\ FACULDADE DE ENGENHARIA \\ CAMPUS DE BAURU}

Curso de Pós-Graduação em Engenharia Elétrica

\section{Avaliação da suscetibilidade eletromagnética dos cabos metálicos dos sistemas de supervisão, proteção, comunicação e controle de subestações de alta tensão}

Antonio Carlos Passos Sartin

Orientador:

Prof. Dr. José Alfredo Covolan Ulson 
Sartin, Antonio Carlos Passos.

Avaliação da suscetibilidade eletromagnética dos cabos metálicos dos sistemas de supervisão, proteção, comunicação e controle de subestações de alta tensão / Antonio Carlos Passos Sartin, 2010.

$127 \mathrm{f}$.

Orientador: José Alfredo Covolan Ulson

Dissertação (Mestrado)-Universidade Estadual Paulista. Faculdade de Engenharia, Bauru, 2010

1. Interferência eletromagnética. 2 . Compatibilidade eletromagnética. 3. Cabos metálicos blindados. I. Universidade Estadual Paulista.

Faculdade de Engenharia. II. Título. 


\title{
UNIVERSIDADE EstaduAL PaULISTA \\ "JÚLIO DE MESQUITA FILHO" \\ CAMPUS DE BAURU
FACULDADE DE ENGENHARIA DE BAURU
}

\begin{abstract}
ATA DA DEFESA PÚBLICA DA DISSERTAÇĀO DE MESTRADO DE ANTONIO CARLOS PASSOS SARTIN, DISCENTE DO PROGRAMA DE PÓS-GRADUAÇÁO EM ENGENHARIA ELETTRICA, DO(A) FACULDADE DE ENGENHARIA DE BAURU.
\end{abstract}

Aos 27 dias do mês de janeiro do ano de 2010, às 10:00 horas, no(a) ANFITEATRO DA PÓSGRADUAÇAO, reuniu-se a Comissâo Examinadora da Defesa Pública, composta pelos seguintes membros: Prof. Dr. JOSE ALFREDO COVOLAN ULSON do(a) Departamento de Engenharia Elètrica / Faculdade de Engenharia de Bauru, Prof, Dr. PAULO ROBERTO DE AGUIAR do(a) Departamento de Engenharia Elètrica / Faculdade de Engenharia de Bauru, Prof. Dr. JOSE CARLOS DE MELO VIEIRA JUNIOR do(a) Departamento de Engenharia Elétrica / Escola de Engenharia de Såo Carlos-USP, sob a presidência do primeiro, a fim de proceder a arguiçâao pública da DISSERTAÇĀO DE MESTRADO de ANTONIO CARLOS PASSOS SARTIN. intitulado "AVALIACĀO DA SUSCETIBILIDADE ELETROMAGNETICA DOS CABOS METALICOS DOS SISTEMAS DE SUPERVISĀO, PROTEÇÃO, COMUNICAÇÃO E CONTROLE DE SUBESTAÇOES DE ALTA TENSÃO". Após a exposiçâo, o discente foi argüido oraimente pelos membros da Comissão Examinadora, tendo recebido o conceits final:ARrova do . Nada mais havendo, foi lavrada a presente ata, que, após lida e aprovada, foi assinada pefos membrps da Comissăo Examinadora.

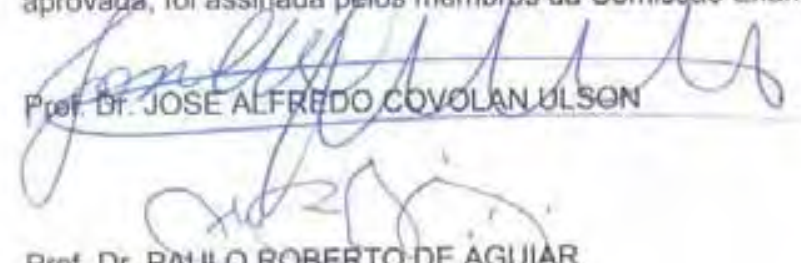

Prof. Dr. PAULO ROBERTO DE AGUIAR

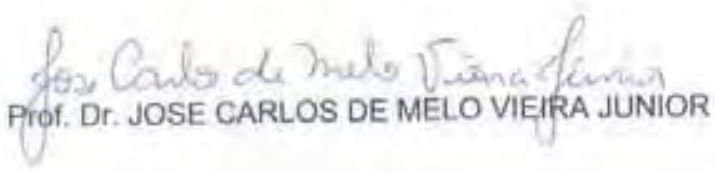




\section{Sumário}

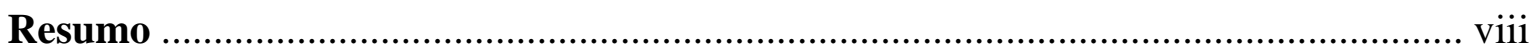

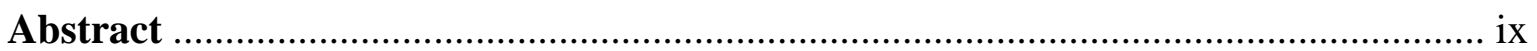

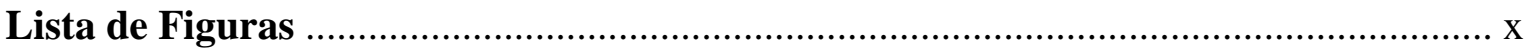

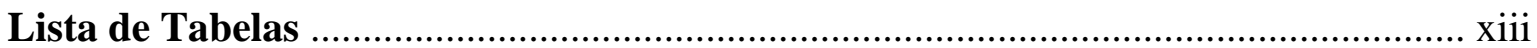

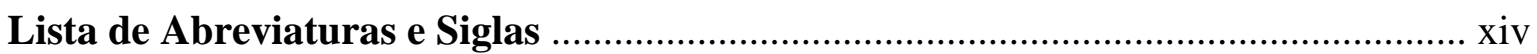

1 Introdução …………………………………………………………………... 1

1.1 Motivações da Dissertação ............................................................................. 1

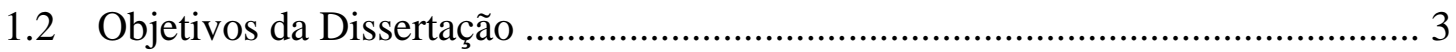

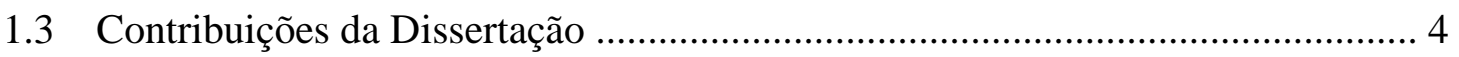

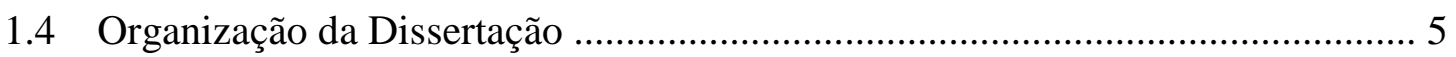

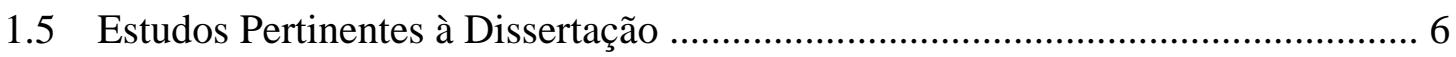

2 Fundamentos de Compatibilidade Eletromagnética e Estado da Arte.................. 11

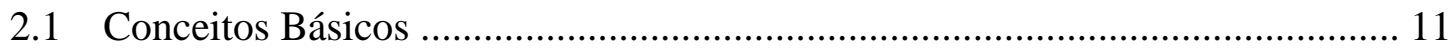

2.1.1 Campo Próximo, Campo Distante e Onda Plana ..................................... 16

2.1.2 Acoplamento Capacitivo, Indutivo e Modo Comum .............................. 18

2.2 Interferência Eletromagnética em Cabos ........................................................ 22

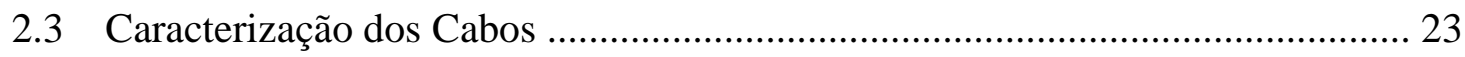

2.3.1 Cabos Telefônicos ............................................................................ 23

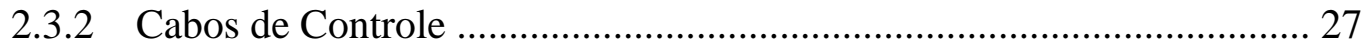

2.3.3 Cabos de Par Trançado ...................................................................... 28

2.4 Interferência Eletromagnética em Subestações ................................................ 28

2.5 Receptores de Interferência Eletromagnética …................................................ 31

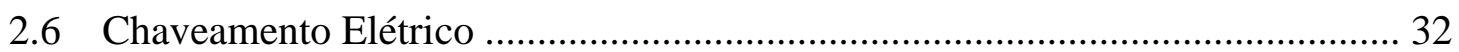




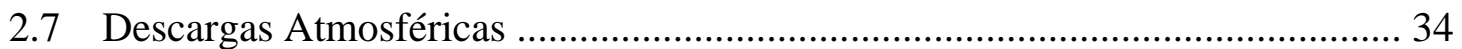

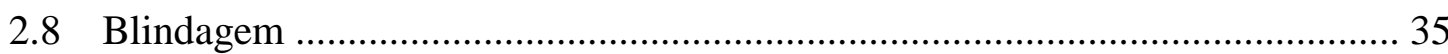

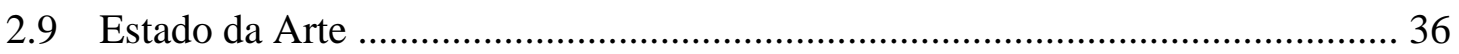

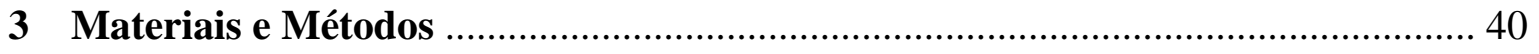

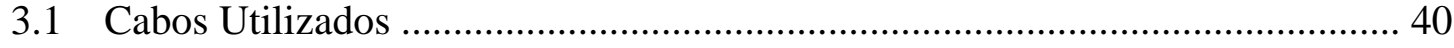

3.2 Bancada de Ensaios ......................................................................................... 43

3.3 Instrumentos Utilizados nos Ensaios Laboratoriais ......................................... 44

3.3.1 Ensaios de Impulso Combinado ...................................................... 44

3.3.2 Ensaios de Transitório Elétrico Rápido ............................................... 45

3.3.3 Ensaios de Campo Magnético Resultante da Corrente na Frequência de

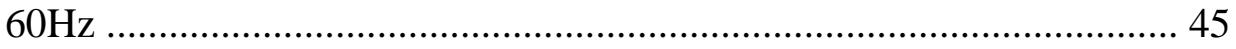

3.3.4 Medição dos Parâmetros Primitivos ..................................................... 46

3.4 Ferramentas Computacionais Utilizadas ....................................................... 47

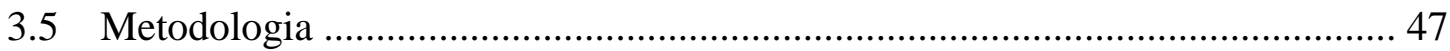

3.5.1 Modelagem e Circuitos Equivalentes para Estudos de Compatibilidade Eletromagnética em Cabos ................................................................. 47

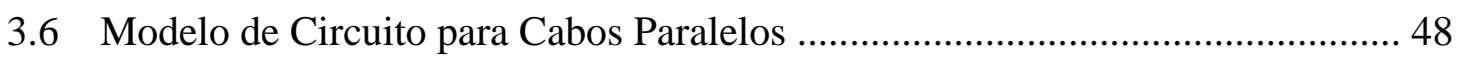

3.6.1 Impedância Primitiva ........................................................................... 49

3.6.2 Impedância de Malha (Loop) ………................................................ 52

3.6.3 Modelo Inicial do Circuito ....................................................................... 53

3.6.4 Modelo Final do Circuito para Cabos Paralelos ................................... 55

3.7 Modelo do Circuito para Cabos Coaxiais .......................................................... 57

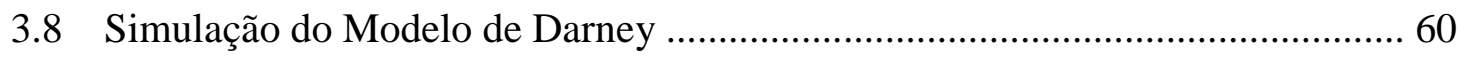

3.9 Medição dos Parâmetros Primitivos .................................................................... 64

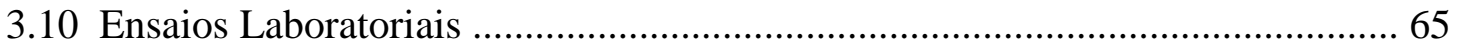

3.10.1 Bancada de Ensaios e Aplicação dos Distúrbios Eletromagnéticos .... 65

3.10.2 Ensaios Laboratoriais Realizados ....................................................... 68

3.10.3 Ensaios de Impulso Combinado ......................................................... 70

3.10.4 Ensaios de Transitório Elétrico Rápido ................................................ 71

3.10.5 Ensaios de Campo Magnético Resultante da Corrente na Frequência de $60 \mathrm{~Hz}$ 
3.10.6 Técnica de Medição da Tensão Induzida ............................................ 72

3.10.7 Amostras dos Cabos Ensaiados ....................................................... 73

3.10.8 Simulação de Transitórios conforme a Norma CEI EN6100-4-4 ....... 73

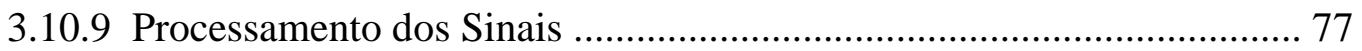

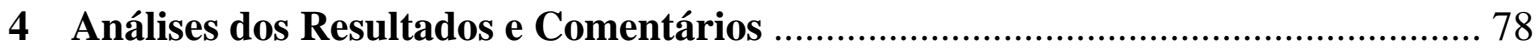

4.1 Implementação Computacional dos Parâmetros Primitivos para os Modelos de Cabos Paralelos e Coaxiais ........................................................................... 78

4.2 Adequação dos Modelos às Condições dos Ensaios Laboratoriais .................... 78

4.2.1 Análise dos Resultados do Ajuste dos Modelos às Condições dos Ensaios

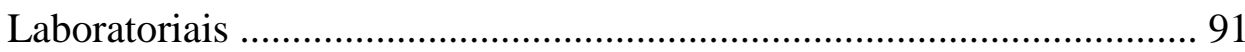

4.3 Resultados e Comparações dos Cabos Analisados ........................................... 92

4.4 Análise dos Resultados dos Ensaios ................................................................ 100

4.5 Recomendações de Utilização dos Cabos Ensaiados ...................................... 101

4.6 Resumo das Recomendações de Instalação .................................................. 103

4.6.1 Cabos sem Blindagem .................................................................... 103

4.6.2 Cabos com Blindagem ............................................................... 104

5 Conclusões e Trabalhos Futuros ..................................................................... 106

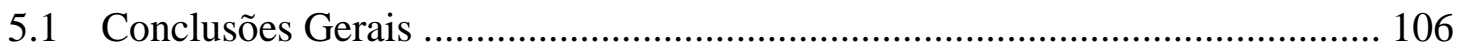

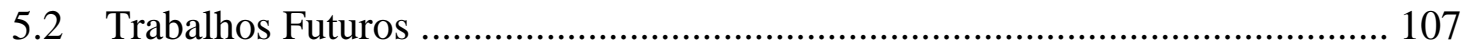

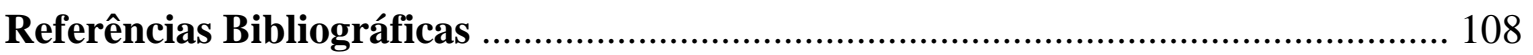


Dedicatória

Dedico esta dissertação com muito carinho à minha esposa Mônica e ao meu filho Alex pela compreensão de ambos durante as pesquisas, os estudos e a elaboração deste trabalho e pelo imenso incentivo para que fosse concluída com êxito. 


\section{Agradecimentos}

Agradeço à minha esposa Mônica e ao meu filho Alex, pela infinita paciência e apoio irrestrito;

Agradeço aos meus pais Joaquim e Maria José, pelo apoio de toda uma vida, e pela infinita marca de excelência que imprimiram na sua dedicação como pais;

Agradeço aos meus irmãos Maria Ângela e Joaquim Augusto, sempre presentes em minha vida, que colaboraram com incentivo e bom humor;

Agradeço aos pesquisadores Prof. Msc. Fábio Romano Lofrano Dotto, Prof. Dr. Paulo Roberto de Aguiar, Prof. Msc. Cezar José Sant'Anna e Prof. Msc. Rogerio Thomazella pelo apoio e colaboração, fundamentais na elaboração deste trabalho;

Ao meu orientador Prof. Dr. José Alfredo Covolan Ulson pelas valorosas sugestões e apoio no decorrer do desenvolvimento deste trabalho;

À CTEEP - Companhia de Transmissão de Energia Elétrica Paulista pelo suporte financeiro, através de projeto $\mathrm{P} \& \mathrm{D}$, tornando possível assim, a realização deste trabalho;

Aos professores e alunos do Programa de Pós-Graduação em Engenharia Elétrica da Faculdade de Engenharia de Bauru, pelo apoio sem barreiras e pela ajuda recebida durante todo o tempo, necessários para concluir este trabalho. 


\section{Epígrafe}

O pesquisador que não sabe o que está procurando nunca entenderá o que ele encontra. Claude Bernard (Fisiologista francês, 1813 - 1878). 
SARTIN, A. C. P. Avaliação da suscetibilidade eletromagnética dos cabos metálicos dos sistemas de supervisão, proteção, comunicação e controle de subestações de alta tensão. Bauru, 2010.

127 p. Dissertação (Mestrado em Engenharia Elétrica) - Faculdade de Engenharia Elétrica, Campus de Bauru, Universidade Estadual Paulista "Júlio de Mesquita Filho".

\section{Resumo}

O presente trabalho possui como foco principal a apresentação de proposições técnicas para a avaliação da suscetibilidade eletromagnética de cabos metálicos isolados, blindados ou não, para atender aos sistemas de supervisão, proteção, comunicação e controle de subestações de alta tensão frente às interferências eletromagnéticas provocadas pelas descargas atmosféricas, manobras de chaveamento, campo magnético na frequência de $60 \mathrm{~Hz}$ e do efeito corona. Para a realização destas proposições foram analisados e estudados diversos cabos usados em uma subestação de 440kV. A diretriz metodológica adotada nesta pesquisa incorporou simulações de modelo computacional, ensaios laboratoriais recomendados pelas normas e publicações técnicas correlatas com a finalidade de identificar os efeitos provocados pelas interferências eletromagnéticas nesses cabos. Os resultados obtidos conduziram a uma análise da interferência eletromagnética nos diversos cabos avaliados fornecendo, assim, um valor de imunidade de cada cabo estudado. Constatou-se que os cabos sem blindagem devem ser usados com reservas e podem ser instalados em sistemas poucos sujeitos a interferências eletromagnéticas ou promover uma blindagem adicional. Os cabos blindados, menos suscetível a interferências eletromagnéticas, podem ser instalados em pátios de subestações, entretanto devem-se tomar os devidos cuidados com o aterramento da blindagem. Desta forma, a pesquisa realizada contribuiu para o desenvolvimento de um procedimento técnico para o uso adequado de cabos em questão visando minimizar os efeitos provocados pelas interferências eletromagnéticas nos sistemas de supervisão, proteção, comunicação e controle presentes em subestações de alta tensão.

\section{Palavras-chave}

1. Interferência eletromagnética. 2. Compatibilidade eletromagnética. 3. Cabos metálicos blindados. 
SARTIN, A. C. P. Electromagnetic susceptibility evaluation of metallic cables of the supervision, protection, communication and control systems for high voltage substation. Bauru, 2010.

127 p. Dissertation (Master's Degree Electrical Engineering) - University of Engineering, Campus of Bauru city, Brazil, Universidade Estadual Paulista "Júlio de Mesquita Filho".

\section{Abstract}

The main focus of this work is the presentation of technical propositions to assessing the electromagnetic susceptibility of isolated metallic cables, shielded or not, in order to comply with the supervision, protection, communication and control systems of high voltage substations in the presence of electromagnetic interferences caused by lightning discharge, switching maneuver, electromagnetic field at $60 \mathrm{~Hz}$ and corona effect. Several cables used in a $440 \mathrm{kV}$ substation were analyzed and studied for accomplishing these propositions. The methodological guideline adopted in this research has included simulations of computational models, laboratorial tests recommended by standards and technical publications correlated in order to identifying the effects provoked by electromagnetic interferences to these cables. The obtained results led to an analysis of the electromagnetic interference in the several cables assessed, thus providing a value of immunity for each cable studied. It was verified that cable without shielding must be employed with restrictions and can be installed in systems which are little subject to electromagnetic interference or to promote an additional shielding. The shielding cables less susceptible to the electromagnetic interference can be installed in substation courtyard; however, it is important to pay special attention to the grounding of the shielding. Thus, this research contributed to the development of a technical proceeding for employing the mentioned cables suitably, aiming at minimizing the effects provoked by the electromagnetic interferences in the supervision, protection, communication and control systems which are present at the high voltage substations.

\section{Keywords}

1. Electromagnetic interference. 2. Electromagnetic compatibility. 3. Shielded metallic cables. 


\section{Lista de Figuras}

Figura 2.1 Elementos básicos da interferência eletromagnética .............................. 12

Figura 2.2 Níveis de interferência eletromagnética .............................................. 12

Figura 2.3 Fontes de interferências eletromagnéticas ............................................ 13

Figura 2.4 Exemplo de interferências eletromagnéticas intrassistema........................ 14

Figura 2.5 Exemplo de interferências eletromagnéticas intersistema ...................... 15

Figura 2.6 Representação do campo próximo e distante .......................................... 17

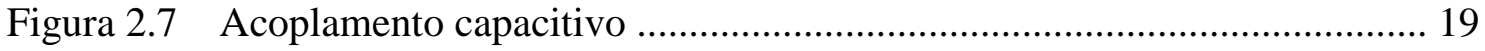

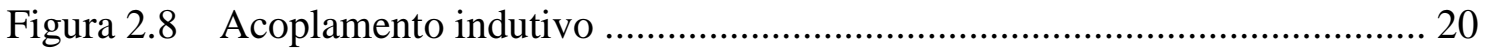

Figura 2.9 Ruído de modo comum e diferencial ................................................... 21

Figura 2.10 Exemplo de cabo telefônico para sistema tronco e primário ................... 24

Figura 2.11 Exemplo de cabo telefônico para sistema secundário .............................. 24

Figura 2.12 Exemplo de cabo telefônico para sistema secundário subterrâneo ......... 25

Figura 2.13 Exemplo de cabo telefônico TILINTER (CI-J) .................................... 25

Figura 2.14 Exemplo de cabo telefônico TILINTER (CIS-J) ................................... 26

Figura 2.15 Exemplo de cabo telefônico tipo drop-wire ............................................. 26

Figura 2.16 Exemplo de cabo telefônico para instalações internas ............................. 26

Figura 2.17 Exemplos de cabo com blindagem simples e blindagem dupla .............. 27

Figura 2.18 Exemplo de um cabo de controle .......................................................... 27

Figura 2.19 Exemplo de um cabo de par trançado categoria 6 ................................ 28

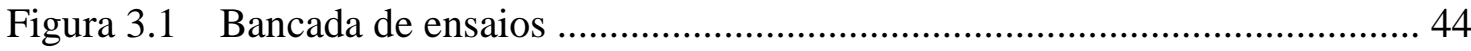

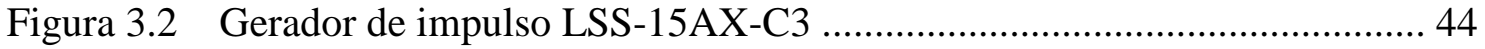

Figura 3.3 Gerador de transitório elétrico rápido FNSAX-II .................................... 45

Figura 3.4 Ponte RLC QuadTech e transformador de corrente ................................ 46

Figura 3.5 Analisador de impedâncias 4192A Agilent ............................................... 46

Figura 3.6 Osciloscópios Rigol 5202 e Tektronix TDS 684B …............................... 47

Figura 3.7 Ponto onde os campos $E$ e $H$ são calculados ........................................... 50

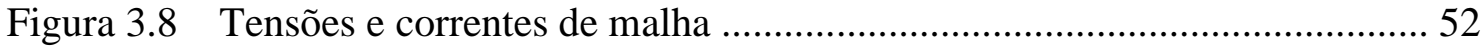

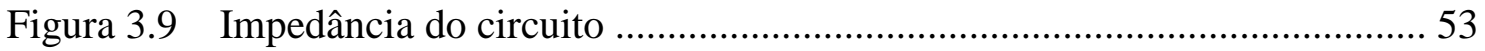




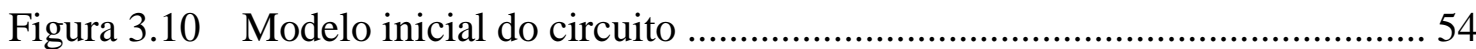

Figura 3.11 Modelo T para linha de transmissão de dois circuitos ............................ 56

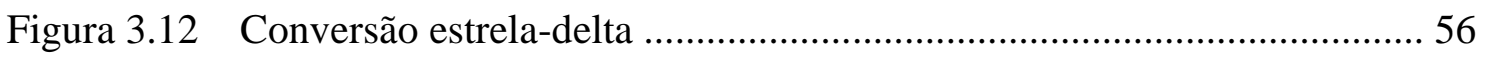

Figura 3.13 Modelo do circuito para cabos paralelos ............................................. 57

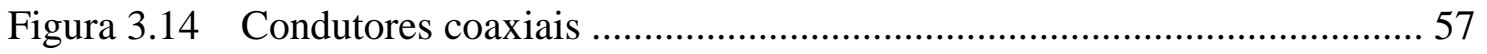

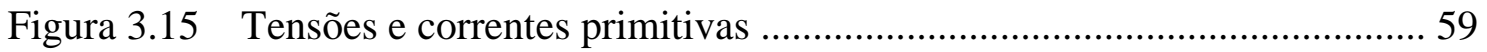

Figura 3.16 Tensões e correntes de malhas ................................................................. 59

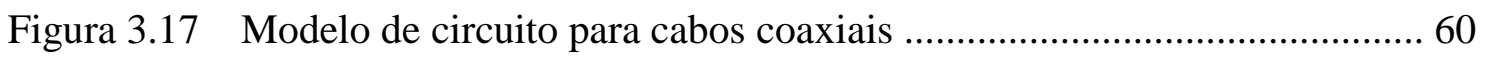

Figura 3.18 Montagem da bancada de ensaios ..................................................... 61

Figura 3.19 Circuito equivalente a bancada de ensaios .......................................... 61

Figura 3.20 Circuito equivalente no MatLab/Simulink ........................................ 62

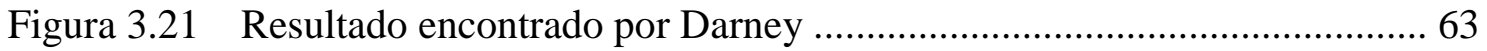

Figura 3.22 Resultado da simulação no Simulink par $\mathrm{r}_{12}=20,5 \mathrm{~mm}$........................ 64

Figura 3.23 Configuração do sistema de medição dos parâmetros RLC ..................... 64

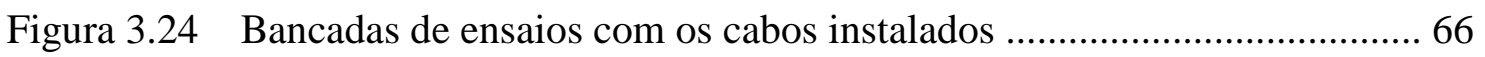

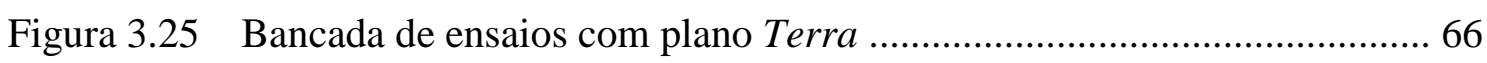

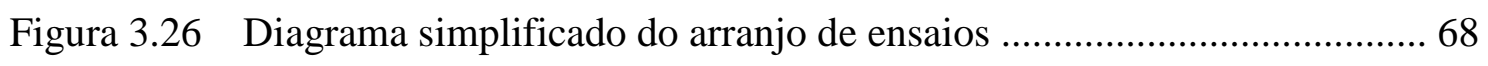

Figura 3.27 Diagrama de ligação dos ensaios de impulso combinado ....................... 70

Figura 3.28 Impulsos de tensão e corrente ......................................................... 70

Figura 3.29 Diagrama de ligação dos ensaios de transitório elétrico rápido ............... 71

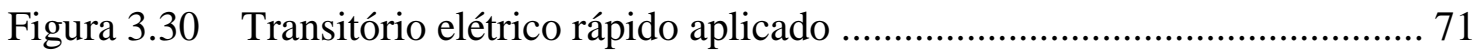

Figura 3.31 Diagrama de ligação dos ensaios de campo magnético na frequência de

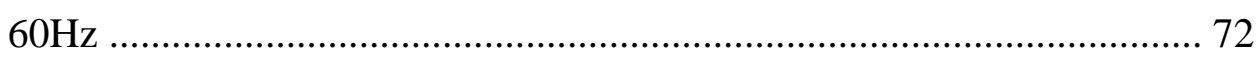

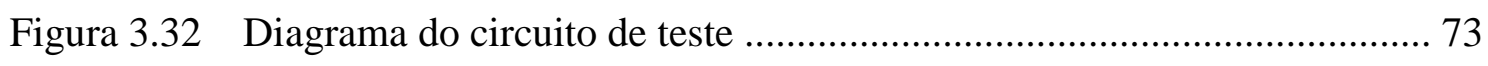

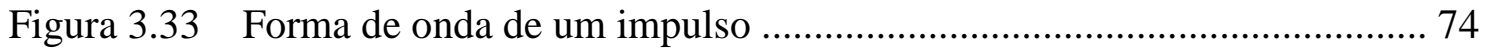

Figura 3.34 Circuito utilizado na simulação de transitórios ...................................... 75

Figura 3.35 Resultado da simulação do circuito para um pulso ................................ 76

Figura 3.36 Espectro de frequência do pulso gerado .................................................. 76

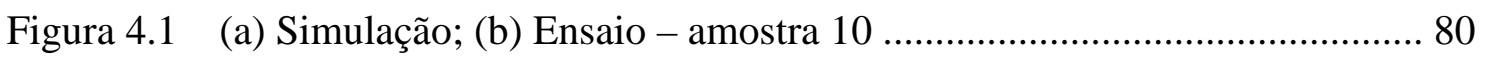

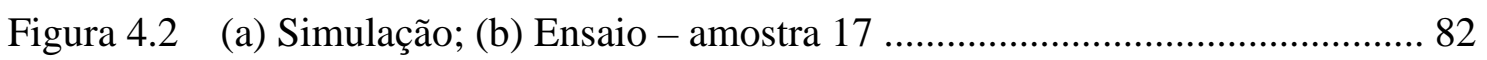

Figura 4.3 (a) Simulação; (b) Ensaio - amostra 12 ............................................... 84

Figura 4.4 (a) Simulação; (b) Ensaio - amostra 13 ..................................................... 86 


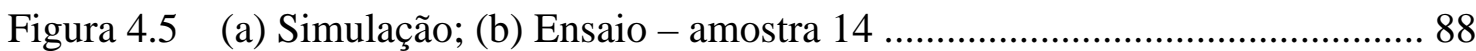

Figura 4.6 (a) Simulação; (b) Ensaio - amostra 18 ................................................. 90

Figura 4.7 Tensão sem aterramento amostra 12 - Burst 500V ................................ 94

Figura 4.8 Tensão com aterramento amostra 12 - Burst 500V ............................... 94

Figura 4.9 Tensão sem aterramento amostra 12 - campo na frequência de $60 \mathrm{~Hz}$..... 94

Figura 4.10 Tensão com aterramento amostra 12 - campo na frequência de $60 \mathrm{~Hz} \ldots 94$

Figura 4.11 Tensão sem aterramento amostra 12 - impulso combinado $1 \mathrm{kV}$...........95

Figura 4.12 Tensão com aterramento amostra 12 - impulso combinado $1 \mathrm{kV}$........... 95

Figura 4.13 Tensão sem aterramento amostra 13 - Burst 500V .............................. 95

Figura 4.14 Tensão com aterramento amostra 13 - Burst 500V .............................. 95

Figura 4.15 Tensão sem aterramento amostra 13 - impulso combinado $1 \mathrm{kV}$.......... 96

Figura 4.16 Tensão com aterramento amostra 13 - impulso combinado $1 \mathrm{kV}$........... 96

Figura 4.17 Tensão sem aterramento amostra 14 - Burst 500V .............................. 96

Figura 4.18 Tensão com aterramento amostra 14 - Burst 500V .............................. 96

Figura 4.19 Tensão sem aterramento amostra 14 - campo na frequência de $60 \mathrm{~Hz}$... 97

Figura 4.20 Tensão com aterramento amostra 14 - campo na frequência de $60 \mathrm{~Hz}$... 97

Figura 4.21 Tensão sem aterramento amostra 14 - impulso combinado $1 \mathrm{kV}$........... 97

Figura 4.22 Tensão com aterramento amostra 14 - impulso combinado $1 \mathrm{kV}$........... 97

Figura 4.23 Tensão sem aterramento amostra 18 - Burst 500V ............................... 98

Figura 4.24 Tensão com aterramento amostra 18 - Burst 500V .............................. 98

Figura 4.25 Tensão sem aterramento amostra 18 - campo na frequência de $60 \mathrm{~Hz} \ldots 98$

Figura 4.26 Tensão com aterramento amostra 18 - campo na frequência de $60 \mathrm{~Hz} \ldots 98$

Figura 4.27 Tensão sem aterramento amostra 18 - impulso combinado 500V ......... 99

Figura 4.28 Tensão com aterramento amostra 18 - impulso combinado 500V ......... 99 


\section{Lista de Tabelas}

Tabela 3.1 Cabos sem blindagem ........................................................................ 40

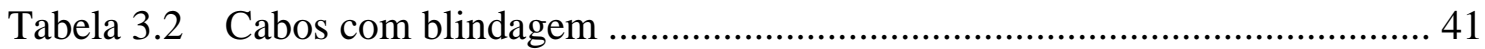

Tabela 3.3 Ensaios realizados para diversos tipos de aterramentos ............................. 69

Tabela 3.4 Ensaios realizados para diversos níveis de sinal ......................................... 69

Tabela 3.5 Valores dos componentes discretos ....................................................... 75

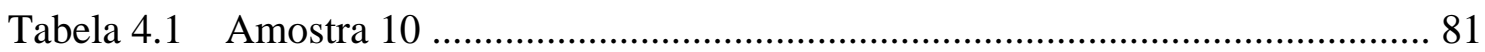

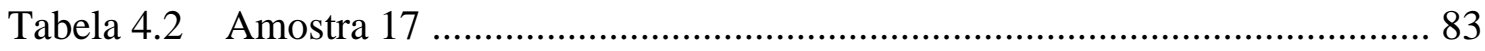

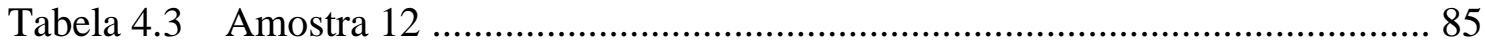

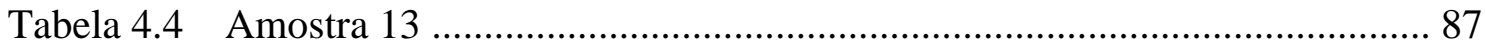

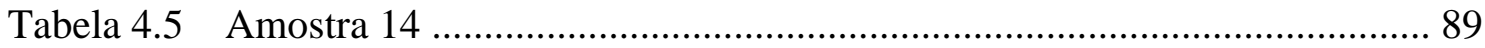

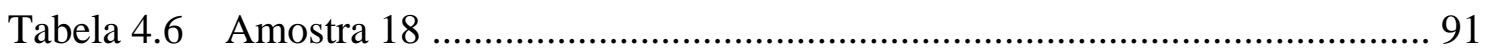

Tabela 4.7 Análise dos resultados gráficos ........................................................... 100

Tabela 4.8 Resumo das recomendações para utilização de cabos sem blindagem ... 104

Tabela 4.9 Resumo das recomendações para utilização de cabos com blindagem .. 105 


\title{
Lista de Abreviaturas e Siglas
}

\author{
ABNT Associação Brasileira de Normas Técnicas \\ AF Audio Frequency \\ ANATEL Agência Nacional de Telecomunicações \\ ANSI American National Standards Institute \\ CA Corrente Alternada \\ CAD Computer-Aided Design \\ CC Corrente Contínua
}

CEI EN 61000 Commission Électrotechnique Internationale Communauté Européenne 61000

CEM Compatibilidade Eletromagnética

CIGRÉ International Council on Large Electric Systems

CISPR Comité International Spécial des Perturbations Radioélectriques

CTEEP Companhia de Transmissão de Energia Elétrica Paulista

EFT Electrical Fast Transient

EIA/TIA Electronic Industries Alliance / Telecommunications Industry Association

EMC Electromagnetic Compatibility

EMI Electromagnetic Interference

EMP Electromagnetic Pulse

ESD Electrostatic Discharge

ETI Equipamento de Tecnologia da Informação

FCC Federal Communications Commission

FFT Fast Fourier Transform

FUNDEB Fundação para o Desenvolvimento de Bauru

GBPS Giga Byte Por Segundo

GPIB General Purpose Interface Bus

HVDC High Voltage Direct-Current

IEC 61000 International Electrotechnical Commission 61000

IEEE-STD Institute of Electrical and Electronics Engineers- Standard

IF Intermediate Frequency 
LACTEC Instituto de Tecnologia para o Desenvolvimento

MBPS Mega Byte Por Segundo

NBR Normas Brasileiras

P\&D Programa e Desenvolvimento

PEDA Pulsos Eletromagnéticos da Descarga Atmosférica

STP Shield Twisted Pair

SVC Static Var Compensator

RF Radio Frequência / Radio Frequency

UHF Ultra High Frequency

USB Universal Serial Bus

UTP Unshielded Twisted Pair

VHF Very High Frequency 


\section{Capítulo 1}

\section{Introdução}

Este capítulo apresenta as motivações, os objetivos e as contribuições deste trabalho de pesquisa bem como as publicações científicas decorrentes.

\subsection{Motivações da Dissertação}

As interferências eletromagnéticas são alguns dos grandes problemas existentes nas subestações das companhias de geração, transmissão e distribuição de energia elétrica. Essas interferências comprometem o funcionamento dos equipamentos eletrônicos instalados nas subestações (unidades remotas, relés de proteção, dentre outros), muitas vezes, danificando-os completamente. Como esses equipamentos eletrônicos atendem os sistemas de supervisão, proteção, comunicação e controle das subestações, o funcionamento inadequado destes, pode causar a interrupção no fornecimento de energia elétrica, fato que degrada a qualidade da energia fornecida.

O funcionamento inadequado dos equipamentos eletrônicos dá-se, na maioria dos casos, pelas interferências eletromagnéticas nos cabos metálicos que servem as entradas e saídas de informação desses equipamentos. Tais interferências eletromagnéticas geram transitórios eletromagnéticos que podem ser interpretados como um ruído nas informações recebidas, e podem gerar ações intempestivas ou causar dano irreparável ao equipamento.

Os cabos metálicos isolados, blindados ou não, continuam sendo o meio mais econômico e mais utilizado nos sistemas de supervisão, proteção e comunicação. Nesse contexto, a correta especificação dos cabos, aliado a um bom entendimento de como instalá-los, contribui para minimizar os efeitos das interferências eletromagnéticas geradas pelas descargas atmosféricas, curtos-circuitos na frequência de $60 \mathrm{~Hz}$, aberturas e fechamentos de chaves e disjuntores e do efeito corona. 
Assim sendo, conhecer os valores da tensão induzida nos cabos e em suas blindagens facilita a escolha e a especificação de um cabo. A possibilidade de ter em mãos, subsídios suficientes para decidir por este ou aquele cabo, por este ou aquele tipo de blindagem e outras necessidades, geram a redução ou até a eliminação de danos aos equipamentos eletrônicos, diminui os custos de manutenção das concessionárias de energia elétrica e reflete diretamente nos índices que quantificam as interrupções de fornecimento. 


\subsection{Objetivos da Dissertação}

O objetivo deste trabalho é apresentar um estudo da suscetibilidade eletromagnética de cabos metálicos isolados blindados ou não, que atendem os sistemas de supervisão, proteção, comunicação e controle de subestações de alta tensão. Especificamente, os cabos metálicos para sinais, mais utilizados em subestações de alta tensão, foram ensaiados em laboratório e modelados matematicamente visando confirmar o método de ensaios e identificar a suscetibilidade eletromagnética destes, frente às interferências eletromagnéticas provocadas pelas descargas atmosféricas, manobras de chaveamento, campo magnético na frequência de $60 \mathrm{~Hz}$ e pelo efeito corona, freqüentes nas subestações das concessionárias de energia elétrica.

Este estudo propõe recomendações para a utilização dos cabos existentes no mercado em novas implantações e ampliações, objetivando uma maior confiabilidade e disponibilidade destes sistemas frente às interferências eletromagnéticas, freqüentes nas subestações das concessionárias de energia elétrica, reduzindo-se assim, de forma significativa, os desligamentos intempestivos. 


\subsection{Contribuições da Dissertação}

Os resultados desse trabalho vêm preencher as necessidades das companhias de energia elétrica no que tange a especificação e a instalação de cabos de sinais dos sistemas de supervisão, proteção, comunicação e controle de subestações. Esta afirmação decorre do fato da restrita disponibilidade de estudos que tratam a interação entre cabos de sinais, interferências eletromagnéticas e suas maneiras de instalação, visando assim reduzir os desligamentos intempestivos.

Nesse contexto, este trabalho traz avanços no entendimento científico do comportamento de cabos metálicos de sinais instalados em subestações de energia elétrica, bem como, benefícios para o cliente na qualidade de consumidor, bem como para a concessionária. $\mathrm{O}$ consumidor será beneficiado com um fornecimento de energia elétrica sem interrupções e transitórios incidentes, resultando assim uma maior satisfação com energia elétrica de qualidade. Já a concessionária será menos onerada no tocante às interrupções indesejáveis e também quanto à manutenção dos equipamentos por problemas com interferências eletromagnéticas, elevando assim, os índices de qualidade do fornecimento de energia elétrica. 


\subsection{Organização da Dissertação}

No capítulo 2 são apresentados os fundamentos de compatibilidade eletromagnética e as obras bibliográficas necessárias para o estudo científico retrospectivo relacionado à interferência/compatibilidade eletromagnética.

No capítulo 3 encontram-se uma descrição técnica dos cabos utilizados e os existentes no mercado, recursos computacionais, ensaios laboratoriais e equipamentos utilizados. Neste capitulo, apresenta-se também, as modelagens de circuitos para compatibilidade eletromagnética e os modelos matemáticos de cabos blindados que norteiam os testes laboratoriais.

No capítulo 4 são apresentadas as análises dos resultados dos testes laboratoriais e os comentários pertinentes. Finalmente, no capítulo 5 encontram-se as conclusões da dissertação e as propostas para trabalhos futuros. 


\subsection{Estudos Pertinentes à Dissertação}

No transcorrer dos anos de 2008 e 2009 foram aprovados 7 títulos de artigos completos, diretamente relacionados a esta dissertação, que foram publicados em seminários nacionais e internacionais, conforme abaixo:

SARTIN, A. C. P.; ULSON, J. A. C.; DOTTO, F. R. L.; AGUIAR, P. R.; SANT'ANNA, C. J.; THOMAZELLA, R.. Avaliação da susceptibilidade eletromagnética dos cabos de supervisão, comunicação, controle e proteção aplicados em subestações de alta tensão. In: XX SNPTEE - SEMINÁRIO NACIONAL DE PRODUÇÃO E TRANSMISSÃO DE ENERGIA ELÉTRICA, 2009, Recife. Avaliação da susceptibilidade eletromagnética dos cabos de supervisão, comunicação, controle e proteção aplicados em subestações de alta tensão. Recife: Cigre-Brasil. CD-ROM.

SARTIN, A. C. P.; SANT'ANNA, C. J.; DOTTO, F. R. L.; AGUIAR, P. R.; THOMAZELLA, R.. Evaluation of electromagnetic susceptibility of metal conductors used in communications, supervision, automation and control that may be installed at the yards of substations. In: X SIPDA - X INTERNATIONAL SYMPOSIUM ON LIGHTNING PROTECTION，2009， Curitiba. Evaluation of electromagnetic susceptibility of metal conductors used in communications, supervision, automation and control that may be installed at the yards of substations. Curitiba: IEE/USP. CDROM.

SARTIN, A. C. P.; DOTTO, F. R. L.; Ulson, J. A. C.; AGUiAR, P. R.; SANT’ANNA, C. J.; THOMAZELLA, R.. Implementação, análise e validação de modelo computacional para a avaliação da suscetibilidade eletromagnética dos cabos de proteção, supervisão comunicação e controle aplicados em subestações de alta tensão. In: CLAGTEE 2009 - THE $8^{\mathrm{TH}}$ LATIN-AMERICAN CONGRESS ON ELECTRICITY GENERATION AND TRANSMISSION, 2009, Ubatuba. Implementação, análise e validação de modelo computacional para a avaliação da suscetibilidade eletromagnética dos cabos de proteção, supervisão comunicação e 
controle aplicados em subestações de alta tensão. Ubatuba: IEEE-Brasil; ABCM; CAPES/CNPq; FAPESP; FINEP/Fundunesp. Anais.

SARTIN, A. C. P.; SANT’ANNA, C. J.; DOTTO, F. R. L.; ULSON, J. A. C.;AGUIAR, P. R.; THOMAZELLA, R.. Avaliação da susceptibilidade eletromagnética dos cabos metálicos de supervisão, proteção, comunicação e controle aplicados em subestações de alta tensão. In: II SIMSE CIER 2009 - SEMINARIO INTERNACIONAL DE MANTENIMIENTO EN SISTEMAS ELÉCTRICOS, 2009, Bogotá. Avaliação da susceptibilidade eletromagnética dos cabos metálicos de supervisão, proteção, comunicação e controle aplicados em subestações de alta tensão. Bogotá: COCIER. CD-ROM.

SARTIN, A. C. P.; DOTTO, F. R. L.; SANT'ANNA, C. J.; ULSON, J. A. C.; AGUIAR, P. R.; THOMAZELLA, R.. Electromagnetic susceptibility evaluation of the metallic cables used in communication, supervision, automation and control systems that are installed at the $440 \mathrm{kV}$ substations. In: EMD 2009 - XIX-TH INTERNATIONAL CONFERENCE ON ELECTROMAGNETIC DISTURBANCES, 2009, Bialystok. Electromagnetic susceptibility evaluation of the metallic cables used in communication, supervision, automation and control systems that are installed at the $440 \mathrm{kV}$ substations. Bialystok: IEEE-Poland; SEP. CD-ROM.

SARTIN, A. C. P.; THOMAZELlA, R.; SANT'ANNA, C. J.; DOTTO, F. R. L.; AGUIAR, P. R.. Electromagnetic susceptibility evaluation of communication and control cables in substations. In: GROUND'2008 \& $3^{\text {RD }}$ LPE - INTERNATIONAL CONFERENCE ON GROUNDING AND EARTHING \& INTERNATIONAL CONFERENCE ON LIGHTNING PHYSICS AND EFFECTS, 2008, Florianopolis. Electromagnetic susceptibility evaluation of communication and control cables in substations. Florianopolis: SB-RAI; LRC; UFMG-CEMIG; ELAT- INPE. CD-ROM.

SARTIN, A. C. P.; THOMAZELlA, R.; SANT'ANNA, C. J.; DOTTO, F. R. L.; AGUIAR, P. R.. Implementation, testing and validation of computational model for evaluating electromagnetic susceptibility in cables for communication and control applied 
to high-voltage substations. In: GROUND`2008 \& $3^{\text {RD }}$ LPE - INTERNATIONAL CONFERENCE ON GROUNDING AND EARTHING \& INTERNATIONAL CONFERENCE ON LIGHTNING PHYSICS AND EFFECTS, 2008, Florianopolis. Implementation, testing and validation of computational model for evaluating electromagnetic susceptibility in cables for communication and control applied to high-voltage substations. Florianopolis: SB-RAI; LRC; UFMG-CEMIG; ELAT-INPE. CD-ROM.

A compilação, durante anos, dos estudos relacionados a esta dissertação, proporcionou a publicação de muitos trabalhos, dentre os quais encontra-se 10 títulos de artigos completos que foram publicados desde 1999 até 2005:

SARTIN, A.C. P.. Aterramento, proteção e compatibilidade eletromagnética das estações de telecomunicações da Transmissão Paulista (CTEEP). In: XVIII SNPTEE SEMINÁRIO DE PRODUÇÃO E TRANSMISSÃO DE ENERGIA ELÉTRICA, 2005, Curitiba. Aterramento, proteção e compatibilidade eletromagnética das estações de telecomunicações da Transmissão Paulista (CTEEP). Curitiba: Cigre-Brasil. CDROM.

SARTIN, A.C. P.; SANT'ANNA, C. J.. ATERRAMENTO NAS ESTAÇÕES DE TELECOMUNICAÇÕES DE UMA EMPRESA DE ENERGIA ELÉTRICA. São Paulo: Revista RTI - Redes, Telecom e Instalações, fev. 2004. p. 42-49.

SARTIN, A.C. P.; DUTRA, A. O.; SANT'ANNA, C. J.. Telecommunication station grounding system installed inside of command building of the $440 \mathrm{kV}$ substation of Ribeirão Preto. In: VII SIPDA - INTERNATIONAL SYMPOSIUM ON LIGHTNING PROTECTION, 2003, Curitiba. Telecommunication station grounding system installed inside of command building of the $440 \mathrm{kV}$ substation of Ribeirão Preto. Curitiba: IEE/USP. Anais. p. 67-72. 
SARTIN, A. C. P.; SANT'ANNA, C. J.. COMO EVITAR INTERFERÊNCIAS ELETROMAGNÉTICAS EM USINAS E SUBESTAÇÕES. São Paulo: Revista Eletricidade Moderna, marc. 2003. p. 92-197.

SARTIN, A.C. P.. Interferência eletromagnética em usinas e subestações - como evitá-las. In: SICEL' 2001 - SIMPOSIO INTERNACIONAL SOBRE CALIDAD DE ENERGÍA ELÉCTRICA DA COLÔMBIA, 2001, Bogotá. Interferência eletromagnética em usinas e subestações - como evitá-las. Bogotá: ACIEM; ICONTEC. CD-ROM.

SANT'ANNA C. J.; SARTIN, A. C. P.. Aterramento e proteção de equipamentos de telecomunicações. In: SICEL'2001 - SIMPOSIO INTERNACIONAL SOBRE CALIDAD DE LA ENERGIA DA COLÔMBIA, Bogotá, 2001. Aterramento e proteção de equipamentos de telecomunicações. Bogotá: ACIEM; ICONTEC. CD-ROM.

SANT'ANNA C. J ; SARTIN, A. C. P.. Model of Information Technology Equipments grounding and protection topology to the earth electrodes system in the CTEEP telecommunication stations. In: VI SIPDA - INTERNATIONAL SYMPOSIUM ON LIGHTNING PROTECTION, São Paulo, 2001. Model of Information Technology Equipments grounding and protection topology to the earth electrodes system in the CTEEP telecommunication stations. São Paulo: IEE/USP. Anais. p. 124-128.

SARTIN, A.C. P.; SANT'ANNA C. J.. Compatibilidade eletromagnética em Usinas e Subestações - como obte-las. In: XVI SNPTEE - SEMINÁRIO NACIONAL DE PRODUÇÃO E TRANSMISSÃO DE ENERGIAS ELÉTRICA, São Paulo, 2001. Compatibilidade eletromagnética em Usinas e Subestações - como obte-las. São Paulo: Cigre-Brasil. Anais.

SARTIN, A. C. P.; SANT'ANNA C. J.. SISTEMA DE PROTEÇÃO DE EQUIPAMENTOS DE TECNOLOGIA DA INFORMAÇÃO. São Paulo: Revista Eletricidade Moderna, jun. 1999. p. 64-73. 
SARTIN, A.C. P.;SANT'ANNA, C. J.. System of protection of ITE - Information Technology Equipment, installed in substation, hydroelectric generating stations and telecommunication stations. In: V SIPDA - INTERNATIONAL SYMPOSIUM ON LIGHTNING PROTECTION, São Paulo, 1999. System of protection of ITE Information Technology Equipment, installed in substation, hydroelectric generating stations and telecommunication stations. São Paulo: IEE/USP. Anais. p. 85-90. 


\section{Capítulo 2}

\section{Fundamentos de Compatibilidade Eletromagnética e Estado da Arte}

Esse capítulo relata os conceitos básicos sobre compatibilidade eletromagnética, além do estudo da suscetibilidade eletromagnética de cabos metálicos de sinais, bem como, as definições necessárias para o entendimento desse trabalho.

\subsection{Conceitos Básicos}

Segundo o American National Standard Dictionary for Technologies of Electromagnetic Compatibility (ANSI C63.14, 1998), a compatibilidade eletromagnética é definida como sendo a capacidade dos sistemas elétricos e eletrônicos, equipamentos e dispositivos de operar em seus ambientes eletromagnéticos planejados, dentro de uma margem definida de segurança e a níveis de desempenho de projeto, sem sofrerem ou causarem degradação inaceitável na presença da interferência eletromagnética. Ainda, segundo (ANSI C63.14, 1998), a interferência eletromagnética é definida como sendo qualquer distúrbio eletromagnético, intencional ou não, que interrompe, obstrui, degrada ou limita o desempenho efetivo de equipamento elétrico ou eletrônico.

Suscetibilidade eletromagnética é a incapacidade de um dispositivo, equipamento ou sistema de funcionar sem degradação na presença de um distúrbio eletromagnético. A suscetibilidade é a falta de imunidade (HERRING, 1993).

Do ponto de vista eletromagnético, a energia é transferida de um emissor (fonte), por meio de um acoplamento (meio), a um equipamento ou sistema qualquer (receptor). $\mathrm{O}$ campo eletromagnético radiado pela fonte pode interferir no desempenho do receptor, dependendo da suscetibilidade eletromagnética deste, aos níveis de energia associados à fonte. A Figura 2.1 mostra diversas fontes, meios de propagação e receptores (WHITE, 1973). 


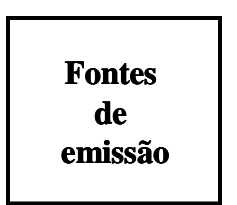

Transmissores de comunicações:

Rádio, celular, TV, FM

Radar e telemetria

Ignição de motores

Arcos voltaicos

Linhas de alta tensão

Manobras de chaveamento elétrico

Descargas atmosféricas

Relâmpagos

Lâmpadas fluorescentes

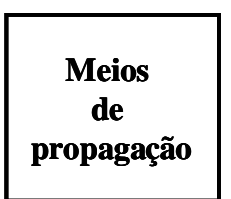

Cabos:

Sinais, alimentação, controle

Linhas de energia e comunica̧ão

Blindagens

Aterramentos
Elementos

receptores

Receptores de comunicação

Receptores de navegação

Computadores

Equipamentos e sistemas eletrônicos

Cabos

Figura 2.1 Elementos básicos da interferência eletromagnética (Adaptado de WHITE,

Para assegurar que exista compatibilidade entre o sistema de potência e os equipamentos eletrônicos inseridos nesse meio agressivo, os níveis das interferências eletromagnéticas geradas pela rede de transmissão, devem estar abaixo do nível de imunidade dos equipamentos eletrônicos, permitindo assim, que tais equipamentos trabalhem de forma adequada, atendendo plenamente seus propósitos (NEKHOUL, 2003).

De acordo com (SUGANYA, 2004), os níveis de imunidade de um dispositivo ou sistema devem se basear nos níveis de interferência de um determinado ambiente eletromagnético. A Figura 2.2 ilustra os níveis de interferência eletromagnética.

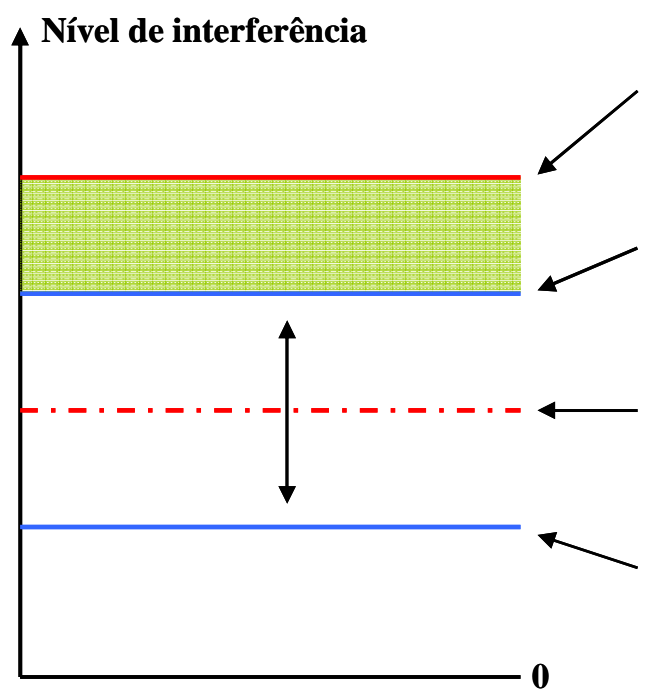

Nível de Suscetibilidade:

Nível máximo que um dispositivo ou sistema pode suportar sem falhas.

Nível de Imunidade:

Nível padronizado que um dispositivo ou sistema deve suportar sem falhas.

\section{Nivel de Compatibilidade Eletromagnética:}

Nível máximo de interferência eletromagnética especificado para um determinado ambiente.

\section{Nível de Emissão:}

Nível padronizado de emissão de um dispositivo ou sistema.

Figura 2.2 Níveis de interferência eletromagnética (Adaptado de SUGANYA, 2004) 
Tanto as fontes quanto os receptores podem ser classificados como intencionais ou não intencionais, dependendo de suas características e do caminho de acoplamento entre os dois. A transferência de energia eletromagnética ocorre, frequentemente, via modos de acoplamento não intencionais, como por exemplo, o próprio espaço livre (SUGANYA, 2004). A Figura 2.3 apresenta algumas fontes de interferências eletromagnéticas e sua classificação.

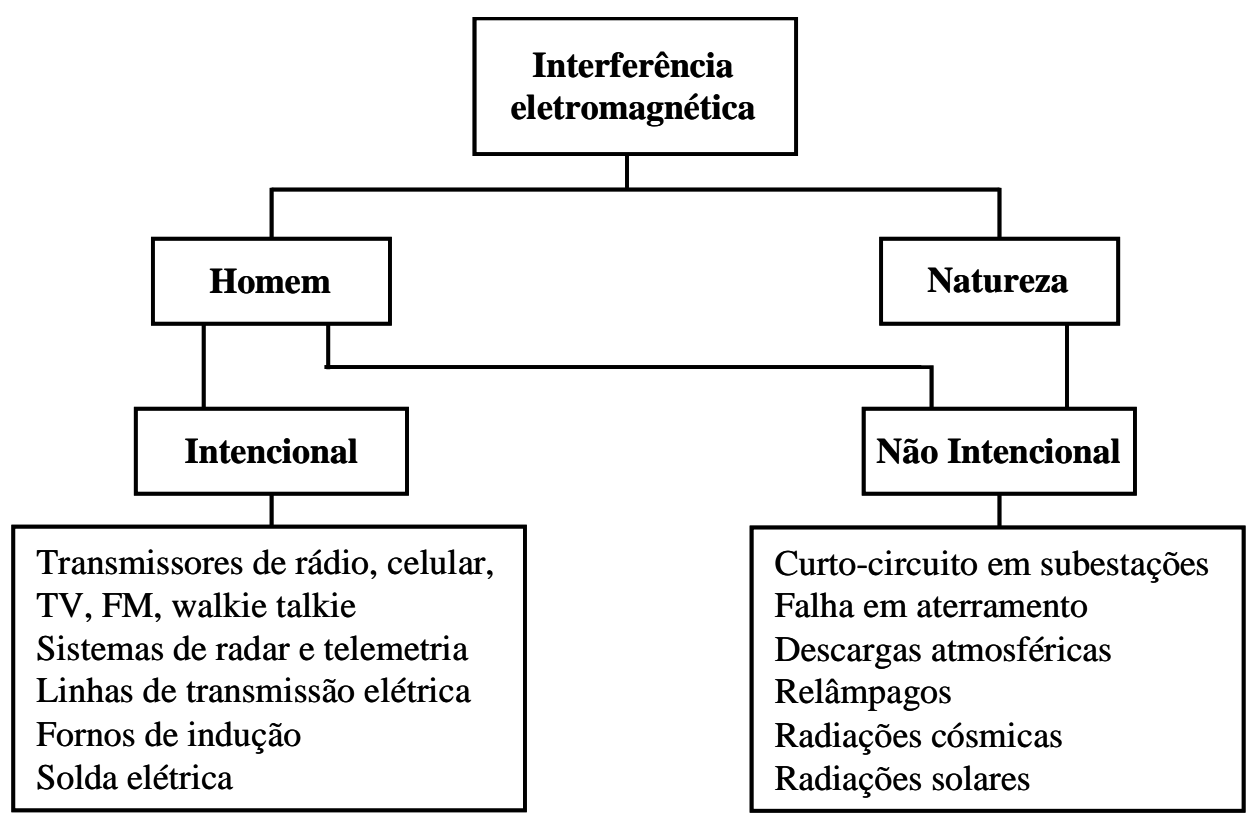

Figura 2.3 Fontes de interferências eletromagnéticas (Adaptado de WHITE, 1973)

A compatibilidade eletromagnética cobre aspectos relacionados com o controle dos efeitos danosos das interferências eletromagnéticas e, portanto, está associada com a concepção e o projeto de dispositivos, equipamentos e sistemas. Neste contexto, as interferências eletromagnéticas também podem ser classificadas em intersistemas e intrassistemas. As interferências eletromagnéticas intra-sistema decorrem de acoplamentos indesejáveis dentro de um único sistema, conforme ilustra a Figura 2.4. Nesse caso, as interferências advêm dos acoplamentos eletromagnéticos entre elementos do próprio sistema, impondo transferências conduzidas, bem, como interferências radiadas, tendo como receptor os condutores internos do sistema funcionando como antenas. 


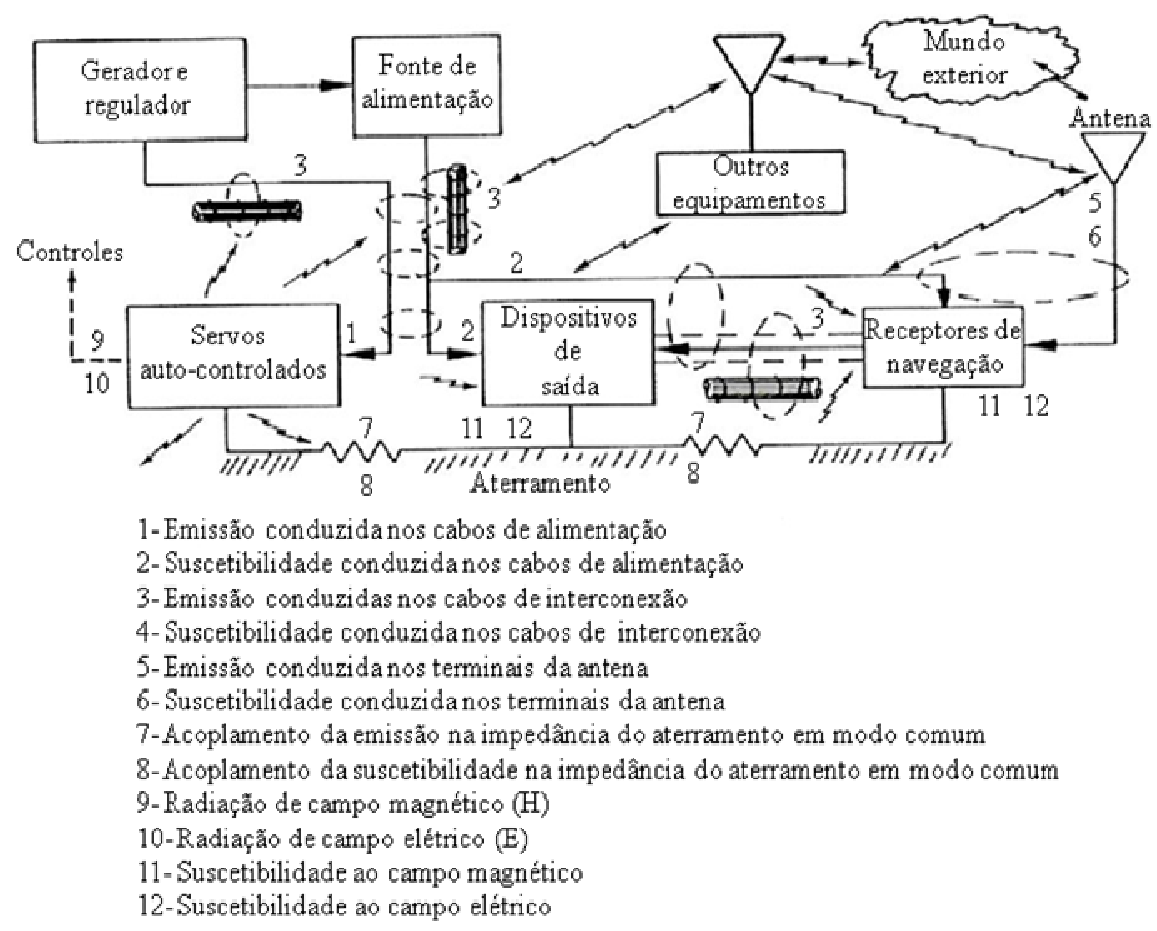

Figura 2.4 Exemplo de interferências eletromagnéticas intrassistema (Adaptado de WHITE, 1973)

As interferências intersistemas, como ilustrado na Figura 2.5, são caracterizadas por diversos tipos de emissores e receptores que podem ser equipamentos ou sistemas. Nesse caso, as EMI (Electromagnetic Interference) decorrem de radiações que podem ter origem em linhas de transmissão, equipamentos de transmissão, links de microondas, descargas atmosféricas (raios), chaveamentos indutivos e capacitivos, dentre outros. De modo geral, as interferências intersistemas apresentam um espectro entre $60 \mathrm{~Hz}$ a $30 \mathrm{GHz}$ (WHITE, 1973). 


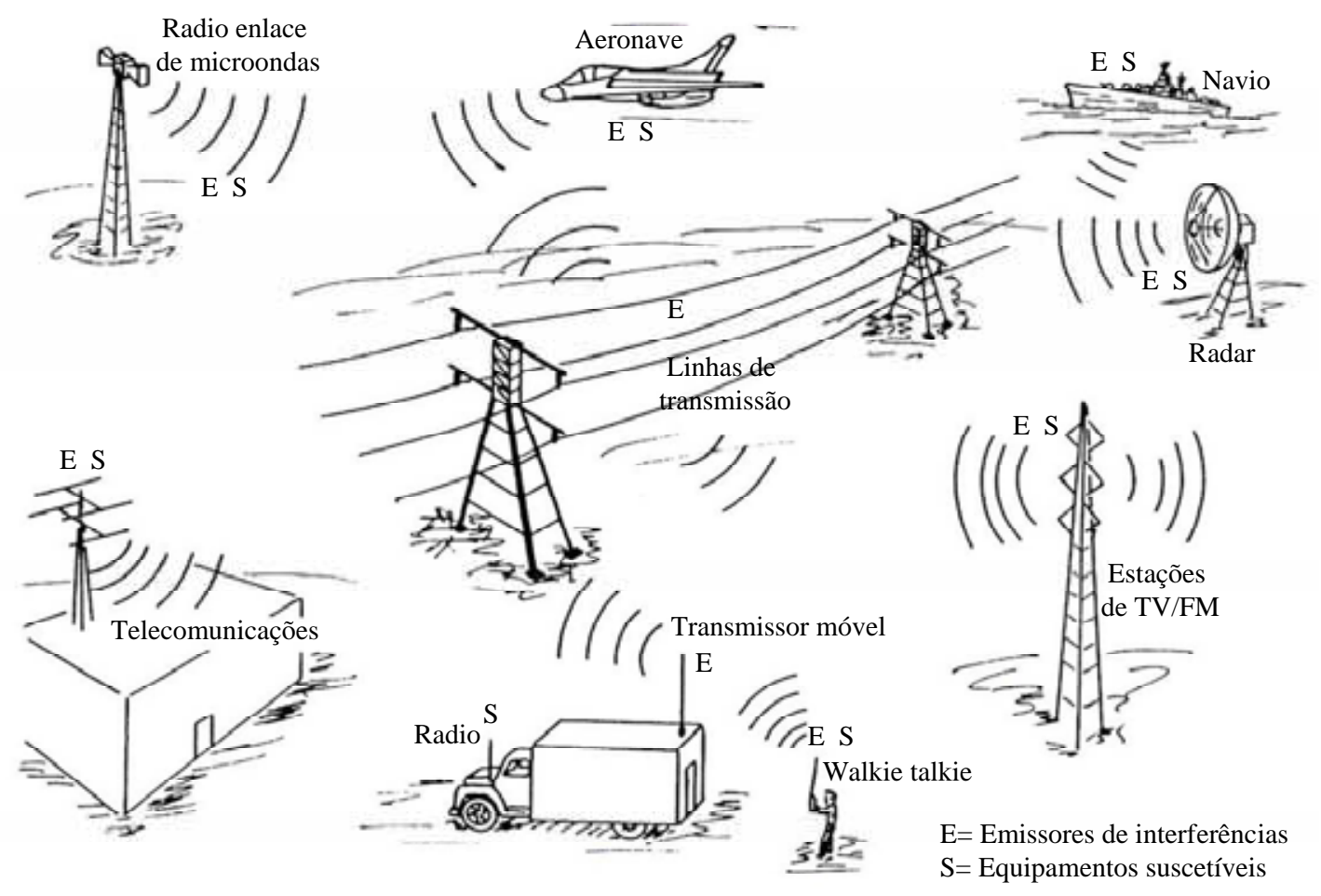

Figura 2.5 Exemplo de interferências eletromagnéticas intersistema (Adaptado de WHITE, 1973)

O processo de estabelecer a compatibilidade magnética com equipamentos ou sistemas eletrônicos geralmente requer dois passos. O primeiro passo é fazer medidas para determinar se qualquer sinal indesejável radiado do equipamento e/ou proveniente da fonte de alimentação, condutores de controle, ou barramentos de dados do equipamento excede aos limites estabelecidos por uma agência reguladora. $\mathrm{O}$ segundo passo é expor o equipamento ou sistema eletrônico à níveis de campo eletromagnético em várias frequências, para determinar se o equipamento pode desempenhar satisfatoriamente suas funções em seu ambiente operacional.

O procedimento de expor o equipamento à campos eletromagnéticos de várias intensidades é chamado de teste de suscetibilidade eletromagnética (WHITE, 1980). Os limites ou requerimentos estabelecidos para os testes de EMC são geralmente estabelecidos por agências reguladoras nacionais e/ou internacionais. 


\subsubsection{Campo Próximo, Campo Distante e Onda Plana}

Para os problemas de EMI, é necessário especificar as características de radiação de uma fonte emissora para as condições da região de campo próximo e de campo distante. Na região de campo próximo, a representação vetorial das características presentes é mais complexa do que a da região do campo distante. Sob condições idealizadas, as características do campo próximo não podem ser representadas por um simples padrão, pois as características da radiação nesta região são funções da posição angular e da distância com relação à fonte emissora. Para uma análise mais exata é necessário considerar cada componente em separado, ou seja, campo elétrico, campo magnético ou campo eletromagnético (CASTRO \& FRANCO, 2002).

As características e o relacionamento entre os campos $\underline{E}(r, \theta, \phi, t)$ e $\underline{H}(r, \theta, \phi, t)$ apresentam comportamento diferenciado em função da distância $r$ do ponto $p(r, \theta, \phi)$ ao dipolo. Este comportamento diferenciado depende especificamente da relação entre $r$ e o comprimento de onda $\lambda$, definindo duas regiões básicas no processo de radiação denominadas de campo próximo, de Fresnel ou de indução $(r<<\lambda)$ e campo distante, de Fraunhofer ou campo de irradiação $(r>>\lambda)$, conforme indicado na Figura 2.6. 


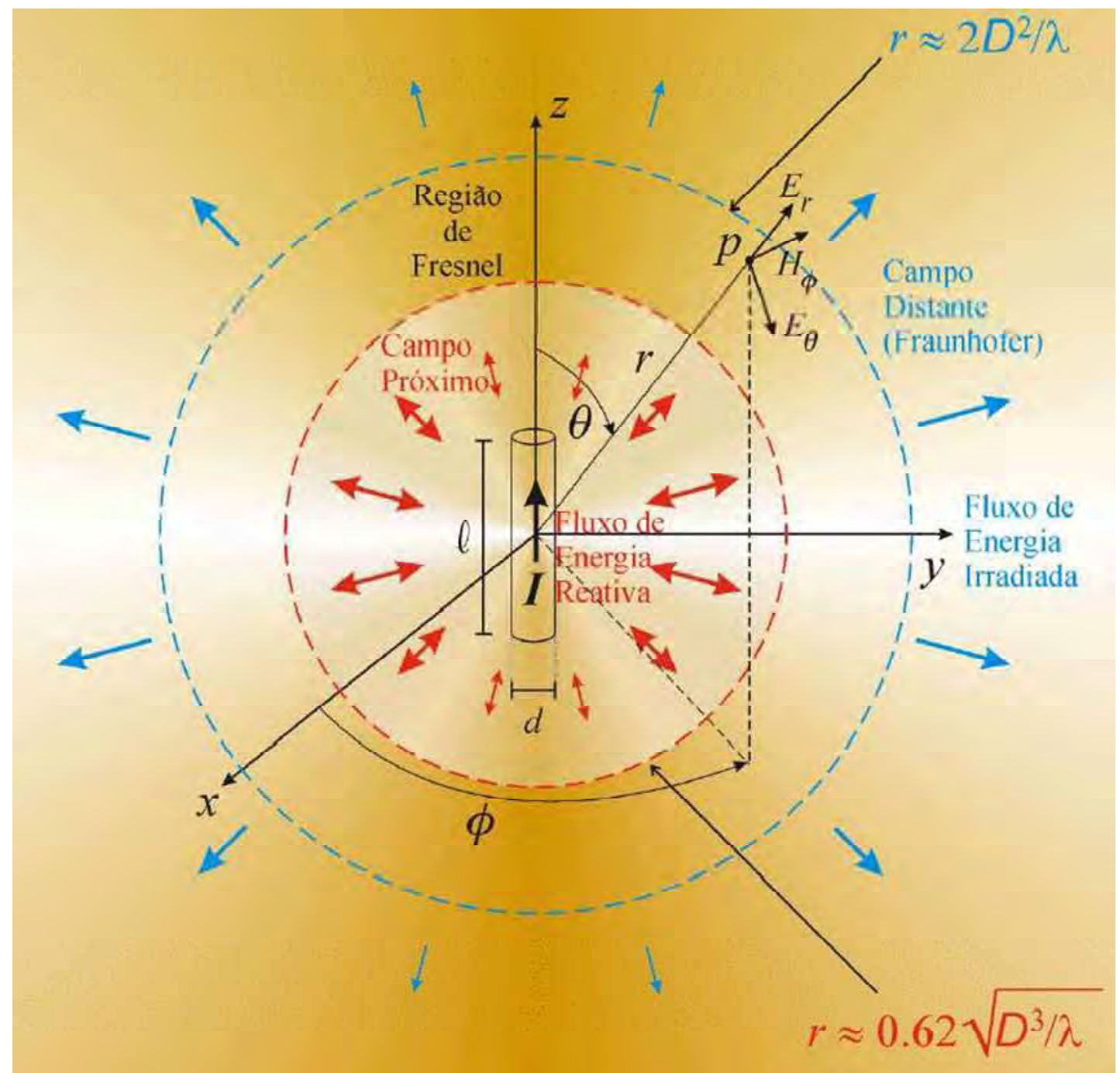

Figura 2.6 Representação do campo próximo e distante (CASTRO \& FRANCO, 2002)

A região do campo próximo é a região do espaço $\mathrm{R}^{3}$, na qual a distância $r$ entre um irradiador e qualquer ponto $p(r, \theta, \phi)$ pertencente à região é tal qual $r<<\lambda$. Esta relação é quantificada, na prática, através de $r<0,62 \sqrt{\frac{D^{3}}{\lambda}}$, onde $D$ é a maior dimensão física do irradiador. Para o caso do dipolo adota-se a relação $r<\frac{\lambda}{2 \pi}$.

A região do campo distante é a região do espaço $\mathrm{R}^{3}$ na qual a distância $r$ entre um irradiador e qualquer ponto $p(r, \theta, \phi)$ pertencente à região é tal qual $r>>\lambda$. 
Na prática, isto é quantificado através da relação $r>\frac{2 D^{2}}{\lambda}$, onde $D$ é a maior dimensão física do irradiador. Esta relação é precisa apenas quando $D>\lambda$, situação que ocorre para antenas de abertura, como refletores parabólicos. Para o caso específico do dipolo adota-se a relação $r>\frac{\lambda}{2 \pi}$ (CASTRO \& FRANCO, 2002).

Para a região de campo próximo, o campo magnético $H$, encontra-se defasado de $90^{\circ}$ no tempo do campo elétrico $E$, o que faz o fluxo de potência, nas proximidades da fonte emissora, ser altamente reativo. O fluxo de potência na região do campo próximo significa implicitamente a existência de ondas estacionárias no interior nesta região que fazem com que a energia eletromagnética flua para frente e para trás duas vezes por período $\mathrm{T}=1 / f$ do gerador (setas vermelhas bidirecionais da Figura 2.6). Apenas no limite externo da região de campo próximo, início da denominada região intermediária de Fresnel, é que começa a haver irradiação efetivamente.

Numa região de campo distante, o modelo de onda plana é uma boa aproximação para a propagação do campo eletromagnético. As características da onda plana são:

i) as frentes de onda têm uma geometria plana; ii) os vetores $E$ e $H$ e a direção de propagação são mutuamente perpendiculares; iii) a fase dos campos $E$ e $H$ é a mesma e iv) o quociente da amplitude de $E$ e $H$ é constante através do espaço. No espaço livre (vácuo), o quociente $E / H$ é igual a $377 \Omega$, que é o valor da impedância característica do espaço livre (CASTRO \& FRANCO, 2002).

\subsubsection{Acoplamento Capacitivo, Indutivo e Modo Comum}

Para simplificar a análise do acoplamento capacitivo, a interação dos campos elétricos entre dois condutores (1 e 2) será representada por meio de capacitâncias parasitas, como se todos os campos entre os elementos estivessem confinados no interior de pequenos capacitores, permitindo assim, trabalhar apenas com uma variável (o tempo) na teoria normal de circuitos, conforme ilustrada na Figura 2.7. 


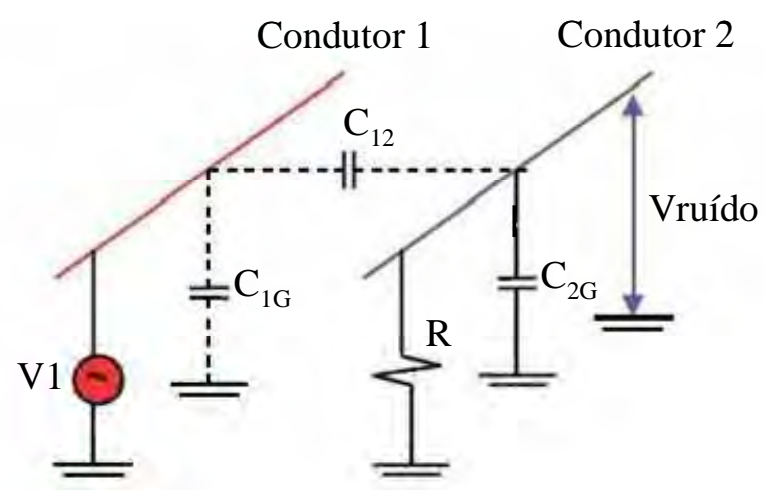

Figura 2.7 Acoplamento capacitivo (Adaptado de WHITE, 1973)
A Figura 2.7 mostra que:
$C_{12}=$ capacitância entre os condutores 1 e 2 ;
$C_{l G}=$ capacitância entre o condutor 1 e o plano de terra;
$C_{2 G}=$ capacitância total entre o condutor 2 e o plano de terra;
$R=$ resistência do condutor 2 para o plano de terra.

Sendo $V 1$ a tensão no condutor 1, a fonte de interferência, pode-se então calcular a tensão de ruído (Vruído) no condutor 2, que estaria sofrendo a influência do condutor 1. De acordo com (WHITE, 1973), o cálculo desta tensão de ruído acoplada, pode ser ainda mais simplificado quando no caso $R$ for menor que a impedância da capacitância parasita $C_{12}$ mais a impedância do condutor 2 (que acontece para frequências mais baixas), resultando na seguinte expressão:

$$
\text { Vruído }=j \omega R C_{12} V 1
$$

Esta expressão mostra claramente como os parâmetros influenciam o acoplamento de ruído e, em particular, como o acoplamento capacitivo aumenta com a frequência, principalmente quando há uma taxa de variação elevada (transição abrupta) da tensão no condutor 1, que irá produzir um maior acoplamento de ruído (WHITE, 1973).

Campos magnéticos existem sempre onde houver circulação de corrente elétrica, seja na geração, transmissão e distribuição de energia elétrica, seja em ambientes industriais e residenciais. Perto de linhas de transmissão, os campos magnéticos podem ir, geralmente, 
até cerca de $20 \mu \mathrm{T}$, enquanto estes valores estão entre $0,025 \mu \mathrm{T}$ a $0,07 \mu \mathrm{T}$ em ambientes residenciais e industriais. A intensidade de campo depende naturalmente da corrente elétrica e da distância no qual o campo é observado (WHITE, 1973).

Quando os campos magnéticos presentes no ambiente atravessam um loop formado por dois cabos quaisquer que se interligam a um mesmo equipamento, ocorre a indução de uma força eletromotriz, resultando em uma tensão de ruído. Para simplificar a análise do acoplamento indutivo, a interação dos campos magnéticos entre dois circuitos será representada por meio de indutâncias mútuas (como se todos os campos entre os elementos estivessem confinados no interior de um transformador de uma espira só), permitindo então trabalhar somente com uma variável (o tempo) na teoria normal de circuitos, conforme ilustra a Figura 2.8.

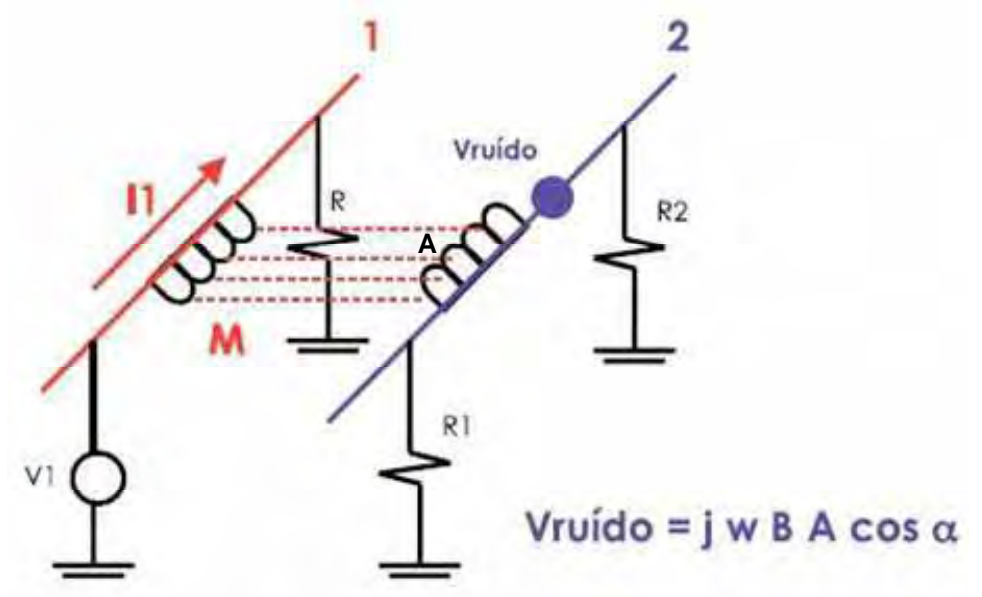

Figura 2.8 Acoplamento indutivo (adaptado de WHITE, 1973)

A expressão para o cálculo da tensão induzida, Vruído, pode ser escrita, portanto, na forma de indutância mútua entre os dois circuitos $(M)$, a qual depende da geometria e das propriedades magnéticas do meio entre os dois circuitos:

Vruído $=j \omega M I_{1}$

Assumindo que a densidade de fluxo varia senoidalmente com o tempo, mas continua constante em toda a área $A$ do circuito afetado, a tensão induzida (que representa a tensão de ruído), tem o valor simplificado para:

Vruído $=j \omega B A \cos \alpha$ 
Onde $\alpha$ = ângulo em que o fluxo corta o vetor área.

Ao analisar a expressão que descreve o acoplamento indutivo, observa-se que nem sempre é possível alterar a fonte (frequência e densidade de fluxo - termo $\omega B$ ). Eventualmente, pode-se alterar a orientação entre os circuitos (termo $\cos \alpha$ ), e principalmente a área do circuito afetado (termo $A$ ).

Ao se considerar os dois condutores em um circuito (fonte, carga e condutores de ida e retorno), devem distinguir-se duas formas de circulação de corrente: modo diferencial, o sinal desejado, significando que a corrente flui da fonte para a carga por um condutor e retorna pelo outro; e modo comum, o sinal indesejado (ruído), significando que a corrente flui na mesma direção em ambos os condutores do circuito, e retorna por um terceiro condutor, em geral um plano terra (origem do termo largamente utilizado - loop de terra) (WHITE, 1973).

Muitas vezes, os circuitos por onde fluem correntes em modo comum não têm uma conexão física (material) para fechar o "loop" para uma referência. Isto pode ser entendido, considerando-se que capacitâncias parasitas fecham o loop para a referência (terra) em um dos extremos do circuito (WHITE, 1973).

A Figura 2.9 ilustra esta situação, em que a circulação das correntes de modo diferencial $(I m d)$ e de modo comum (Imc, devido à capacitância fechar o loop com a fonte $(V s))$ caracterizam na carga $Z_{L}$ duas tensões: a tensão desejada, de sinal $(V s)$, e a tensão indesejada, de ruído $\left(V^{\prime} m c\right)$. Portanto, a circulação das correntes de modo diferencial produz a tensão desejada de sinal $(V s)$ e modo comum produz a tensão indesejada de ruído $\left(V^{\prime} m c\right)$.

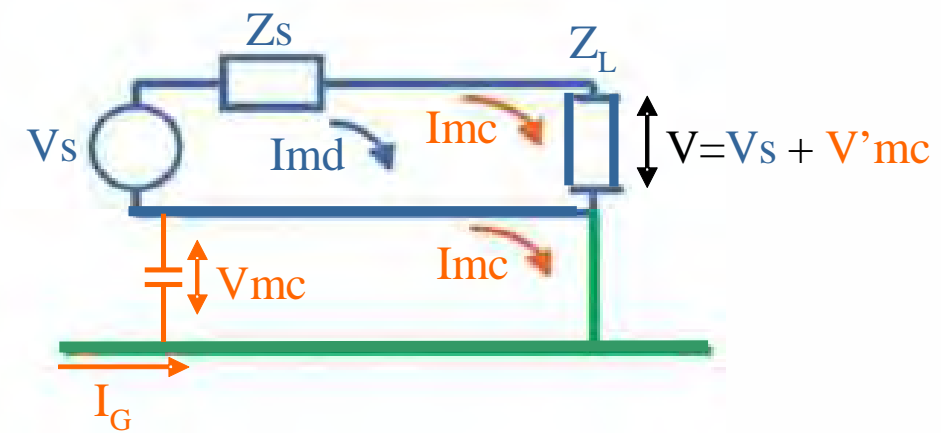

Figura 2.9 Ruído de modo comum e diferencial (adaptado de WHITE, 1973) 
As correntes em modo comum são as responsáveis pela maior parte dos problemas de interferências que aparecem em sistemas eletrônicos. A solução para estes problemas poderá estar pautada na redução de $I_{G}$ pelo terra de referência, de forma a evitar uma diferença de potencial entre os extremos do circuito, a qual pode ser obtida com a utilização de reatâncias (atenuação das componentes de alta frequência de $I_{G}$ ) e com a diminuição do comprimento dos cabos ou a utilização de blindagem (redução do valor da capacitância $C$ ), por exemplo.

\subsection{Interferência Eletromagnética em Cabos}

Existem três mecanismos básicos através dos quais a interferência pode ser acoplada e afetar um circuito: i) por campo elétrico, ii) por campo magnético e iii) por campo eletromagnético. Em alguns casos, somente um desses mecanismos pode efetivamente existir, enquanto em outros casos, todos podem estar presentes. Além disso, de forma a se obter uma análise global do problema, é necessário conhecer a fonte a partir da qual a interferência emana, bem como, a sensibilidade do equipamento perturbado (PAVIÉ \& STIH, 2004).

Sob o ponto vista dos cabos de uma subestação, não existe uma resposta única que atenda à todas as questões relativas às interferências eletromagnéticas. No ambiente de uma subestação, as interferências eletromagnéticas envolvem frequências que vão desde $60 \mathrm{~Hz}$ até $20 \mathrm{MHz}$. Devido, principalmente, às capacitâncias parasitas presentes nos cabos e nos equipamentos e circuitos terminais, o desempenho das soluções para mitigação do problema não se apresenta com comportamento uniforme em todo o espectro de frequências de interesse (PAVIÉ \& STIH, 2004).

Tensões de modo transversal (tensão gerada com orientação em paralelo ao condutor em relação ao seu eixo longitudinal) podem ocorrer diretamente por acoplamento capacitivo, enquanto que, os acoplamentos condutivo e indutivo desenvolvem tensões de modo comum (tensão gerada com orientação normal ao loop formado pelo cabo e o plano terra). Num circuito aterrado em apenas um dos extremos, o efeito inicial da tensão em modo comum é romper o isolamento (do cabo ou equipamento), enquanto que a tensão transversal apresenta-se como um sinal de tensão no circuito e funciona como uma perturbação (ruído) a seu funcionamento (WHITE, 1980). 
Para circuitos de baixa impedância, as tensões transversais são da ordem de milivolts, enquanto que, em circuitos de alta impedância essas tensões podem ser consideravelmente maiores. A questão de se utilizar ou não cabos blindados e, neste último caso, como escolher a blindagem, depende da intensidade da fonte, do maior ou menor acoplamento desta com o circuito, da sensibilidade (relação sinal/ruído) e do modo de aterrar este circuito.

\subsection{Caracterização dos Cabos}

Para melhor compreensão deste trabalho, faz-se necessário uma pequena explanação sobre cabos de sinais, suas classificações e utilizações.

\subsubsection{Cabos Telefônicos}

Os cabos telefônicos são frequentemente utilizados em subestações e também estão presentes em diversos setores. Esses cabos são caracterizados de diversas formas que serão descritas a seguir. Utilizou-se a nomenclatura encontrada em catálogos comerciais da Pirelli (Catálogo Divisão Cabos Pirelli, 1980), atualmente Prysmian (Catálogo Prysmian Cables \& Systems, 2008) que se baseia na nomenclatura da ABNT (Associação Brasileira de Normas Técnicas) e atende a uma ampla quantidade de cabos. As normas ABNT usadas são: NBR9124-1999, NBR9886-2005, NBR10484-1988, NBR10488-2001, NBR104971991, NBR10500-1988, NBR10501-2001, NBR11880-2000 e NBR14607-2000.

Os cabos telefônicos podem ser divididos em:

a) Cabos telefônicos para redes urbanas;

b) Cabos telefônicos para centrais e instalações telefônicas internas;

c) Fios para linhas de serviço de assinantes (drop-wire) e fios telefônicos para instalações internas;

d) Cabos coaxiais flexíveis para radiofrequência.

A seguir serão caracterizados os cabos telefônicos descritos acima e que são frequentemente encontrados em subestações. 


\section{a) Cabos Telefônicos para Redes Urbanas}

Os cabos telefônicos para redes urbanas podem ser subdivididos em três grupos:

a.1) Cabos telefônicos do sistema tronco e primário:

São cabos do tipo CT-APL, com isolamento em papel e capa APL (fita de alumínio politenada lisa, rigidamente colocada à capa externa de polietileno da cor preta).

Esses cabos podem ser compostos de 200 a 2400 ou mais pares de fios nos calibres 26 AWG $\left(0,40 \mathrm{~mm}^{2}\right), 24$ AWG $\left(0,51 \mathrm{~mm}^{2}\right), 22$ AWG $\left(0,64 \mathrm{~mm}^{2}\right)$ e 19 AWG $\left(0,91 \mathrm{~mm}^{2}\right)$ e são formados em grupos de 25, 50 ou 100 pares. Devem ser instalados em dutos e são cabos pressurizados, como exemplificado na Figura 2.10.

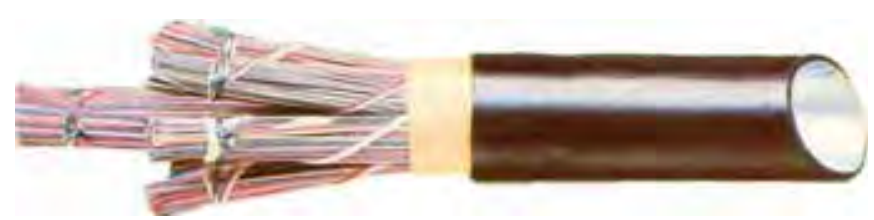

Figura 2.10 Exemplo de cabo telefônico para sistema tronco e primário

a.2) Cabos telefônicos do sistema secundário aéreo:

São cabos do tipo CTP-APL, com isolamento em polietileno ou polipropileno em capa APL e têm normalmente capacidade entre 10 a 200 pares nos calibres 26, 24, 22 e 19 AWG e são projetados para atenderem sistema de ondas portadoras até $150 \mathrm{kHz}$. A Figura 2.11 ilustra um cabo telefônico para sistema secundário.

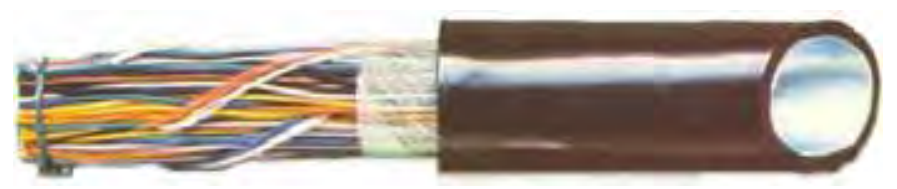

Figura 2.11 Exemplo de cabo telefônico para sistema secundário

a.3) Cabos telefônicos do sistema secundários subterrâneos em dutos ou diretamente enterrados no solo:

São cabos do tipo CTP-APL/G, com isolamento em polietileno ou polipropileno, com capa APL e com seus interstícios preenchidos com geléia de petróleo. Esses cabos são 
normalmente encontrados com capacidade de 10 a 200 pares, nos calibres 26, 24, 22 e 19 AWG. Esses cabos são projetados para atenderem sistema de ondas portadoras até 150 kHz. A Figura 2.12 ilustra um cabo telefônico para sistemas secundários subterrâneos.

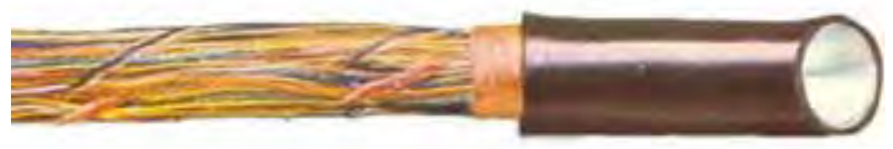

Figura 2.12 Exemplo de cabo telefônico para sistema secundário subterrâneo

\section{b) Cabos Telefônicos para Centrais e Instalações Telefônicas Internas}

Os cabos telefônicos para centrais telefônicas e instalações telefônicas internas podem ser subdivididos em dois grupos (considerando-se o catálogo do fabricante Pirelli como referência):

b.1) Cabos telefônicos tipo TILINTER (CI-J):

São cabos utilizados em instalações internas de centrais telefônicas, em edifícios, indústrias, etc, e são encontrados com 1 par até 1000 pares. Esses cabos têm blindagem que são construídas com fitas de alumínio e com dois fios de cobre. A Figura 2.13 ilustra um cabo telefônico tipo TILINTER (CI-J).

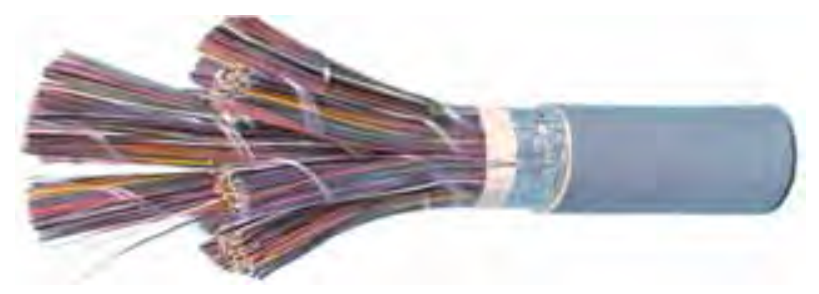

Figura 2.13 Exemplo de cabo telefônico TILINTER (CI-J)

b.2) Cabos telefônicos tipo TILISTA (CIS-J):

São cabos utilizados em instalações internas de centrais telefônicas, em edifícios, indústrias, etc. A sua principal diferença em relação aos cabos tipo TILINTER é a ausência de blindagem. A Figura 2.14 ilustra um cabo telefônico tipo TILINTER (CIS-J). 


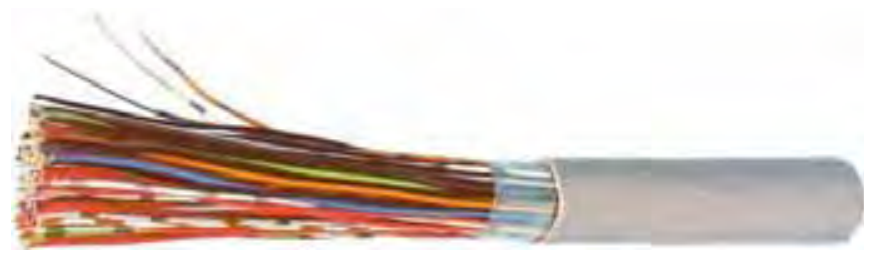

Figura 2.14 Exemplo de cabo telefônico TILINTER (CIS-J)

\section{c) Condutores para Linhas de Serviço de Assinantes (drop-wire) e Condutores Telefônicos para Instalações Internas}

A grande maioria deste cabo é utilizada para interligar assinantes ao longo da planta de uma subestação. Por essa característica é um dos cabos mais utilizados em instalações e mais suscetível às interferências eletromagnéticas dentro das subestações.

c.1) Fios para linhas de assinantes tipo drop-wire:

Estes fios são utilizados em instalações aéreas como derivação a partir de caixas de distribuição até as entradas dos assinantes. Pode ser utilizado embutido em eletrodutos e não possuem blindagem. A Figura 2.15 ilustra um cabo telefônico tipo drop-wire.

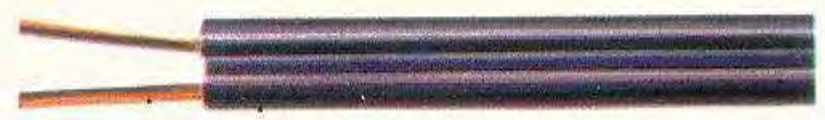

Figura 2.15 Exemplo de cabo telefônico tipo drop-wire

c.2) Fios telefônicos para instalações internas:

Os fios telefônicos para instalações internas possuem os condutores isolados e são reunidos helicoidalmente. Não possuem blindagem e normalmente são encontrados na cor cinza claro. Comparando-se com o drop-wire a sua isolação é menor, porém mais maleável para ser instalado. A Figura 2.16 ilustra um cabo telefônico para instalações internas.

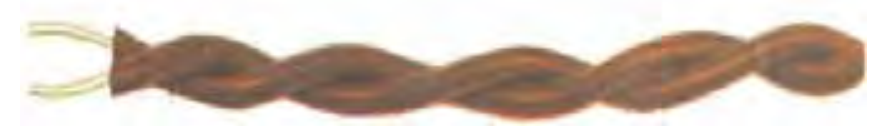

Figura 2.16 Exemplo de cabo telefônico para instalações internas 


\section{d) Cabos Coaxiais Flexíveis para Radiofrequência}

Os cabos coaxiais foram desenvolvidos para sistemas de alta-frequência, oferecendo uma boa qualidade de transmissão e recepção, com baixa atenuação, ausência de distorções e de reflexões e blindagem contra ruídos externos. Esses cabos têm baixo fator de perdas, baixa constante dielétrica e regularidade de impedância. Os cabos coaxiais são encontrados também com blindagem dupla para assegurar uma melhor proteção contra interferências eletromagnéticas. A Figura 2.17a e b ilustra cabos coaxiais flexíveis para radio frequência com blindagem simples e dupla respectivamente.

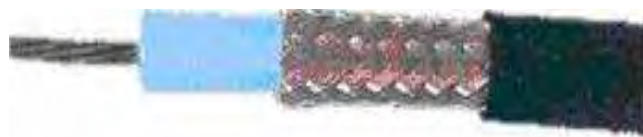

a)

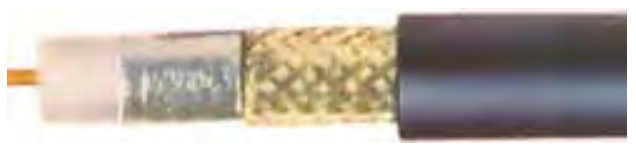

b)

Figura 2.17 Exemplos de cabos coaxiais com blindagem simples(a) e blindagem $\operatorname{dupla}(b)$

\subsubsection{Cabos de Controle}

Os cabos de controle são destinados a transmissões de baixa potência com baixa tensão, e muitas vezes em corrente contínua. Normalmente são cabos com vários condutores, encontrados com ou sem blindagem e são fabricados sob encomenda (com duas ou três blindagens). A Figura 2.18 ilustra um cabo de controle.

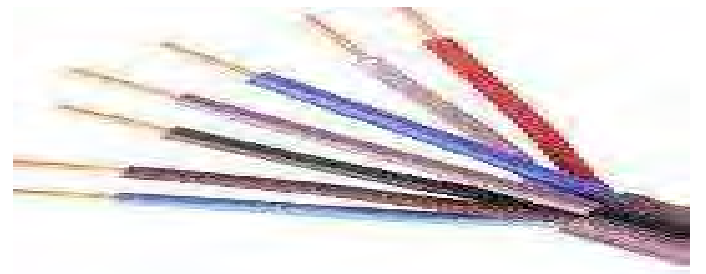

Figura 2.18 Exemplo de um cabo de controle 


\subsubsection{Cabos de Par Trançado}

O cabo de par traçado foi originalmente projetado para voz, porém, o mesmo passou por vários avanços que o tornaram adequado para telefones, workstations, terminais $\mathrm{e}$ sistemas computacionais. Podem ser encontrados em diversos padrões que suportam diferentes taxas de transferência e de acordo com a padronização (EIA/TIA 568-1991) (Electronic Industries Alliance / Telecommunications Industry Association) são classificados:

- $\quad$ Cabo flat satin silver (voz) até 1 MBPS;

- $\quad$ Cabo categoria 3 (voz/dados) até 10 MBPS;

- $\quad$ Cabo categoria 4 (voz/dados) até 16 MBPS;

- $\quad$ Cabo categoria 5 (vos/dados) até 100 MBPS;

- $\quad$ Cabo categoria 6 (voz e dados) até 10 GBPS.

Além dos cabos de par trançado sem blindagens (UTP), podem-se encontrar cabos par trançado com blindagem coletiva (STP) e com blindagem individual para cada par. $\mathrm{O}$ cabo par trançado sem blindagem categoria 6 é mais comumente utilizado, devido a seu baixo custo e fácil instalação. Entretanto, o nível de interferência é o que normalmente determina a escolha deste cabo. A Figura 2.19 ilustra um exemplo de cabo de par trançado categoria 6 para rede de computadores.

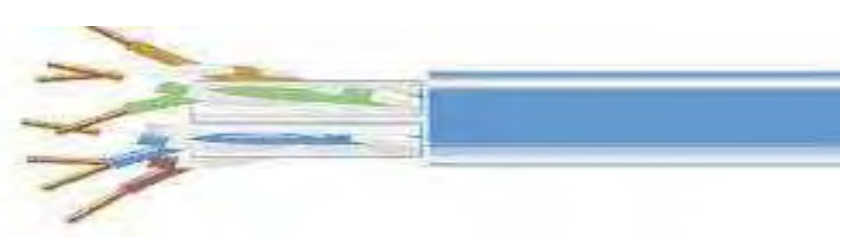

Figura 2.19 Exemplo de um cabo de par trançado categoria 6

\subsection{Interferência Eletromagnética em Subestações}

A interferência eletromagnética é um grande problema gerado pelas subestações de alta tensão que interligam as redes de transmissão, comprometendo não só o meio, mas também interferindo em dispositivos eletrônicos instalados dentro da subestação, tais como: equipamentos de medidas, de comandos e de controles (PAVIÉ \& STIH, 2004). 
Em subestações de potência, o número de equipamentos eletrônicos utilizados tem aumentado tanto no pátio como nas salas de controle. Operações de chaveamento, faltas espontâneas ou descargas atmosféricas dentro da subestação podem causar grandes danos decorrentes das interferências eletromagnéticas de alta frequência. Essas interferências podem acoplar-se em circuitos de controle e supervisão de baixa tensão e equipamentos eletrônicos, desde que os mesmos não estejam adequadamente protegidos. Este ambiente de interferência eletromagnética transitória necessita ser completamente caracterizado pelas formas de ondas e seus espectros para os níveis mais altos esperados em ambos os locais (pátio e dentro da sala de comando). Esses níveis de interferências eletromagnéticas podem então ser comparados com os níveis de suscetibilidade dos equipamentos para verificação de distúrbios, danos e também da capacidade de suportarem níveis de surtos para avaliação de suas capacidades mútuas e adequações (WIGGINS et al., 1994).

Segundo (WIGGINS et al., 1994) os níveis e mecanismos de acoplamento das interferências conduzidas e radiadas nos condutores em subestações são descritos usandose resultados de medidas realizadas e modelos eletromagnéticos validados por meio das medidas. O campo eletromagnético máximo e os níveis de interferências nos cabos de controle e supervisão, esperados no pátio da subestação e dentro da sala de comando, a partir de operações de chaveamentos, faltas e de descargas atmosféricas são estimadas utilizando-se modelos de acoplamento transitório de alta frequência. Adicionalmente, comparações com padrões são realizadas e recomendações são dadas com respeito à blindagem do equipamento e proteção contra surtos.

Outras pesquisas mais recentes abordam distúrbios (interferências, transitórios rápidos, entre outros eventos) produzidos por circuitos de disjuntores, chaves a gás e barramentos em subestações (BARRACK et al., 1997) e (RAO et al., 2003).

Para (WHITE, 1973), a interferência eletromagnética pode causar vários problemas nos equipamentos eletroeletrônicos, quando um condutor de eletricidade percorrido por uma corrente elétrica gera ao seu redor um campo eletromagnético. Dependendo da frequência e da intensidade da corrente, esse campo pode comprometer equipamentos mais sensíveis. Se a intensidade ultrapassar determinados valores, alguns defeitos podem ocorrer, tais como: falhas de comunicação entre equipamento e computador; erros na execução do programa, geralmente sem seguir um padrão específico; falhas intempestivas 
e que não seguem uma lógica; danos aos circuitos eletrônicos, mesmo sendo novos e confiáveis.

A proteção de equipamentos e seus periféricos sejam eles os cabos de comunicação ou alimentação, multiplexadores ou sensores a eles acoplados, é necessário considerar os seguintes itens (WHITE, 1973) e (CHRISTOPOULOS, 1995):

a) Proteção primária: protege a rede de energia elétrica que alimenta os equipamentos/ periféricos;

b) Proteção secundária: melhora a proteção primária na etapa de alimentação dos equipamentos/periféricos;

c) Proteção contra descargas atmosféricas: protege equipamentos/periféricos e principalmente o operador (ser humano);

d) Proteção contra campos eletromagnéticos gerados por descargas nuvem-nuvem, nuvem-terra e redes de alta tensão: protege equipamentos/periféricos contra IEM.

Segundo (WIGGINS et al., 1995) e (GRIJP \& BORN, 1996) as principais fontes de interferências são:

a) Circuitos Primários - Circuitos primários normalmente possuem tensões e correntes na frequência de 50/60Hz. Eventos como chaveamentos, descargas atmosféricas e condições de faltas, podem ocasionar tensões e correntes com frequências até $10 \mathrm{MHz}$. Os circuitos primários incluem as linhas, barras, transformador de potencial e corrente.

b) Equipamentos Primários - Equipamentos primários são fontes de campos em altas freqüências, tanto em funcionamento normal, quanto em transitórios. Transformadores podem, dependendo da sua função e construção, amplificar transitórios oriundos de chaveamentos. Dispositivos de potência, tais como, o conversor HVDC (High Voltage Direct-Current) e SVC (Static Var Compensator), são fontes de interferências de grande magnitude;

c) Circuitos Secundários - Transitórios de tensões podem ser induzidos nos circuitos do secundário, devido a operações de chaveamento. Os circuitos secundários incluem disjuntores, circuitos de desconexão de bobinas e todos os circuitos dos relés; 
d) Descargas Atmosféricas - As descargas atmosféricas diretas nos circuitos primários, ou muito próxima deles (descargas indiretas), podem interferir nos equipamentos instalados nos circuitos secundários, dispositivos de medidas, comandos e sinais de proteção, por meio da radiação eletromagnética ou por meio de diferentes tensões de modo comum (aterramento), resultantes da descarga;

e) Problemas no Sistema de Medição - Nos circuitos primários de medição de tensão e corrente, durante um transitório, existirão componentes de frequência muito maiores que seus valores nominais de transferências desses sinais. Normalmente esses equipamentos trabalham na faixa de até $10 \mathrm{kHz}$, portanto, durante os transitórios, surgirão medidas incoerentes na medição dessas grandezas.

\subsection{Receptores de Interferência Eletromagnética}

Nas subestações, os receptores de EMI podem ser desde o cabeamento de interligação dos equipamentos (interferência conduzida) até o espaço livre (interferência radiada). Os distúrbios podem afetar a fonte de alimentação e conexões de um equipamento, conduzindo/radiando a interferência em circuitos internos, causando degradação temporária ou permanente no funcionamento do dispositivo (KOUYOUMDJIAN, 1998).

O distúrbio elétrico mais comum é a rajada (Burst) ou EFT (Electrical Fast Transient), um ruído de alta frequência que "entra" pela alimentação e/ou conexões do equipamento, afetando componentes, como por exemplo, os reguladores de tensão. Alguns equipamentos estão preparados para filtrar os ruídos de baixa frequência, mas não estão preparados para filtrar os de alta (Burst), sendo assim, totalmente danosos aos equipamentos eletrônicos. Alguns equipamentos digitais utilizados nas subestações podem ser bastante vulneráveis ao Burst, pois podem interpretar os transientes como informação válida e gerar uma operação ou comando errado (KOUYOUMDJIAN, 1998).

Ainda tratando-se de EMI, podem-se destacar também as formas com que esses distúrbios afetam os equipamentos de uma subestação. Existem três caminhos de EMI entre a fonte emissora e o receptor: radiação, condução e indução. A EMI radiada se propaga a partir da fonte, por meio do espaço livre até o receptor. Um sinal conduzido viaja através de fios conectados entre a fonte e o receptor, sendo o mais representativo para 
a análise desta etapa. Os induzidos são gerados pelo acoplamento eletromagnético dos circuitos e também representa um ponto a ser discutido exaustivamente. Pode ainda existir a composição de mais de uma das interferências até aqui apresentadas, como por exemplo, a indução em circuitos externos de um equipamento e a condução de outra interferência pela rede de alimentação de circuitos auxiliares de uma subestação.

O modo de acoplamento está relacionado com a frequência e ao comprimento de onda de um sinal/ruído. Baixas frequências propagam-se facilmente por meios condutivos, mas não tão eficientemente por um meio radiado. Altas frequências se propagam eficientemente pelo ar e são bloqueadas pelas indutâncias e blindagens do cabeamento. Quando o receptor está próximo da fonte (campo próximo), os campos elétricos e magnéticos são considerados separadamente. Quando o receptor está longe da fonte (campo distante), a radiação é considerada como eletromagneticamente combinada (KOUYOUMDJIAN, 1998).

Essas distinções são importantes, pois alguma medida de prevenção só elimina um tipo de ruído. Além disso, o modo do ruído (assinatura) normalmente dá pistas de sua origem. Distúrbios de modo diferencial provavelmente provêm do mesmo circuito, ou seja, são conduzidos. Ruídos de modo diferencial predominam em frequências abaixo de $1 \mathrm{MHz}$, enquanto que os de modo comum predominam em frequências acima de $1 \mathrm{MHz}$ (KOUYOUMDJIAN, 1998).

\subsection{Chaveamento Elétrico}

Segundo (GREENWOOD, 1992), os transitórios de chaveamento decorrem das operações de ligar e desligar chaves e disjuntores. Estas operações estão associadas a manobras de equipamentos e sistemas, rejeição de carga, eliminação de faltas, dentre outras. Sua magnitude é influenciada pela configuração e potência de curto-circuito do sistema, bem como, pelas características dos equipamentos envolvidos nas operações de chaveamento. A probabilidade de ocorrência de defeitos em sistemas elétricos varia de sistema para sistema, em média, menos de 1 (um) porcento das faltas tem origem em operações de chaveamentos. Para estudos de EMI, os chaveamentos elétricos dão origem a dois tipos de perturbação (fontes de EMI): 
a) Geração de arco elétrico e

b) Transitórios eletromagnéticos.

A caracterização de transitórios eletromagnéticos para estudo de EMI advém do principal elemento envolvido no fenômeno. Assim, tem-se:

- Surtos devido ao chaveamento de linhas;

- Surtos decorrentes do chaveamento de pequenas correntes capacitivas;

- Surtos decorrentes do chaveamento de grandes transformadores ou indutores;

- $\quad$ Surtos decorrentes da rejeição de carga;

- $\quad$ Surtos decorrentes de faltas (a maioria é fase-terra ou fase-fase).

As operações de chaveamentos em sistemas elétricos podem dar origem a transitórios eletromagnéticos com características diversas. Entretanto, o espectro de frequências de interesse situa-se entre $60 \mathrm{~Hz}$ e $300 \mathrm{kHz}$ (DIMCHEV et al., 1998).

O arco elétrico decorrente de um chaveamento ou de um defeito é uma fonte importante de EMI e o seu comportamento sofre a influência de fatores como:

a) Meio no qual ocorre o arco;

b) Tipo de corrente que vai ser estabelecida ou interrompida;

c) Instante em que ocorre o chaveamento;

d) Velocidade do chaveamento;

e) Ponto do sistema elétrico onde ocorre o chaveamento.

O ruído de chaveamento é um tipo especial de EMI constituído por pulsos repetitivos de amplo espectro de frequências que ocorrem continuamente e são, geralmente, de modo diferencial. A propagação destes ruídos se dá por condução e um forte aliado para a atenuação dos mesmos são as indutâncias dos condutores, as quais criam uma alta impedância que dificulta a circulação destas correntes (SANCHES, 2003).

Por conterem componentes em altas frequências, estes ruídos tendem a propagar-se pela superfície dos condutores. Os fios rígidos por apresentarem pouca superfície de 
condução, favorecem a atenuação deste ruído. Entretanto, os ruídos que não são atenuados e penetram nos equipamentos impõem o mau funcionamento dos mesmos. O que ocorre nestes equipamentos poderá contaminar os sinais analógicos e digitais que levam os circuitos a interpretarem as funções erroneamente, impondo, por exemplo, um falso desligamento (trip).

Principalmente nos circuitos digitais, que trabalham com processamento de dois níveis discretos de tensão, a forma de onda deve ter as bordas de mudança de estado sem ruído, caso contrário, a interpretação dos níveis lógicos será alterada e ocorrerá modificação nos bytes a serem processados. Um único byte alterado significa uma informação errada e o cumprimento de uma determinada função acaba por ficar comprometida. Isso é especialmente ruim para circuitos de controle que realizam tarefas importantes na subestação (SANCHES, 2003).

\subsection{Descargas Atmosféricas}

As descargas atmosféricas são as maiores fontes de radiação eletromagnética que interferem na operação de equipamentos elétricos e eletrônicos. O conhecimento de como se comportam os pulsos eletromagnéticos de uma descarga atmosférica, em uma dada região, é essencial para estabelecer os níveis de proteção dos sistemas elétricos e eletrônicos, bem como, de edificações que contenham sistemas sensíveis à transitórios eletromagnéticos. Baseando-se nas características dos PEDA (Pulsos Eletromagnéticos da Descarga Atmosférica) e no risco aceitável, um sistema ou equipamento pode ser protegido contra descargas atmosféricas de maneira eficaz e econômica (WHITE, 1980).

De acordo com a (IEC 61312-1, 1995), um PEDA é definido como "a corrente e os campos de um impulso eletromagnético, como uma fonte de interferência". Contudo, para propósitos de estudo, um PEDA pode ser definido como qualquer corrente, campo elétrico ou campo magnético decorrente de uma descarga atmosférica que tem potencial para causar interferência eletromagnética em sistemas construídos pelo homem.

Embora o raio possa parecer para o olho humano uma descarga contínua, na verdade em geral ele é formado de múltiplas descargas, denominadas descargas de retorno, que se sucedem em intervalos de tempo muito curtos. Ao número destas descargas, dá-se o nome 
de multiplicidade de raio. Durante o intervalo entre as descargas, variações lentas e rápidas de corrente podem ocorrer.

Para efeito do estudo da influência indireta (indução eletromagnética) de descargas ao solo, quatro parâmetros são importantes (KOUYOUMDJIAN, 1998):

- $\quad$ Corrente de pico (Ip): o valor de crista da descarga ao solo é responsável pela queda de tensão em malhas de aterramento e afeta o grau de penetração em cabos e equipamentos;

- Taxa de variação máxima da corrente de descarga $(d i / d t)_{\max }$ : determina todos os tipos de indução eletromagnética, sendo, um parâmetro importante no estudo da EMI;

- $\quad$ Carga elétrica total $\left(Q=\int i \cdot d t\right)$ : trata-se da energia transmitida pela descarga ao solo ou blindagem. Afeta a difusão do transitório eletromagnético em blindagens metálicas;

- Integral de Joule ( $\left.\int i^{2} d t\right)$ : quantifica os efeitos mecânicos em elementos condutores.

De forma geral, o espectro de frequências das descargas atmosféricas normalmente utilizadas para estudos de EMI situa-se entre 0 e $1 \mathrm{MHz}$ (WHITE, 1980).

\subsection{Blindagem}

Segundo (MARIN, 2008), "a blindagem eletromagnética é uma técnica empregada para reduzir ou prevenir o acoplamento de sinais indesejados em um dado sistema para que ele opere de forma adequada em seu ambiente do ponto de vista da interferência eletromagnética. A blindagem pode ser usada também para minimizar o nível de emissão de um dado sistema em seu ambiente de operação. É uma técnica eficiente em vários graus dentro uma ampla faixa do espectro eletromagnético, desde frequências muito baixas até microondas".

A blindagem é uma das técnicas empregadas em sistemas de cabeamento em geral, para proteger os sinais que se propagam por eles, dos efeitos da interferência eletromagnética. Tecnicamente, a blindagem é uma forma eficiente para a redução dos 
acoplamentos capacitivos e indutivos sem que a distância de separação entre os circuitos interferentes e interferidos tenha de ser aumentada.

\subsection{Estado da Arte}

Esta seção apresenta os estudos, as pesquisas e as publicações científicas relacionadas com o tema desta dissertação.

A avaliação da suscetibilidade eletromagnética de cabos metálicos isolados, blindados ou não, para atender aos sistemas de supervisão, proteção, comunicação e controle de subestações de alta tensão frente às interferências eletromagnéticas, provocadas pelas descargas atmosféricas, manobras de chaveamento, campo magnético na frequência de $60 \mathrm{~Hz}$ e do efeito corona é um assunto muito complexo, restrito e muito pouco explorado na literatura científica internacional ou nacional. Os trabalhos existentes não abordam diretamente o assunto e sim de uma forma mais genérica, ora focando um modelo matemático para representar os fenômenos eletromagnéticos presente em dispositivos, malhas de aterramento e cabos em geral, ora focando uma ferramenta matemática para medir os campos elétrico ou magnético presentes em plantas industriais e subestações sobre um dispositivo eletrônico ou cabos de energia e de sinal. Por esta razão a maioria das publicações aqui apresentadas não está diretamente relacionada com este trabalho de pesquisa. Apenas duas das publicações científicas têm relação com este trabalho e foram amplamente utilizadas na elaboração desta dissertação.

Segundo (LEE \& BAUM, 1975), no estudo teórico dos cabos blindados com cordoalha, o objetivo principal é derivar um conjunto de equações de linha de transmissão das quais se podem calcular a tensão e a corrente induzida pelas fontes externas em uma impedância de carga que pode ser representado por um equipamento eletrônico conectado a este cabo. Para desenvolver um conjunto de equações de uma linha de transmissão a partir das equações de Maxwell que irão envolver as polarizabilidades (componentes tangenciais e longitudinais dos campos elétrico e magnético no interior do cabo) e também as correntes e cargas na superfície externa da blindagem, é mais conveniente utilizar análise modal. Propõe-se um modelo inicial, baseado em pequenas aberturas ou falhas nas cordoalhas, para depois chegar a um modelo experimental, com várias equações para 
calcular a interferência eletromagnética acoplada ao cabo blindado com cordoalha. Não propõe nenhuma simulação para verificar a validade das equações em situações práticas, embora faça considerações matemáticas de parâmetros reais dos cabos.

De acordo com (THOMAS et al., 1994), é possível elaborar modelos preditivos para os transientes de EMI acoplados direta ou indiretamente nos cabos, provenientes de chaveamentos elétricos em subestações normais (isoladas a ar) ou blindadas (isoladas a gás) e podem ser comparados com os transientes medidos nesses próprios cabos. Apresenta valores obtidos através de medições feitas em cabos que foram escolhidos, segundo a importância e suscetibilidade do mesmo (mais crítico). Os cabos foram colocados nos pátios das subestações, paralelos aos cabos existentes, e daí foram feitas as medições das tensões e correntes induzidas nesses cabos guias. Um modelo foi descrito para predizer os transientes que podem ser acoplados nos cabos presentes em uma subestação. Este modelo foi desenvolvido baseado em um programa de análise de redes METAP da McGrawEdison. Para o acoplamento de campos magnéticos foi usado um modelo de (GREENWOOD, 1971) adaptado. Uma comparação dos dados obtidos das medições de campos foi confrontada com os dados obtidos das simulações encontradas dos modelos propostos, mostrando que valores medidos e simulados são próximos, mas nunca iguais, devido a fatores que fogem do controle no modelo e na medição em campo.

(DARNEY, 1997), propôs analisar interferências eletromagnéticas em cabos, inclusive blindados, com o uso de ferramentas de circuitos elétricos. Seu modelo permite um sistema que envolva interferências eletromagnéticas em uma linha de transmissão seja analisado como um circuito elétrico simples, sendo que o comportamento eletromagnético das correntes é tratado como indutâncias mútuas e capacitâncias de acoplamento. A formulação apresentada pode ser considerada como uma solução dentro do escopo da teoria de eletromagnetismo e circuitos.

Os modelos apresentados por (DARNEY, 1997), tanto para cabo paralelo como para cabo coaxial serão utilizados neste trabalho para confirmar a configuração dos ensaios laboratoriais dos cabos ensaiados, conforme detalhes no Capítulo 3.

Para (RAO et al., 2003), para o cálculo da impedância de transferência (eficiência da blindagem) de um cabo é preciso estudar: i) a influência dos campos eletromagnéticos, ii) 
como aterrar a blindagem dos cabos, iii) contribuição dos componentes vertical e horizontal dos transientes, iv) comprimentos dos cabos, v) altura dos cabos em relação à malha de aterramento da subestação, vi) corrente e tensões induzidas. Um modelo é proposto, baseado na média da impedância característica distribuída ao longo da blindagem do cabo. Para simplificar o modelo é desprezado o campo magnético e elétrico de uma forma separada (campo próximo) e é considerado apenas o campo eletromagnético (campo distante). A simulação foi feita usando vários comprimentos de cabos e com várias frequências de corte para simular interferência em uma faixa larga $(0,5 \mathrm{MHz}-200 \mathrm{MHz})$. Como resultado foi observado que as tensões induzidas no condutor central do cabo são dependentes do tipo de aterramento da blindagem usada, direção do campo, comprimento do cabo, altura do cabo em relação à malha de aterramento, componentes frequenciais dos campos, impedância de transferência do cabo e configuração da subestação.

Segundo (HE et al., 2002), apresenta-se um método de calcular as interferências eletromagnéticas nos cabos de controles, causadas pelas faltas provocadas por curtoscircuitos. A diferença de potencial presente no condutor central e na blindagem é calculada, considerando a influência da altura da malha de aterramento enterrada no solo em relação aos cabos e à resistividade do solo. Foi simulada uma malha de aterramento usando um circuito equivalente tipo T, para os cálculos da impedância e da admitância da mesma. Uma malha com um tamanho definido (10m de largura e $10 \mathrm{~m}$ de comprimento) foi estabelecida e um cabo de controle foi ligado a dois pontos distantes da mesma e foram simuladas várias correntes de curto-circuito de diferentes intensidades com vários valores de resistividade do solo. Como resultado das simulações, conclui-se que a resistividade do solo tem uma pequena influência na magnitude da diferença de potencial entre o condutor central e a blindagem do cabo. $\mathrm{O}$ aumento da malha de aterramento tem uma grande influência na diferença de potencial entre o condutor central e a blindagem. Portanto o autor recomenda uma atenção maior para subestações de $500 \mathrm{kV}$, pois essas diferenças de potenciais tendem a ficarem maiores.

De acordo com (ARDJOMAND et al., 2005), em subestações novas, os requisitos de compatibilidade são levados em conta desde a fase inicial do projeto, o que representa uma grande economia de tempo e de recursos financeiros. Desta forma, para subestações 
antigas em fase de digitalização, medidas especiais devem ser tomadas na instalação de novos equipamentos sensíveis. Tais medidas, como a segregação de cabos ou ainda a troca de cabos antigos por cabos blindados, são inviáveis de serem realizadas com a instalação em funcionamento.

A pesquisa desenvolvida teve como objetivo primordial o desenvolvimento de uma blindagem com características de maleabilidade que permitam sua implantação em instalações antigas em fase de digitalização ou mesmo em novas instalações a custos competitivos com as tecnologias utilizadas atualmente. Para a realização da pesquisa com blindagens, construiu-se uma bancada específica para este tipo de ensaio, que é composta de várias mesas de madeira com um comprimento total de 14 metros. As mesmas foram colocadas sobre um plano metálico composto de chapas de aço galvanizado, medindo 14 metros de comprimento e 1 metro de largura. O arranjo permite a realização de ensaios com blindagens através da colocação de cabos geradores de distúrbios em paralelo com cabos sensíveis, de modo a se avaliar o acoplamento entre estes dois tipos de cabos para diferentes tipos de transitórios eletromagnéticos aplicados.

Embora a finalidade deste projeto de pesquisa fosse para pesquisar novas formas de blindar os leitos dos cabos (canaletas), viabilizou o arranjo da montagem da bancada de ensaios deste trabalho, que é discutida no Capítulo 3. 


\section{Capítulo 3}

\section{Materiais e Métodos}

Por se tratar de um trabalho de cunho experimental, este capítulo foi divido em materiais (que descreverá os equipamentos), instrumentos e montagens realizadas, e métodos, que abordará a modelagem de cabos (circuitos equivalentes) e os ensaios laboratoriais.

\subsection{Cabos Utilizados}

As Tabelas 3.1 e 3.2 apresentam os cabos elencados como objeto de estudo deste trabalho, bem como, o emprego mais comum de cada tipo. O critério de escolha deu-se devido à grande utilização destes cabos em sistemas supervisão, proteção, comunicação e controle de subestações de alta tensão.

Tabela 3.1 Cabos sem blindagem

\begin{tabular}{|c|c|c|}
\hline Amostra & Tipo de Cabo & Utilização \\
\hline 10 & $\begin{array}{l}\text { Cabo com } 20 \text { condutores } \\
\left(1,5 \mathrm{~mm}^{2}\right) \text { isolados, sem } \\
\text { blindagem e envoltos em } \\
\text { folha de plástico } \\
\text { transparente. Capa } \\
\text { externa de PVC na cor } \\
\text { preta. } \\
\text { FNCE controle metanax - } \\
\text { 20x1,5mm², cobre - } \\
\text { 1kV - PVC/A STI - } \\
\text { NBR7289, 2004. }\end{array}$ & $\begin{array}{l}\text { Este cabo é normalmente utilizado em } \\
\text { comando e controle e pode também ser } \\
\text { utilizado em supervisão, proteção, sinalização } \\
\text { e teleproteção. O cabo é raramente utilizado } \\
\text { em telecomunicações e informática. Este cabo } \\
\text { é muito utilizado no interior de eletrodutos e } \\
\text { canaletas, porém nunca imerso em água. }\end{array}$ \\
\hline
\end{tabular}




\begin{tabular}{|l|l|l|}
\hline 17 & $\begin{array}{l}\text { Cabo para rede de } \\
\text { computadores - categoria } \\
5 \text { UPT sem blindagem. }\end{array}$ & $\begin{array}{l}\text { Este cabo é normalmente utilizado para redes } \\
\text { internas de computadores e pode ser utilizado } \\
\text { em telecomunicações, principalmente para } \\
\text { Capa externa na cor azul } \\
\text { e condutores de cobre } \\
\text { isolados com PVC. } \\
\text { Catálogo AMP: categoria } \\
\text { ligações dos ramais das centrais telefônicas. } \\
\text { riser (CMR) rated - } \\
\text { 24AWG - 100 ohms. }\end{array}$ \\
\hline
\end{tabular}

Tabela 3.2 Cabos com blindagem

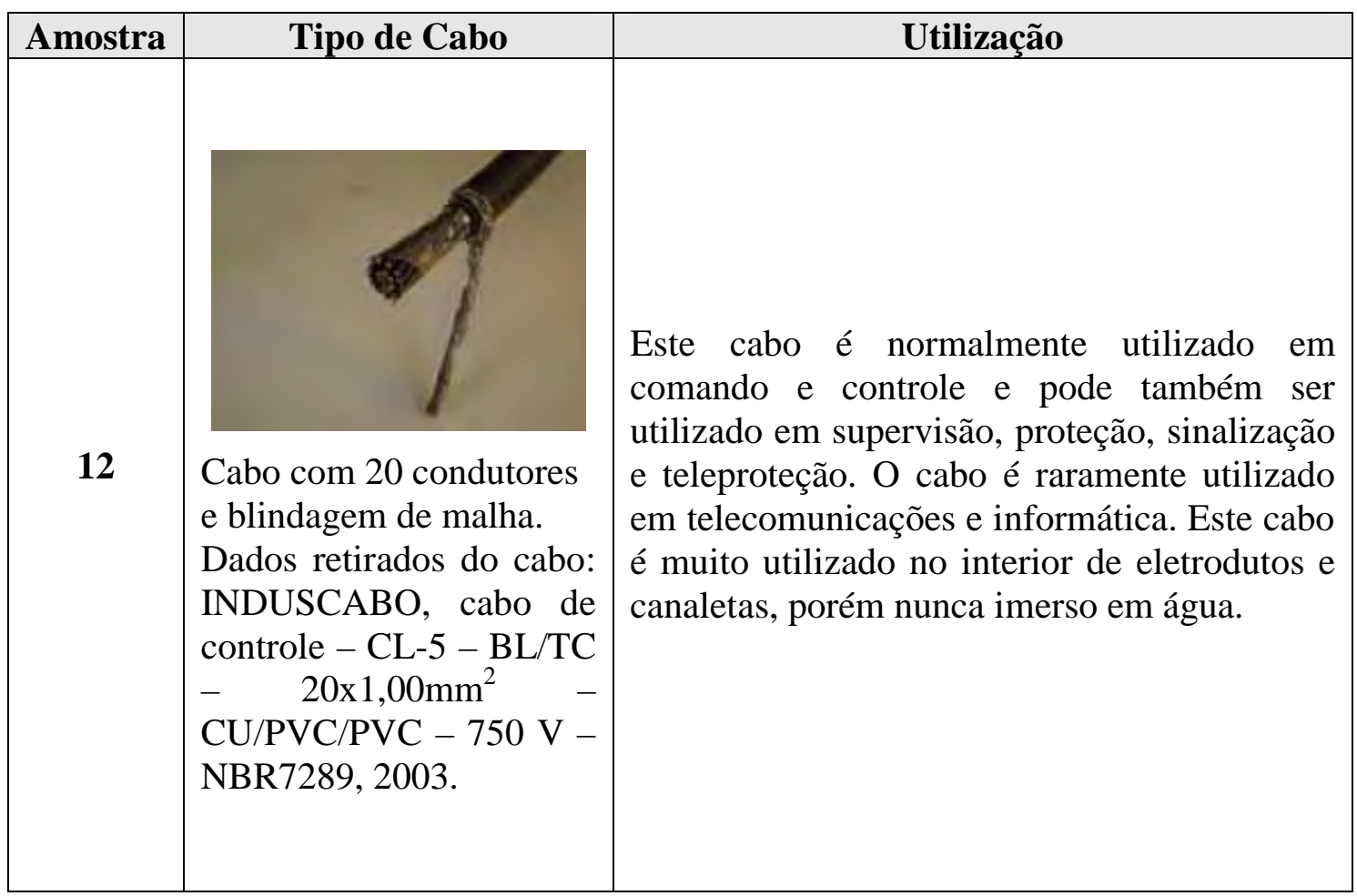




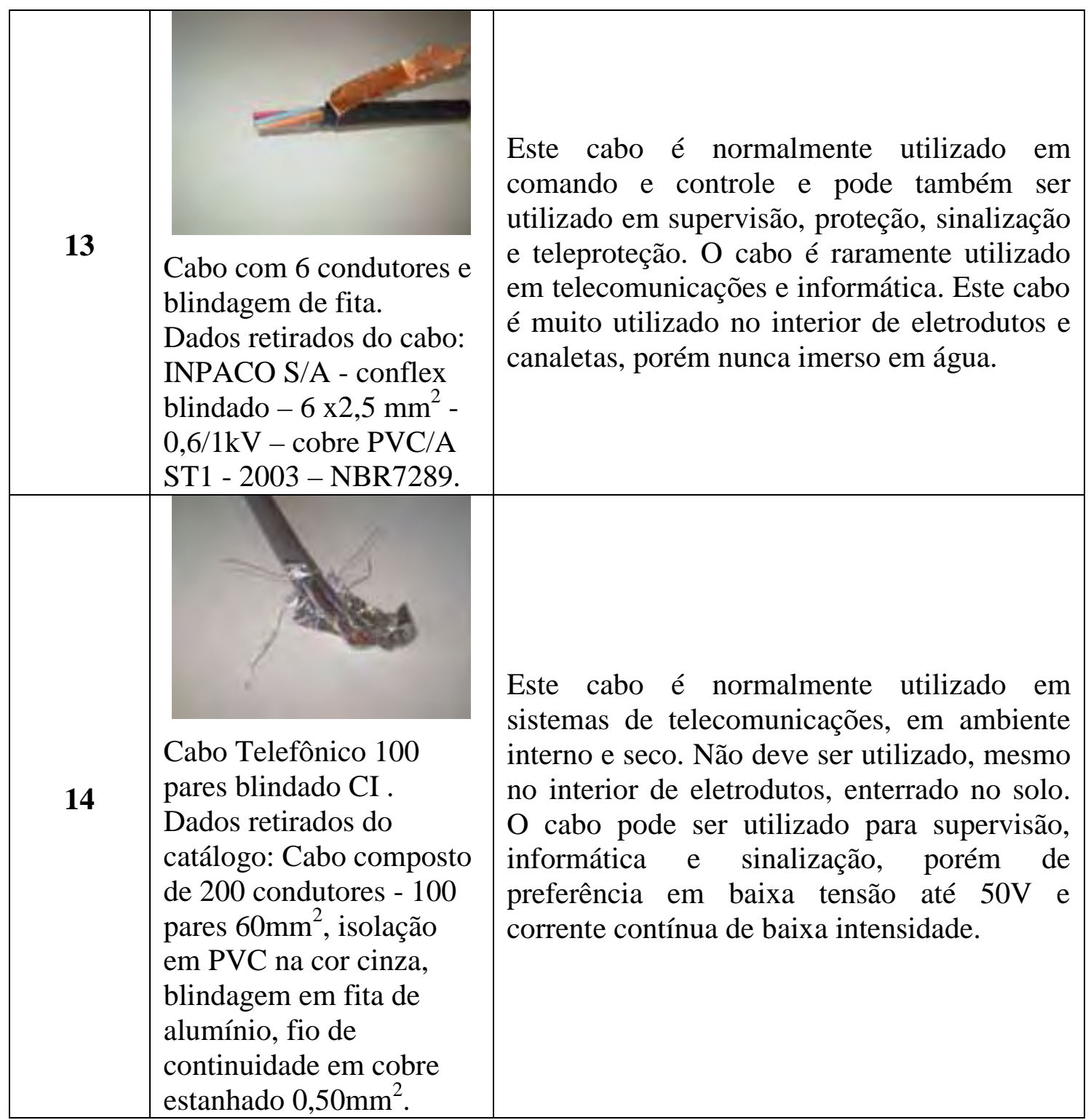




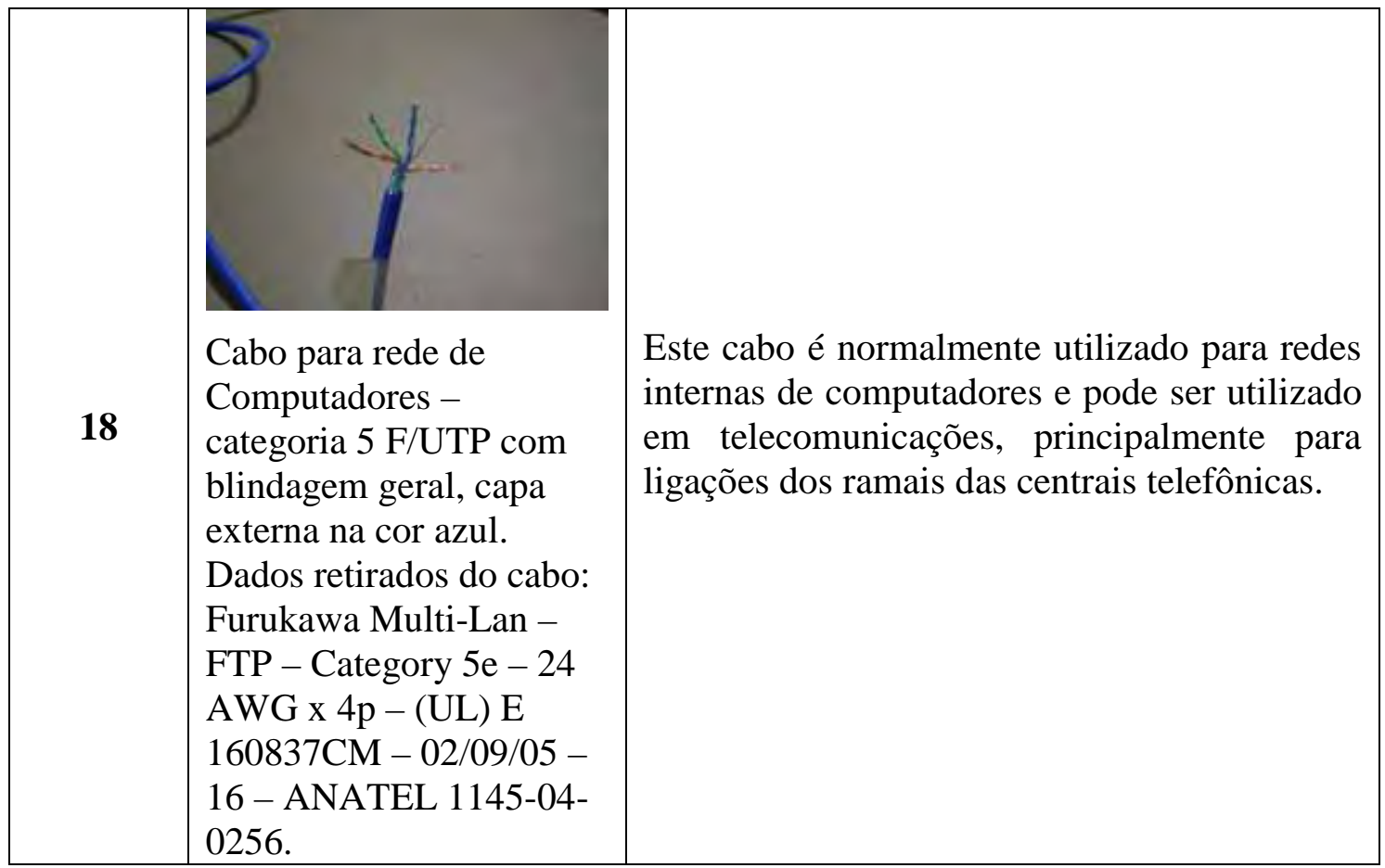

\subsection{Bancada de Ensaios}

Para a realização dos ensaios laboratoriais (impulso combinado, transitório elétrico rápido e campo magnético na frequência de $60 \mathrm{~Hz}$ ) foi construída uma bancada específica composta de cinco mesas de suporte, cada uma medindo $2,40 \mathrm{~m}$ de comprimento, $50 \mathrm{~cm}$ de largura e $100 \mathrm{~cm}$ de altura em relação ao solo.

As mesas foram construídas totalmente em madeira, sem nenhum tipo de objeto metálico, para evitar qualquer tipo de interferência na área dos ensaios. As mesmas foram colocadas sobre um plano metálico composto de chapas de aço galvanizado, medindo $15 \mathrm{~m}$ de comprimento e 1,5m de largura como mostra a Figura 3.1. 


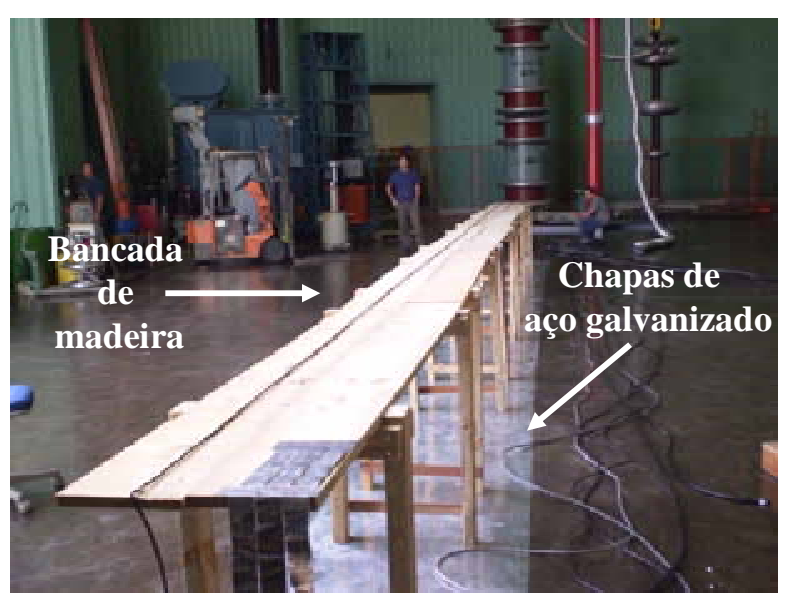

Figura 3.1 Bancada de ensaios

\subsection{Instrumentos Utilizados nos Ensaios Laboratoriais}

Os instrumentos empregados nos ensaios e medições realizadas visando atingir os objetivos propostos foram:

\subsubsection{Ensaios de Impulso Combinado}

Para os ensaios de impulso combinado que visam simular as ondas impulsivas provocadas por descargas atmosféricas, foram aplicados impulsos com forma de onda

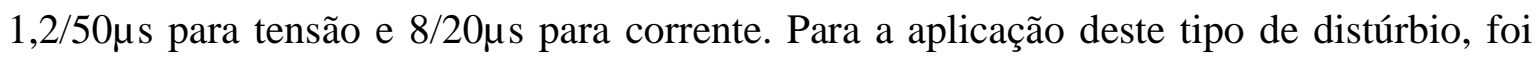
utilizado um gerador de impulsos, fabricante NoiseKen, modelo LSS-15AX-C3, como mostra a Figura 3.2.

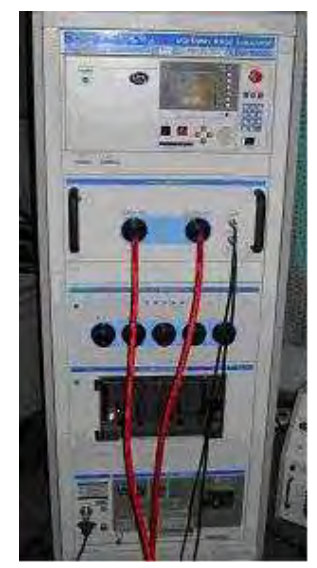

Figura 3.2 Gerador de impulsos LSS-15AX-C3 


\subsubsection{Ensaios de Transitório Elétrico Rápido}

Para os ensaios de transitório elétrico rápido que visam simular o chaveamento eletromecânico de cargas elétricas indutivas (motores e solenóides), ruído caracterizado por rajadas de sinais de alta frequência, e espaçados por certo intervalo de tempo, foi utilizado um gerador de transitório elétrico rápido da NoiseKen, modelo FNSAX-II, como mostra a Figura 3.3.

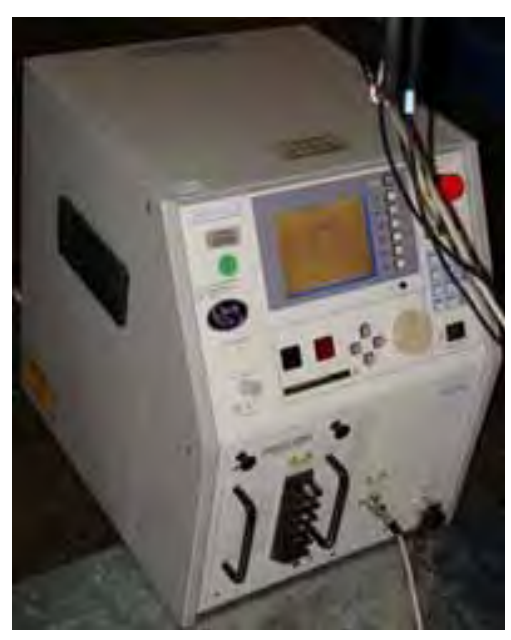

Figura 3.3 Gerador de transitório elétrico rápido FNSAX-II

\subsubsection{Ensaios de Campo Magnético Resultante da Corrente na frequência de $60 \mathrm{~Hz}$}

Para os ensaios de campo eletromagnético resultante da corrente na frequência de $60 \mathrm{~Hz}$, em regime permanente, foram utilizados os equipamentos: i) Ponte RLC da QuadTech, tipo 1693 RLC Digibridge e ii) Transformador especialmente construído para os ensaios, com baixa impedância de saída e capacidade máxima de corrente de $500 \mathrm{~A}$, como mostra a Figura 3.4a e b respectivamente 


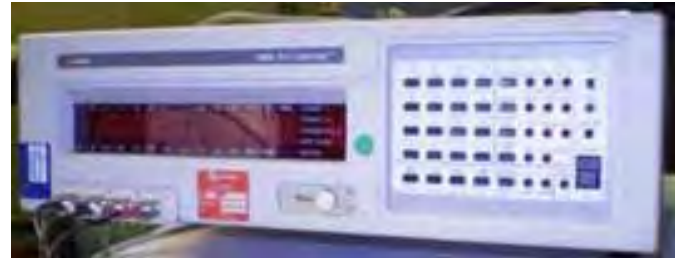

a)

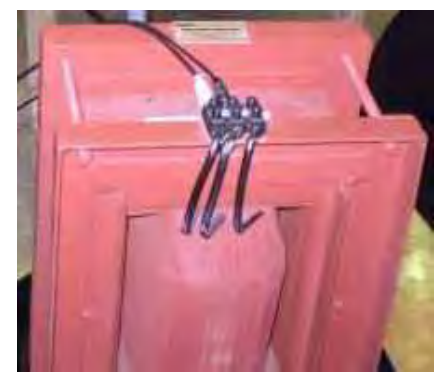

b)

Figura 3.4 Ponte RLC QuadTech e transformador de corrente

\subsubsection{Medição dos Parâmetros Primitivos}

Com a finalidade de se obter os parâmetros de resistência, indutância e capacitância (parâmetros primitivos) dos condutores ensaiados no laboratório, na faixa de frequências até $12 \mathrm{MHz}$, foi utilizado o analisador de impedâncias modelo 4192A marca Agilent, como mostra a Figura 3.5.

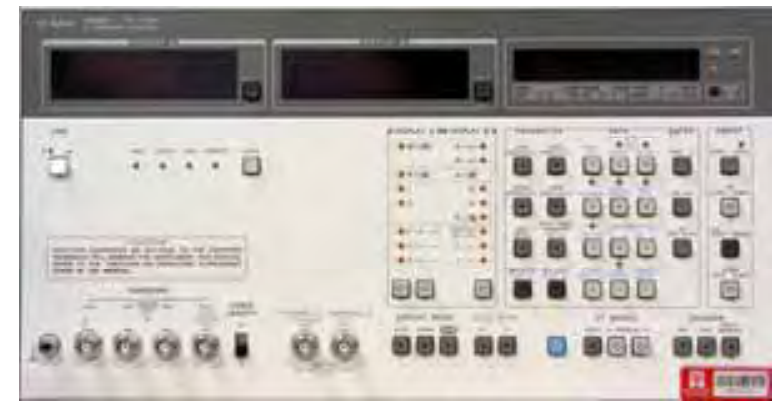

Figura 3.5 Analisador de Impedâncias 4192A Agilent

Para a aquisição dos dados dos ensaios dos itens 3.3.1 a 3.3.3 foram utilizados os seguintes equipamentos: i) Osciloscópio modelo 5202, marca Rigol e ii) Osciloscópio modelo TDS 684B, marca Tektronix, como mostra a Figura 3.6a e b respectivamente. 


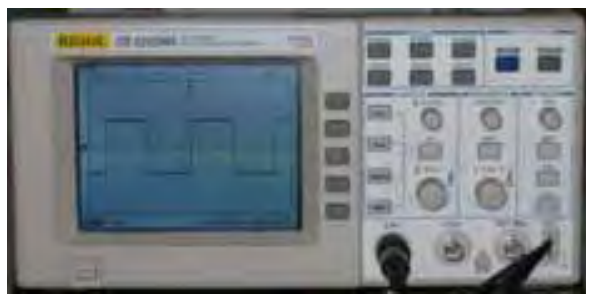

a)

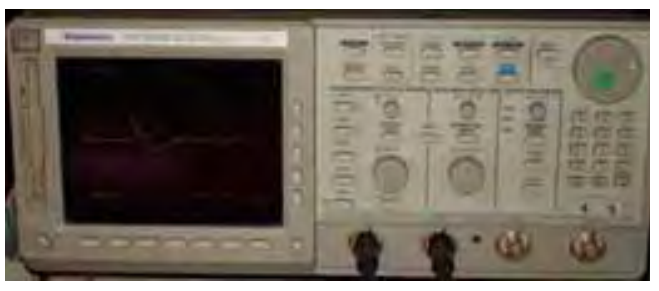

b)

Figura 3.6 Osciloscópio Rigol 5202 e Tektronix TDS 684B

\subsection{Ferramentas Computacionais Utilizadas}

Para as simulações dos modelos de EMI entre cabos paralelos e coaxiais foi utilizado o software MatLab/Simulink versão 7.0.

\subsection{Metodologia}

Esta seção abordará modelos equivalentes para estudos de compatibilidade eletromagnética de cabos de sinais, a obtenção dos parâmetros primitivos dos cabos e os ensaios laboratoriais.

\subsubsection{Modelagem e Circuitos Equivalentes para Estudos de Compatibilidade Eletromagnética em Cabos}

Quando as teorias de eletromagnetismo e circuitos elétricos foram inicialmente desenvolvidas, o conceito de compatibilidade eletromagnética não existia e consequentemente, não existiam ferramentas para tratar esses sinais indesejáveis. À medida que se adotavam técnicas de análise computacionais cada vez mais sofisticadas, as duas teorias seguiram caminhos diferentes. Análises eletromagnéticas tendem a focar na avaliação das intensidades de campo magnético e elétrico na região de montagens condutivas. A teoria de circuitos elétricos considera a hipótese de que cada componente pode ser tratado como uma entidade independente, ou seja, a idéia de interferência é desprezada a partir das definições fundamentais.

Mesmo assim, as técnicas de análises de circuitos são mais adequadas para tratar com os requisitos da compatibilidade eletromagnética, os quais são partes da definição funcional de um sistema elétrico. Entretanto, as derivações são baseadas em experiência 
prática (intuição) e o acoplamento dos campos elétrico e magnéticos são tratados separadamente (GOESDBLOED, 1990).

Se a compatibilidade eletromagnética pode ser analisada com o mesmo rigor que outras características elétricas, um método sistemático para obter modelos de circuitos se torna necessário, isto é, um método que defina precisamente os parâmetros que acoplam a interferência eletromagnética dentro ou fora de um sistema.

Utilizando-se a dualidade de acoplamento elétrico e magnético, os componentes indutivos e capacitivos podem ser derivados e isto torna possível a análise de circuito para determinar as ressonâncias, pois os problemas de compatibilidade eletromagnética aparecem frequentemente nos picos de resposta em frequência da ressonância.

Uma característica essencial de procedimento é a separação das quantidades elétricas em tipos diferentes. Parâmetros primitivos relacionam tensões e correntes na montagem do campo eletromagnético. Parâmetros em loop são aqueles que podem ser medidos com equipamentos de teste e parâmetros de circuitos são encontrados nos ramos de um modelo do circuito. A formulação é introduzida em termos da configuração mais simples possível, chamada de três condutores e dois loops, e esta pode ser aplicada a qualquer montagem com cabos. Em cada aplicação, o processo começará com o estabelecimento de um número de equações primitivas e finalizará com termos para os parâmetros individuais de circuito. O conjunto de equações pode ser inserido em um computador, cujos valores numéricos, estão relacionados com os parâmetros físicos e assim, o modelo pode ser simulado.

\subsection{Modelo de Circuito para Cabos Paralelos}

De acordo com (DARNEY, 1997) é possível analisar interferências eletromagnéticas em cabos, inclusive blindados, com o uso de ferramentas de circuitos elétricos. Seu modelo permite um sistema que envolva interferências eletromagnéticas em uma linha de transmissão, seja analisado como um circuito elétrico simples, sendo que o comportamento eletromagnético das correntes é tratado como indutâncias mútuas e capacitâncias de acoplamento. A formulação que segue pode ser considerada como um caminho dentro do escopo da teoria de eletromagnetismo e circuitos. Uma vez conhecido o caminho, o mesmo pode ser remodelado facilmente. 


\subsubsection{Impedância Primitiva}

Considere um condutor singelo de raio $r_{11}$, comprimento $l$, como mostra a Figura 3.7 e assumindo que o mesmo esteja carregado com uma corrente $I$, uniformemente distribuída ao redor da circunferência e ao longo do comprimento. Para esta configuração, o fluxo magnético consiste de uma série de círculos concêntricos com o eixo do condutor. No ponto $P(r, z)$, a intensidade do campo magnético, $H$, é definida por (SKITEK \& MARSHALL, 1982) e dada pela equação:

$$
H=\frac{I}{4 \pi r}\left[\operatorname{sen}\left(\alpha_{1}\right)+\operatorname{sen}\left(\alpha_{2}\right)\right]
$$

Uma hipótese inerente nesta relação é que os efeitos das extremidades são desprezíveis e a densidade de fluxo é o produto da intensidade de campo pela permeabilidade relativa. Integrando-se a função de densidade em um comprimento de 0 a $l$ em relação a $z$ e depois sobre o raio de $r_{11}$ a infinito, um termo para o fluxo total pode ser obtido para esta região. Definindo-se a indutância como a relação deste fluxo e a corrente, e simplificando a expressão com a hipótese de que $r_{11}<<l$, resulta na equação:

$$
L_{P 11}=\frac{\mu_{0} \mu_{r} l}{2 \pi}\left[\ln \left(\frac{2 l}{r_{11}}\right)-1\right]
$$

Onde $\mu_{0}=$ permeabilidade do espaço livre e $\mu_{\mathrm{r}}=$ permeabilidade relativa do material. 


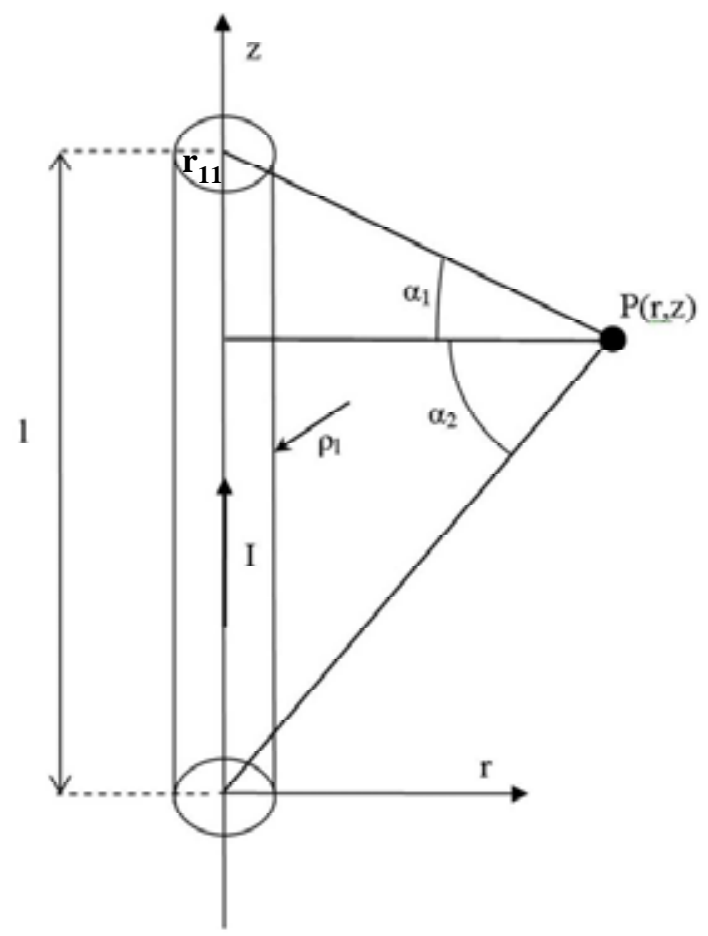

Figura 3.7 Ponto onde os campos $E$ e $H$ são calculados

Embora tal indutância somente exista como um conceito matemático, avaliações de relações mais familiares dependerão dela, portanto, o parâmetro pode ser descrito como um parâmetro primitivo, e assinalado com o índice ' $P$ '. Os dois dígitos após a letra ' $P$ ' identificam a indutância do condutor 1 devido à corrente no condutor 1 . De forma a manter a descrição matemática mais simples possível, o acoplamento de campo magnético dentro do condutor é desprezado.

Se um segundo condutor estiver do lado, ao longo do primeiro condutor, a uma distância axial de separação $r_{12}$, então a indutância primitiva do condutor 2 , devido à corrente no condutor 1 é expressa por:

$$
L_{P 12}=\frac{\mu_{0} \mu_{r} l}{2 \pi}\left[\ln \left(\frac{2 l}{r_{12}}\right)-1\right]
$$

O método utilizado para formular a capacitância primitiva é um pouco diferente, sendo que o mesmo envolve o campo elétrico (SKITEK \& MARSHALL, 1982). 
Considere novamente a Figura 3.7 e assuma que ao longo do eixo existe uma linha de carga de densidade $\rho_{l}$. Segundo (SKITEK \& MARSHALL, 1982), a componente radial de campo elétrico no ponto $P(r, z)$ é dado por:

$$
E=\frac{\rho_{l}}{4 \pi \varepsilon_{o} \varepsilon_{r}} \frac{1}{r}\left[\sin \left(\alpha_{1}\right)+\sin \left(\alpha_{2}\right)\right]
$$

Em que $\varepsilon_{0}=$ permissividade elétrica no vácuo e $\varepsilon_{r}=$ permissividade relativa do material .

Fazendo $\alpha_{1=} \alpha_{2}$ e integrando-se esta função em relação a $r$ na faixa de $r_{11}$ até o infinito, resulta no trabalho máximo para mover a carga unitária até a superfície do condutor (potencial). A capacitância é a razão de carga na superfície para este potencial. Lembrando-se que $r_{11}<l$, tem-se a capacitância primitiva do condutor 1 dada pela equação:

$$
C_{p 11}=\frac{2 \pi \varepsilon_{o} \varepsilon_{r} l}{\ln \left(\frac{l}{r_{11}}\right)}
$$

A capacitância primitiva de um segundo condutor devido à carga no condutor 1 é definida pela equação:

$$
C_{p 12}=\frac{2 \pi \varepsilon_{o} \varepsilon_{r} l}{\ln \left(\frac{l}{r_{12}}\right)}
$$

Para a indutância primitiva, a relação é entre uma corrente unidirecional e a energia total armazenada no campo magnético. Na presença de capacitância primitiva, a mesma está entre a carga de superfície e a energia total do campo elétrico. Esses valores primitivos são entidades diferentes das indutâncias e capacitâncias, usualmente associadas com os componentes eletrônicos. Outra característica dos parâmetros primitivos é que, se considerarmos $r_{12}=r_{21}$, então, $L_{P 12=} L_{P 21}$ e $C_{P 12=} C_{P 21}$. 


\subsubsection{Impedância de Malha (Loop)}

Qualquer sistema elétrico em funcionamento é formado por um conjunto de malhas completas, como ilustra a Figura 3.8. As relações existentes entre correntes de malha e correntes primitivas podem ser determinadas por inspeção (SKITEK \& MARSHALL, 1982). Tensões de malha são derivadas à partir do cálculo da diferença entre linhas adjacentes nas equações primitivas. Substituindo-se as correntes primitivas pelas correntes de malha, e calculando-se as tensões de malha, obtêm-se as seguintes equações de malha:

$$
\begin{aligned}
& V_{L 1}=Z_{L 11} i_{L 1}+Z_{L 12} i_{L 2} \\
& 0=Z_{L 21} i_{L 1}+Z_{L 22} i_{L 2}
\end{aligned}
$$

Sendo:

$$
\begin{aligned}
& Z_{L 11}=Z_{P 11}-Z_{P 12}-Z_{P 21}+Z_{P 22} \\
& Z_{L 12}=Z_{P 12}-Z_{P 13}-Z_{P 22}+Z_{P 23} \\
& Z_{L 21}=Z_{P 21}-Z_{P 22}-Z_{P 31}+Z_{P 32} \\
& Z_{L 22}=Z_{P 22}-Z_{P 13}-Z_{P 32}+Z_{P 33}
\end{aligned}
$$

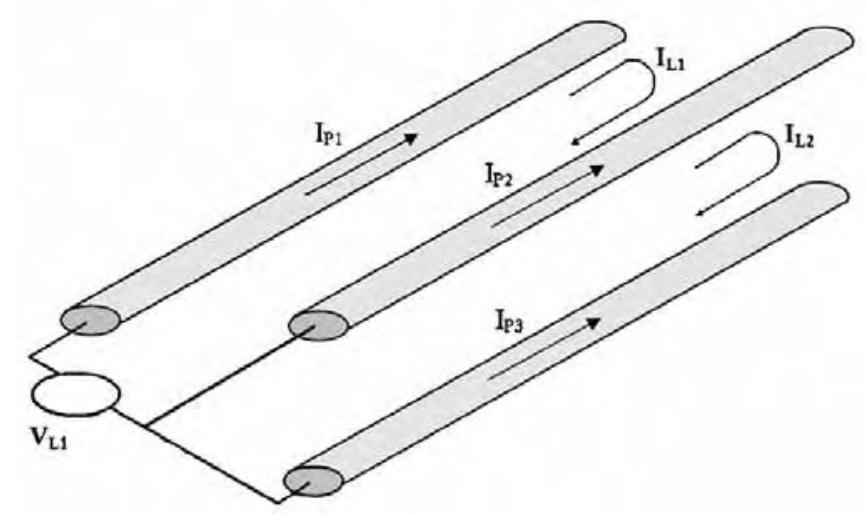

Figura 3.8 Tensões e correntes de malha

Subscritos nas equações de malha são usados para identificar as diferentes malhas, enquanto, subscritos nos parâmetros primitivos definem os condutores. Uma vez que as impedâncias primitivas são simétricas, então as impedâncias de malha também são simétricas, isto é, $Z_{L 12}=Z_{L 21}$. 


\subsubsection{Modelo Inicial do Circuito}

Até este ponto, a análise tem sido em termos da teoria do campo eletromagnético. Para utilizar as ferramentas da teoria de circuitos elétricos é necessário recomeçar a formulação com um diagrama de circuito que possua propriedades particulares. Essas propriedades devem ser tais que, quando o circuito é analisado, um conjunto de equações é criado de forma que a mesma se iguala às equações de malha. Para a configuração de duas malhas mostrada na Figura 3.8, a solução é simples, ou seja, como mostra a Figura 3.9. A análise desta figura resulta nas seguintes equações:

$$
\begin{aligned}
& V_{L 1}=\left(Z_{C 11}+Z_{C 22}\right) i_{L 1}-Z_{C 12} i_{L 2} \\
& 0=-Z_{C 12} i_{L 1}+\left(Z_{C 12}+Z_{C 22}\right) i_{L 2}
\end{aligned}
$$

Onde $Z_{C 11}=$ impedância do circuito 1 e $Z_{\mathrm{C} 22}=$ impedância do circuito 2

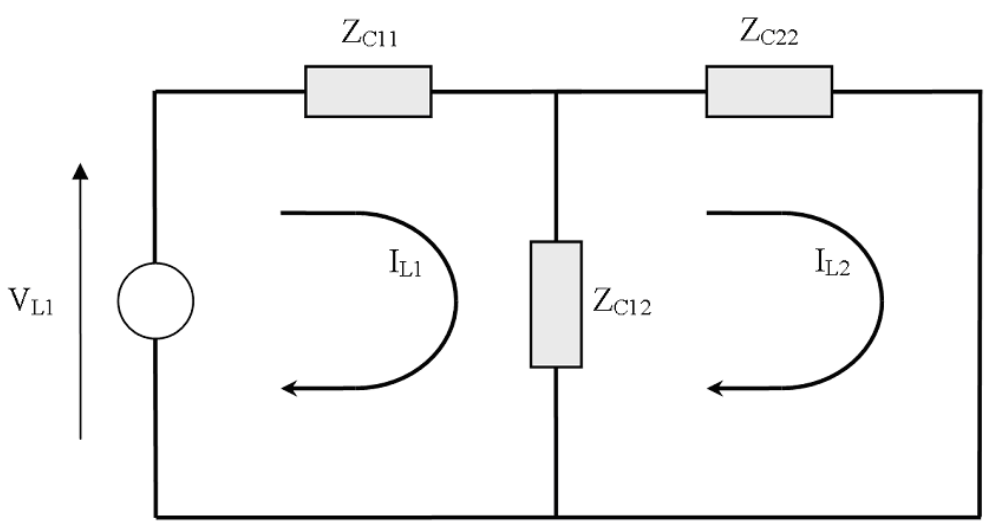

Figura 3.9 Impedâncias do circuito

Isto introduz um terceiro tipo de parâmetro, a impedância do circuito, com seu próprio subscrito. Uma vez que o objetivo é fazer os termos das equações do circuito idênticos aos termos das equações de malha, o identificador " $L$ ” permanece nos subscritos das correntes e tensões. Uma comparação termo a termo, entre as equações de malha e do circuito, permite que cada impedância de malha seja definida em termos de uma impedância do circuito (SKITEK \& MARSHALL, 1982). Agora é possível formular as 
impedâncias em termos das impedâncias de malha, e então, em termos das impedâncias primitivas, conforme as equações:

$$
\begin{aligned}
& Z_{C 11}=Z_{L 11}+Z_{L 12}=Z_{P 11}-Z_{P 12}-Z_{P 13}+Z_{P 23} \\
& Z_{C 12}=-Z_{L 12}=Z_{P 22}-Z_{P 23}-Z_{P 12}+Z_{P 13} \\
& Z_{C 22}=Z_{L 22}+Z_{L 12}=Z_{P 33}-Z_{P 23}-Z_{P 13}+Z_{P 12}
\end{aligned}
$$

Considerando cada impedância primitiva como uma combinação em série de componentes R, L e C, as componentes de circuito da Figura 3.10, podem ser agora derivadas usando a forma geral das equações (3.2), (3.3), (3.5) e (3.6), resultando nas equações:

$$
\begin{aligned}
& L_{C 12}=\frac{\mu_{0} \mu_{r} l}{2 \pi} \ln \left(\frac{r_{12} r_{23}}{r_{22} r_{13}}\right) \\
& C_{C 12}=\frac{2 \pi \varepsilon_{0} \varepsilon_{r} l}{\ln \left(\frac{r_{12} r_{23}}{r_{22} r_{13}}\right)} \\
& R_{C 12}=R_{P 22}
\end{aligned}
$$

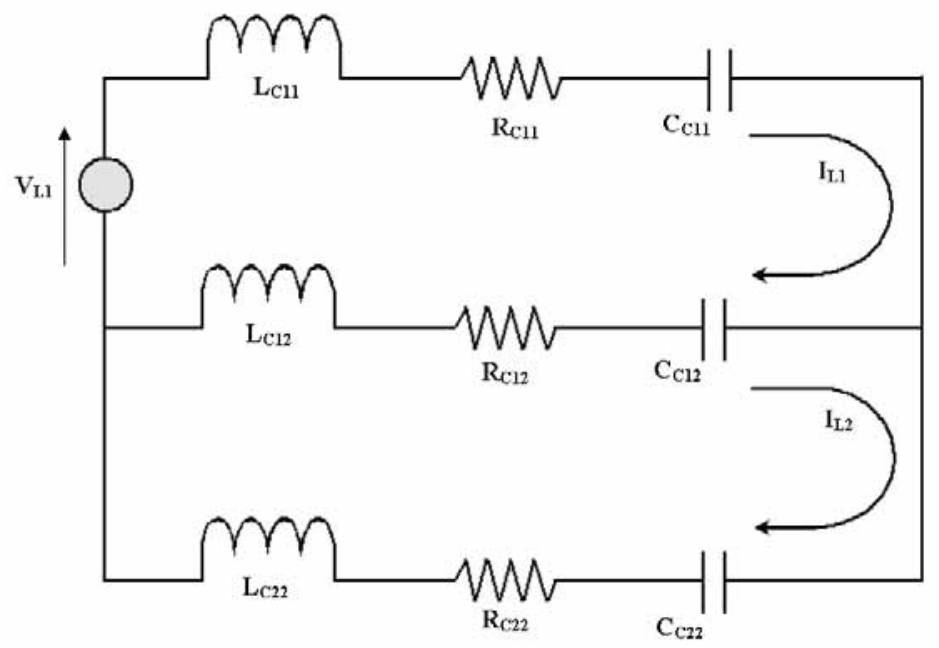

Figura 3.10 Modelo inicial do circuito 


\subsubsection{Modelo Final do Circuito para Cabos Paralelos}

As equações para $L_{C}$ e $C_{C}$ foram obtidas com base em um padrão ideal para os campos elétrico e magnético, bem como, as componentes de $Z_{C 11}$ e $Z_{C 22}$ são derivadas de uma forma análoga. Portanto, descontinuidades na construção física e efeitos de extremidades causarão inevitavelmente alguns erros.

A utilização de parâmetros concentrados resultará em um erro entre as frequências de ressonância reais e as frequências preditas. Este erro pode ser reduzido utilizando-se o modelo de rede T, para representar as linhas de transmissão. Os termos logaritmos podem ser eliminados a partir das equações (3.11) e (3.12) formando os produtos $L C$ :

$$
\sqrt{L_{C 12} C_{C 12}}=l \sqrt{\mu_{0} \mu_{r} \varepsilon_{0} \varepsilon_{r}}=l \frac{\sqrt{\mu_{r} \varepsilon_{r}}}{c}=\frac{l}{v}=\frac{l}{\lambda f}=\frac{1}{4 f_{\text {stub }}}
$$

Sendo:

$C=$ velocidade da luz;

$V=$ velocidade de propagação de onda;

$\lambda=$ comprimento de onda;

$f=$ frequência;

$f_{\text {stub }}=$ frequência quando $l=\lambda / 4$.

Essas equações podem ser encontradas em (EDMINISTER, 1987) e são válidas para todas as reatâncias não primitivas. Se $f_{\text {circuit }}$ é a frequência na qual a impedância de entrada do circuito da Figura 3.11 é zero, então:

$$
f_{\text {circuit }}=\frac{1}{2 \pi \sqrt{L C / 2}} \frac{2 \sqrt{2}}{\pi} f_{\text {stub }}
$$




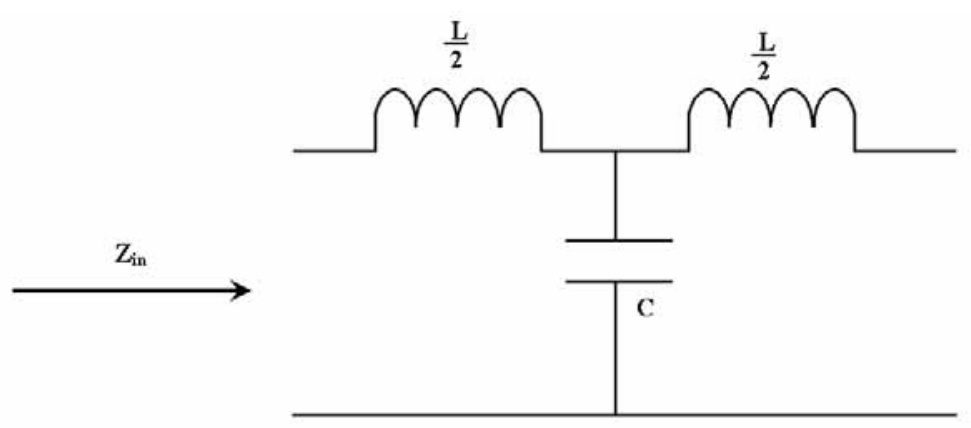

Figura 3.11 Modelo T para linha de transmissão de dois condutores

Representando cada parâmetro de impedância como uma rede T, e então fazendo a transformação estrela-delta nos capacitores, pode-se obter o modelo do circuito de uma linha de transmissão de três condutores. As Figuras 3.11 e 3.12 ilustram os dois estágios do processo de conversão.
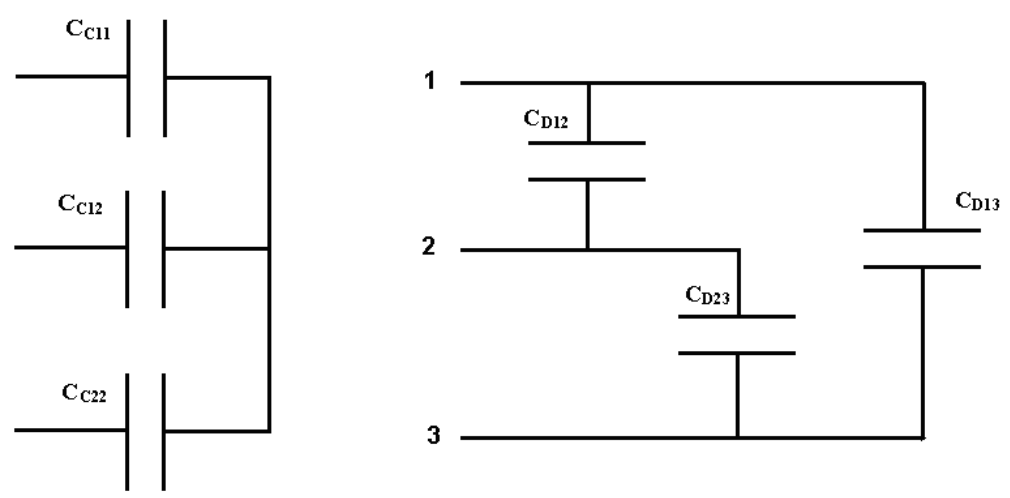

Figura 3.12 Conversão estrela-delta

A Figura 3.13 mostra o resultado final do circuito para o cabo paralelo, onde:

$R_{C 11}=$ resistência do condutor 1 ;

$R_{C 12}=$ resistência do condutor $1 /$ condutor 2 ;

$R_{C 22}=$ resistência do condutor 2 ;

$L_{C 11}=$ Indutância do condutor 1;

$L_{C 12}=$ Indutância do condutor $1 /$ condutor 2 ;

$L_{C 22}=$ Indutância do condutor 2;

$C_{D 12}=$ Capacitância do condutor $1 /$ condutor 2 ; 
$C_{D 13}=$ Capacitância do condutor $1 /$ malha (estrutura);

$C_{D 23}=$ Capacitância do condutor $2 /$ malha (estrutura).

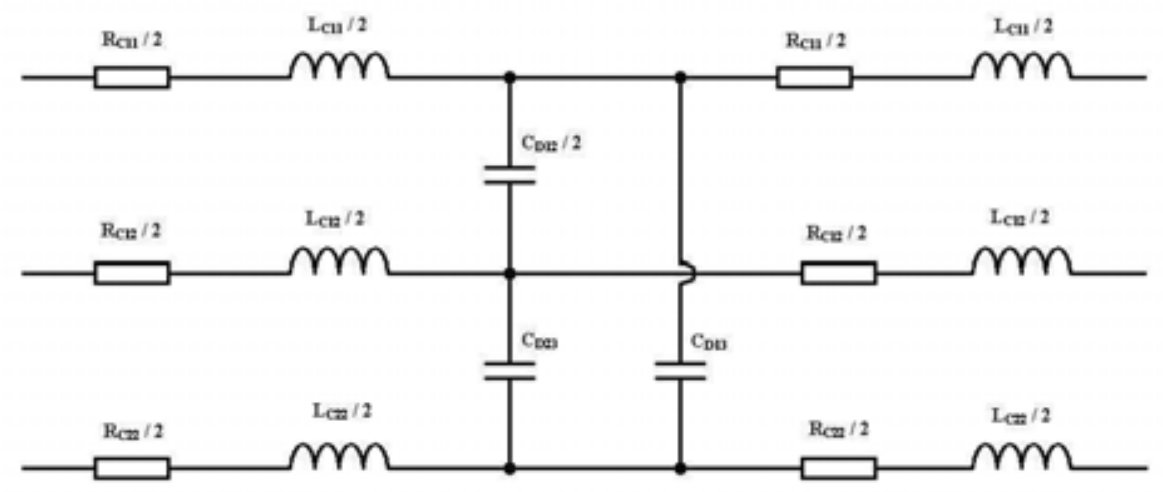

Figura 3.13 Modelo do circuito para cabos paralelos

O modelo da Figura 3.13 pode ser expandido em uma rede linear (ladder) da mesma forma que o modelo de dois condutores da Figura 3.11. Isto aumenta a precisão e estende a faixa de frequência. $\mathrm{O}$ modelo pode ser simplificado como, por exemplo, ignorando a capacitância, tornando o processo ainda mais fácil.

\subsection{Modelo do Circuito para Cabos Coaxiais}

O cabo coaxial é um caso especial, pois o segundo condutor está distribuído ao redor do condutor 1, conforme mostra a Figura 3.14. A separação entre qualquer ponto no condutor 2 e o eixo do condutor 1 é $r_{12}$. Portanto, $r_{22=} r_{12}, L_{p 12=} L_{p 22}$ e $C_{p 12=} C_{p 22}$.

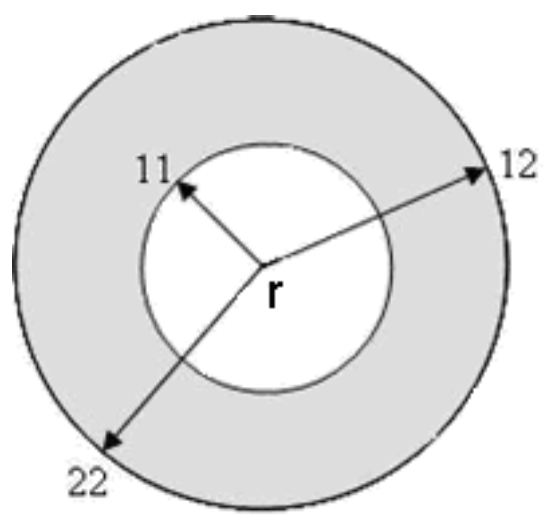

Figura 3.14 Condutores coaxiais 
A formulação do modelo para o cabo coaxial segue um desenvolvimento semelhante ao obtido para o modelo de cabo paralelo. Segundo (DARNEY, 1997), consideram-se as impedâncias primitivas dos cabos e a influência das correntes dos outros cabos no cabo em análise.

Para um único condutor, a energia elétrica armazenada no condutor é função da corrente e de três fatores: resistência, indutância e capacitância. Assim, em qualquer instante, a tensão pode ser determinada por:

$$
V(t)=L_{p 11} \frac{d i_{p 1}}{d t}+R_{p 11} i_{p 1}+\frac{1}{C_{p 11}} \int i_{p 1} d t
$$

Quando a corrente é descrita como uma função senoidal no tempo, com frequência angular $\omega$, a impedância primitiva deste condutor isolado pode ser definida como:

$$
Z_{p 11}=j \omega L_{p 11}+R_{p 11}+\frac{1}{j \omega C_{p 11}}
$$

As impedâncias primitivas dos outros condutores e dos pares condutores podem ser definidas de forma semelhante. Para a secção de um conjunto de três condutores como ilustra a Figura 3.15, a tensão em qualquer condutor é função da corrente em todos os três condutores, conforme as equações:

$$
\begin{aligned}
& V_{P 1}=Z_{P 11} i_{P 1}+Z_{P 12} i_{P 2}+Z_{P 13} i_{P 3} \\
& V_{P 2}=Z_{P 21} i_{P 1}+Z_{P 22} i_{P 2}+Z_{P 23} i_{P 3} \\
& V_{P 3}=Z_{P 31} i_{P 1}+Z_{P 32} i_{P 2}+Z_{P 33} i_{P 3}
\end{aligned}
$$

Este conjunto de equações primitivas descreve as características de uma matriz de condutores paralelos. O número de equações é igual ao número de condutores. Os números de identificação de todos os parâmetros primitivos referem-se aos condutores. 


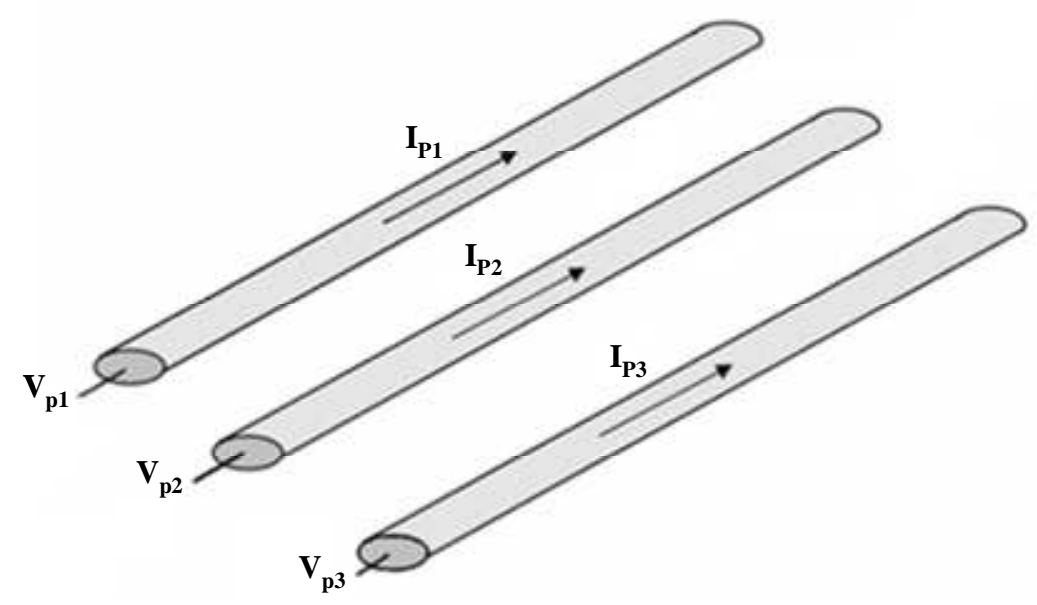

Figura 3.15 Tensões e correntes primitivas

No caso do cabo coaxial, os três condutores da Figura 3.15 representam o condutor central, a blindagem e o outro condutor, cujo sinal pode interferir no condutor central.

A Figura 3.16 representa um conjunto de malhas completas para o estudo da interferência eletromagnética de cabos coaxiais onde, o condutor 1 representa o condutor interferente, o condutor 2 representa a blindagem e o condutor 3 o condutor central. As variáveis $I_{p 1}, I p_{2}$ e $I p_{3}$ representam as correntes primitivas nos condutores, e $I_{L 1}, I_{L 2}$ e $I_{L 3}$ representam as correntes nas três malhas.

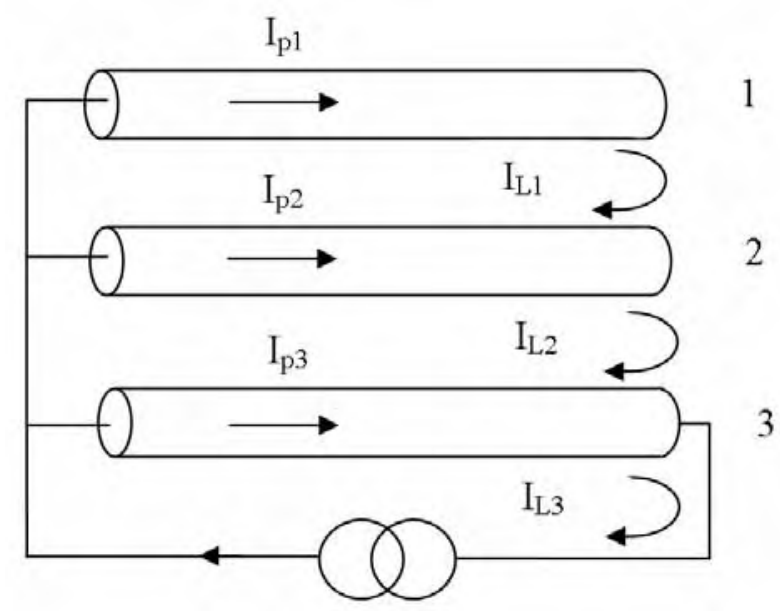

Figura 3.16 Tensões e correntes de malhas 
A partir da formulação das tensões e correntes de malha, impedâncias primitivas e impedâncias de circuito, chega-se ao modelo de circuito da Figura 3.17 para o cabo coaxial, onde:

$R_{C 12}=$ resistência do condutor interferente ou de uma estrutura sob interferência;

$L_{C 12}=$ indutância de transferência do condutor interferente/blindagem;

$L_{C 22}+L_{C 12}=$ indutância de malha da blindagem/condutor interferente;

$R_{C 23}=$ resistência da blindagem;

$L_{C 33}=$ indutância da malha do condutor central/blindagem;

$R_{C 33}=$ resistência do condutor central;

$C_{D 12}=$ capacitância da blindagem/condutor interferente;

$C_{D 23}=$ capacitância do condutor central/blindagem;

$Z_{A} e Z_{B}=$ impedâncias de entrada do equipamento/terminação $\mathrm{A}$ e $\mathrm{B}$ respectivamente.

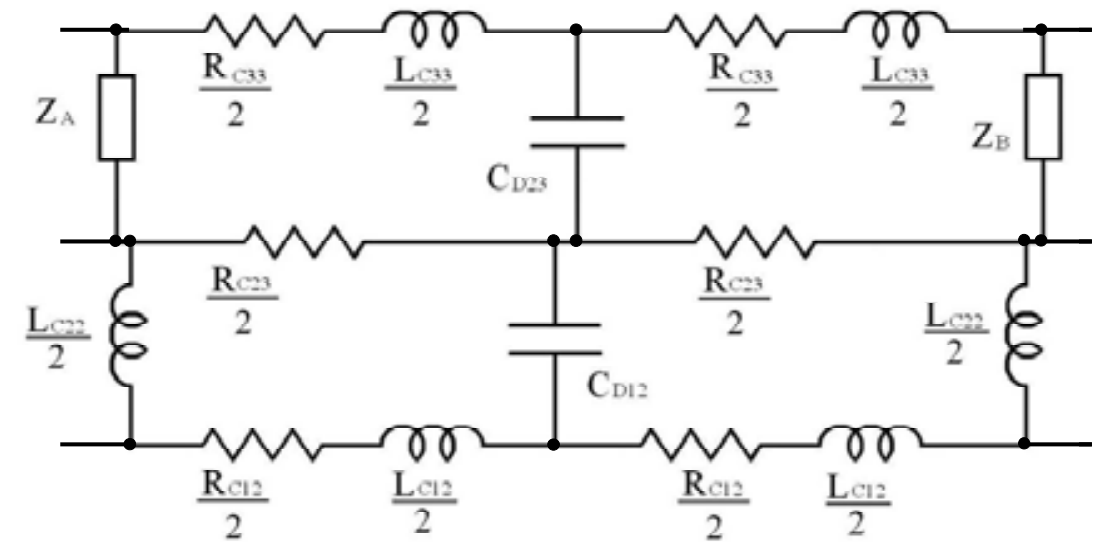

Figura 3.17 Modelo de circuito para cabos coaxiais

\subsection{Simulação do Modelo de Darney}

Para demonstrar a eficácia da modelagem de (DARNEY, 1997), executaram-se simulações da montagem mostrada na Figura 3.18. O cabo sob teste é um cabo paralelo com um condutor ligado nas duas extremidades do cabo e a estrutura. Uma tensão de modo comum é aplicada na malha cabo/estrutura e uma tensão diferencial é monitorada entre os dois condutores do cabo, por um osciloscópio, através de um divisor resistivo. A tensão aplicada é monitorada por uma única espira enrolada em um toróide e conectada ao outro canal do osciloscópio, através de um resistor. 


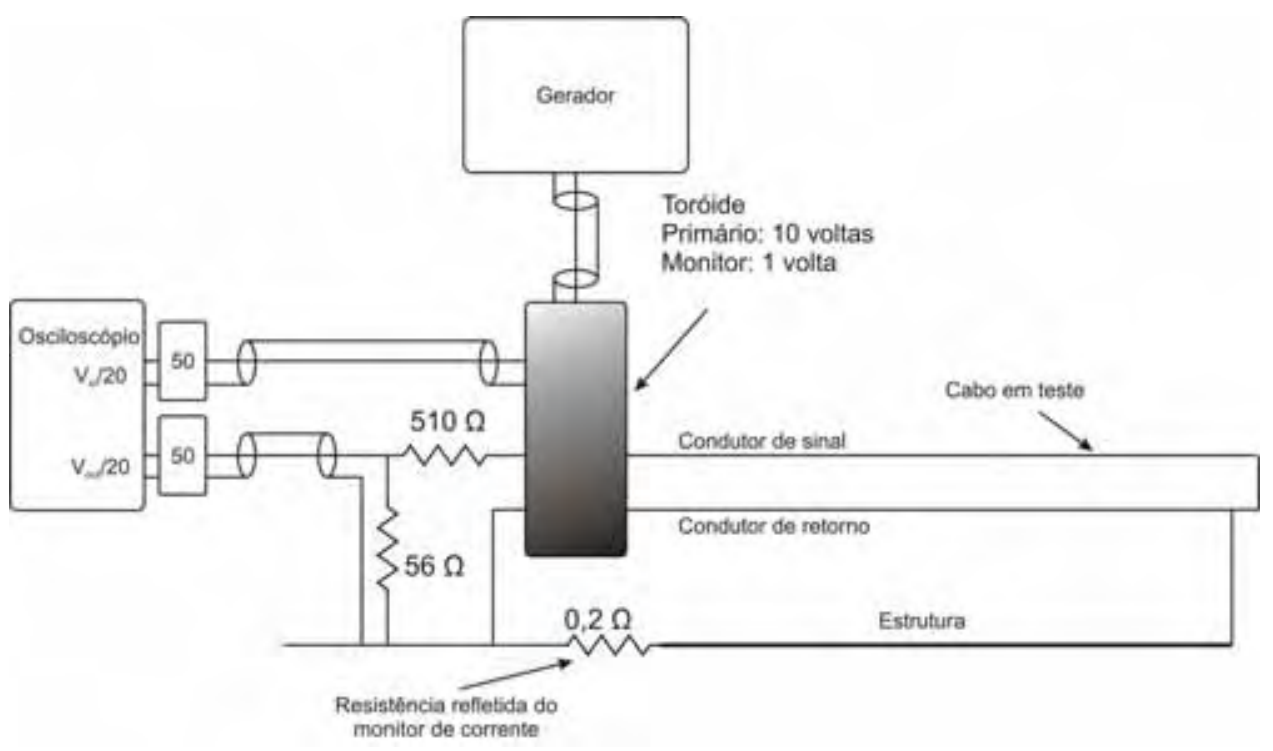

Figura 3.18 Montagem da bancada de ensaios (Adaptado de DARNEY, 1997)

Os dados da bancada de ensaios são os seguintes:

- $r_{11}=7,5 \mathrm{~mm}$ (raio do condutor1);

- $\quad r_{12}=20,5 \mathrm{~mm}=r_{13}$ (distância do centro (eixo) do condutor 1 até o condutor2);

- $r_{22}=0,292 \mathrm{~mm}=r_{33}$ ( raio do condutor1 e condutor3 (estrutura) respectivamente);

- $\quad r_{23}=1,98 \mathrm{~mm}$ (distância do centro (eixo) do condutor2 até o condutor3 (estrutura));

- $l=11,7 \mathrm{~m}$ (comprimento do condutor).

Na Figura 3.19 mostra-se o circuito equivalente obtido através da montagem da Figura 3.18. A resistência de $0,2 \Omega$ é a impedância refletida do enrolamento secundário do transformador de corrente.

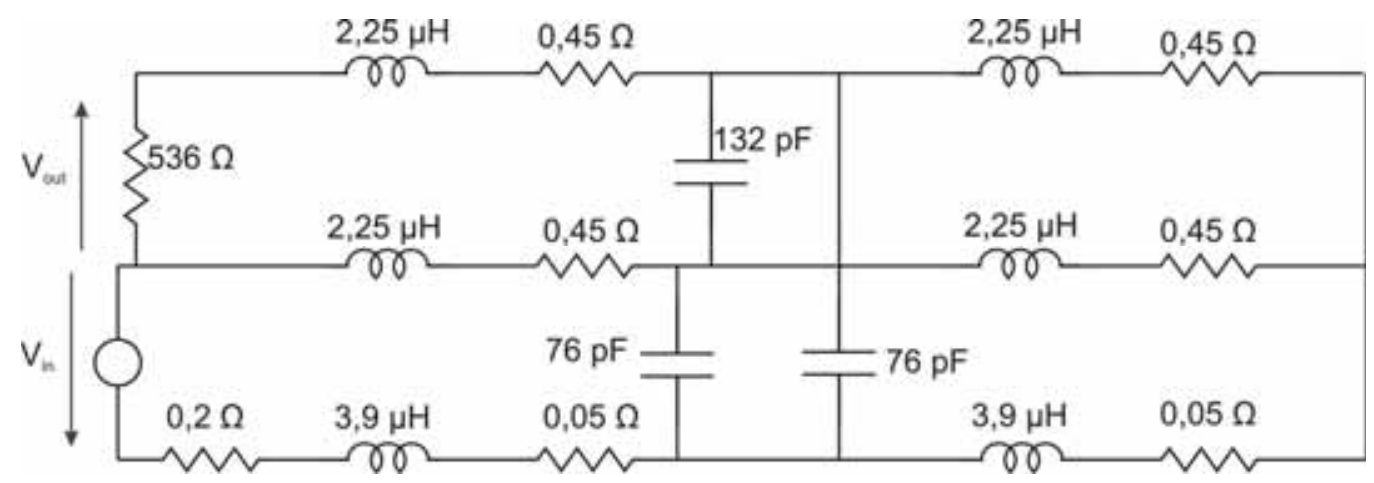

Figura 3.19 Circuito equivalente a bancada de ensaios 
O circuito equivalente no Matlab/Simulink é mostrado na Figura 3.20. O circuito é exatamente igual ao circuito da Figura 3.19, com exceção dos blocos:

i) "VMI" e "VM2" - medidores de tensão, ii) "RMS1" e "RMS2" - cálculo do valor $R M S$ dos sinais de entrada e saída, iii) "Dividel" - responsável pela relação entre a saída e a entrada, iv) "Vout", "Vin" e "Vout/Vin" - indicadores numéricos e v) "To Workspace" envia o sinal resultante da divisão entre a tensão de saída e a tensão de entrada para o ambiente do Matlab/Simulink.

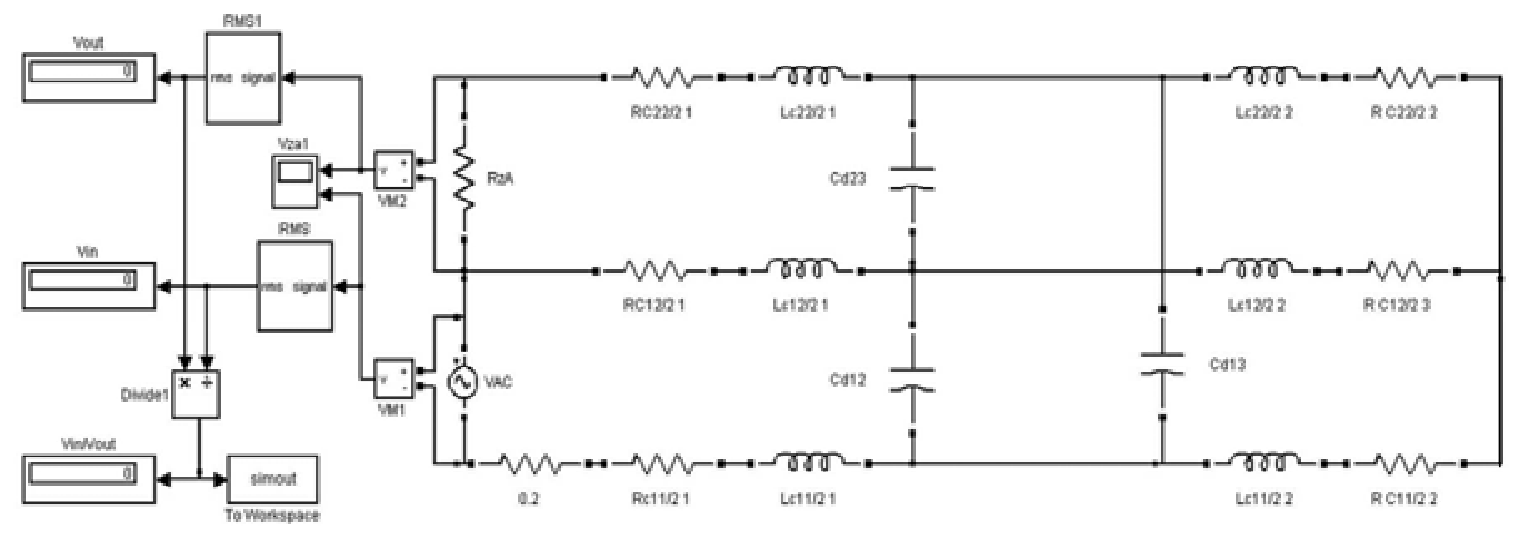

Figura 3.20 Circuito equivalente no MatLab/Simulink

A simulação consistiu em aplicar tensão senoidal de $100 \mathrm{~V}$ de amplitude por meio da fonte de tensão "VAC", com várias frequências. A Figura 3.21 mostra o resultado encontrado por (DARNEY, 1997) para o sistema, com o cabo em teste. A curva mostrada no gráfico é a relação entre a tensão de saída e a tensão entrada, medida sobre o resistor de $536 \Omega$ e $r_{12}=20,5 \mathrm{~mm}$. 


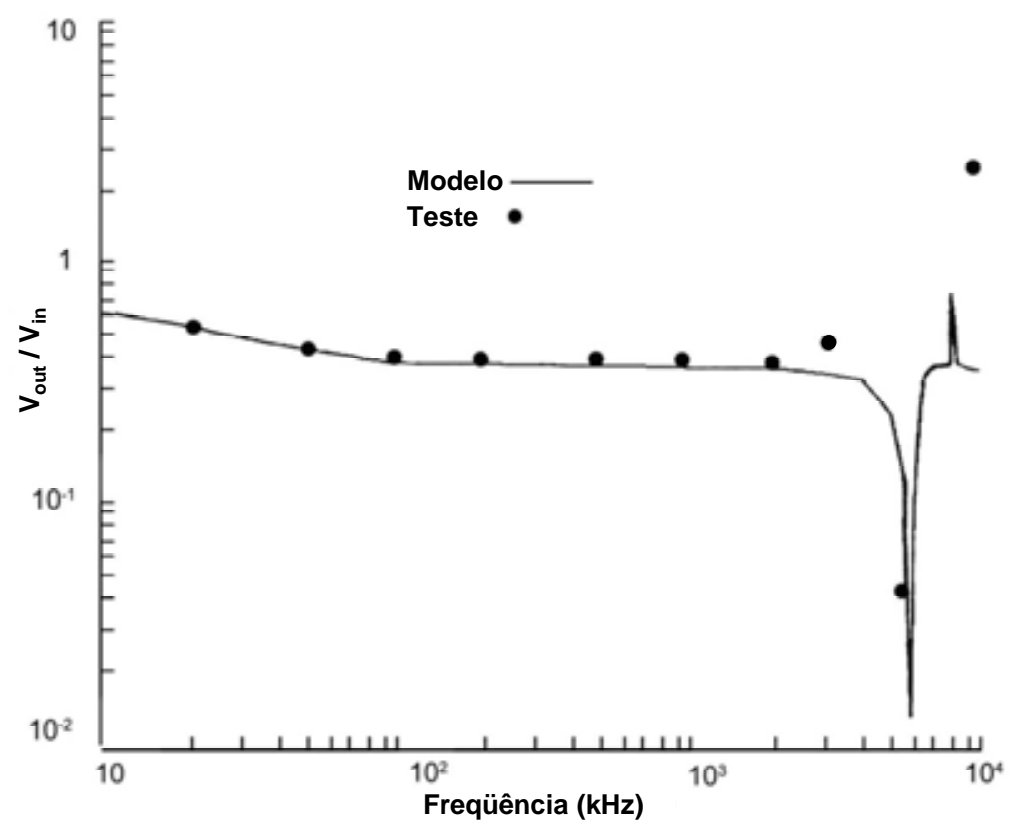

Figura 3.21 Resultado encontrado por (DARNEY, 1977)

Para a simulação deste trabalho foi utilizado o modelo da Figura 3.20 desenvolvido no Matlab/Simulink. Foi realizado um total de 15 simulações com diferentes frequências na fonte de tensão "VAC". Para cada frequência específica foi tomado como tempo total de aquisição, o tempo correspondente a vinte ciclos completos da tensão, e a frequência de amostragem, como sendo quinze vezes a frequência da tensão "VAC". A Figura 3.22 mostra a curva encontrada na simulação feita no Matlab/Simulink. Nota-se que o gráfico resultante da simulação teve uma curva muito semelhante à encontrada por (DARNEY, 1997) - (Figura 3.21), concluindo que o modelo idealizado pelo mesmo tem repetibilidade, mesmo utilizando outros valores para as variáveis $r_{12}$ e $r_{23}$. 


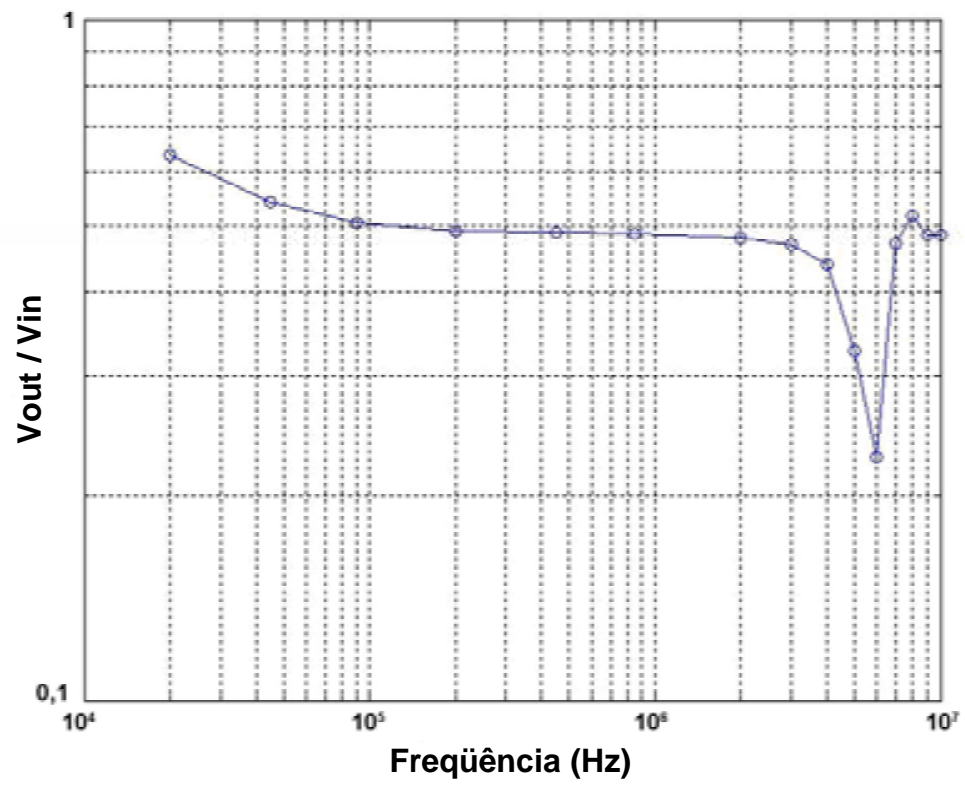

Figura 3.22 Resultado da simulação no Simulink para $r_{12}=20,5 \mathrm{~mm}$

\subsection{Medição dos Parâmetros Primitivos}

A obtenção dos parâmetros primitivos foi por medição direta através da configuração da Figura 3.23, usando os instrumentos conforme descritos na seção 3.3.4.

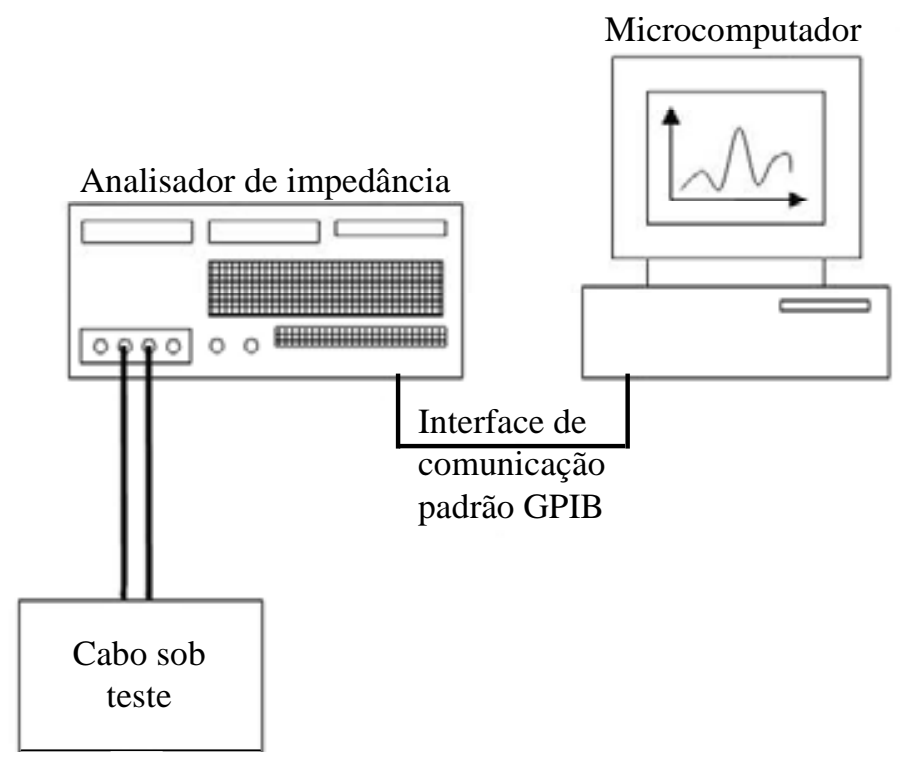

Figura 3.23 Configuração do sistema de medição dos parâmetros RLC 


\subsection{Ensaios Laboratoriais}

Este item consiste na apresentação dos ensaios laboratoriais realizados (impulso combinado, transitório elétrico rápido e campo magnético na frequência de $60 \mathrm{~Hz}$ ) para a obtenção dos efeitos provocados nos cabos, frente às principais fontes de interferências eletromagnéticas geradas em laboratório, que reproduzem com eficácia o meio agressivo presente nas subestações, tais como: descargas atmosféricas, manobras de chaveamento, campo magnético na frequência de $60 \mathrm{~Hz}$ e do efeito corona.

\subsubsection{Bancada de Ensaios e Aplicação dos Distúrbios Eletromagnéticos}

Para a realização dos ensaios laboratoriais, construiu-se uma bancada específica conforme descrita no item 3.2. As mesas de suporte da bancada foram construídas totalmente em madeira, sem nenhum tipo de objeto metálico, de modo a evitar qualquer tipo de interferência na área dos ensaios, bem como, proporcionar repetibilidade em todas as medições realizadas. As mesmas foram colocadas sobre um plano metálico composto de chapas de aço galvanizado, visando criar um plano Terra (de referência) para os ensaios. Este plano oferece uma baixa impedância de retorno aos transitórios eletromagnéticos aplicados nos ensaios, assim como, características físicas dos mesmos passíveis de reprodução durante todos os ensaios. As Figuras 3.24 e 3.25 mostram a bancada de ensaios com os cabos sob a mesma, bem como o plano Terra. 


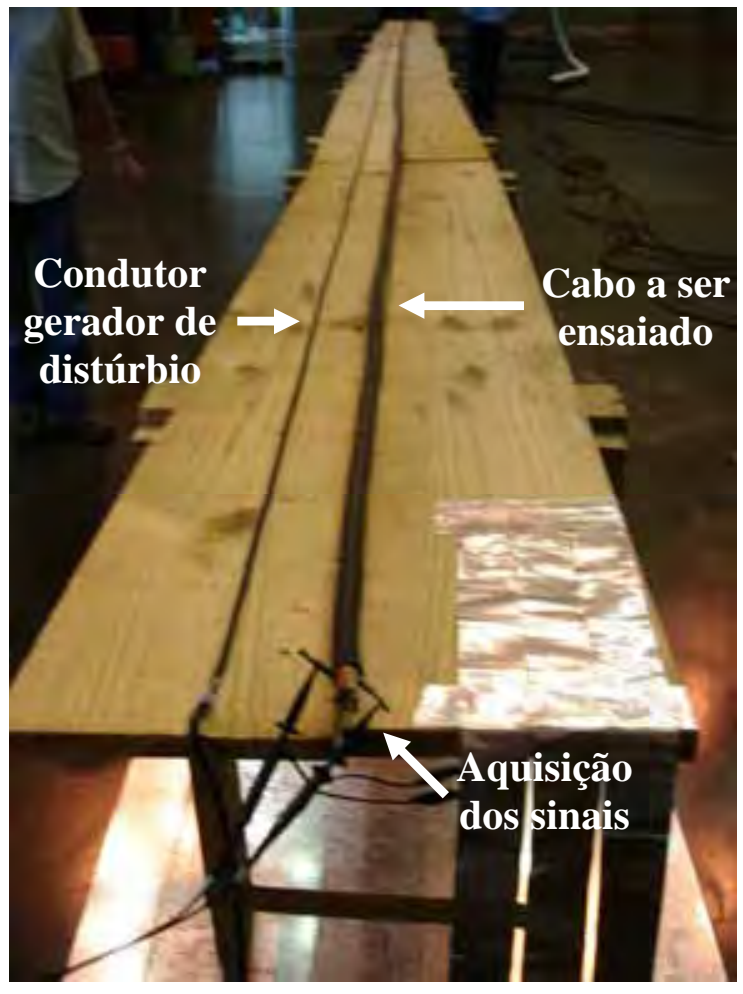

Figura 3.24 Bancada de ensaios com os cabos instalados

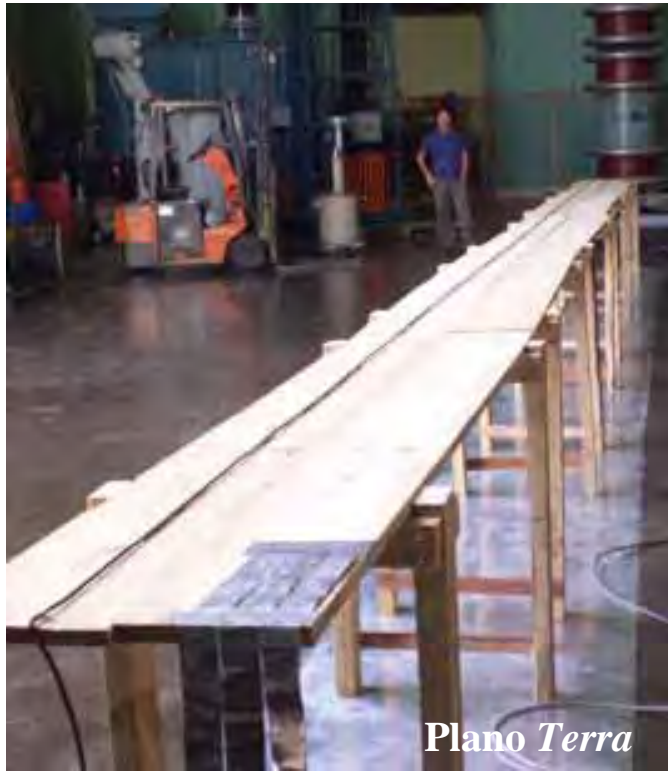

Figura 3.25 Bancada de ensaios com plano Terra 
O arranjo permite a realização de ensaios de indução por meio da utilização de um cabo gerador de distúrbios em paralelo com os cabos a serem analisados. Assim, conseguese avaliar o acoplamento entre esses dois cabos para cada um dos diferentes tipos de transitórios eletromagnéticos aplicados. Portanto, os cabos a serem ensaiados foram colocados sobre a bancada de ensaio em paralelo ao cabo em que são aplicados distúrbios eletromagnéticos conhecidos. A configuração em paralelo para os ensaios dos cabos foi utilizada, pela razão de que todos os cabos presentes em uma subestação ou edificação pertencente à mesma estão dispostos de forma paralela em todas as situações possíveis.

O cabo contendo os distúrbios foi separado do cabo em análise a uma distância de $10 \mathrm{~cm}$ durante todo o trajeto sobre a bancada de ensaio. Esta distância entre os cabos (de referência e sob teste) foi adotada como a distância média entre os cabos que estão nas canaletas, esteiramento ou outros leitos de cabos presentes nas subestações. O tamanho da bancada foi adotada em 12m, baseada em um valor porcentual (um porcento) das distâncias médias, em que os cabos percorrem a subestação até alcançarem a sala de comando, e nas dimensões existentes dos possíveis laboratórios que poderiam executar os ensaios. A bancada de ensaios foi instalada no laboratório de alta tensão do LACTEC (Curitiba) que possui paredes blindadas, evitando as interferências externas ao arranjo dos ensaios.

Os distúrbios eletromagnéticos foram aplicados em um cabo convencionado "cabo de referência", com retorno via o plano metálico de aterramento. A aplicação dos distúrbios foi realizada em uma das extremidades deste cabo em relação ao plano metálico de acoplamento. A outra extremidade foi conectada ao plano, através de uma terminação específica. A Figura 3.26 apresenta um diagrama simplificado do arranjo de ensaios.

Nos ensaios de impulsos e de corrente na frequência de $60 \mathrm{~Hz}$, a terminação foi realizada através da soldagem direta do cabo de referência ao plano metálico. Na aplicação de transitórios elétricos rápidos, a terminação foi feita através de uma carga resistiva de $50 \Omega$, e está representada pela letra $\mathbf{R}$ na Figura 3.26. Nos pontos $\mathbf{X}$ e $\mathbf{Y}$ são conectadas as fontes geradoras de sinais para os testes, nos pontos A e B são conectados os equipamentos de medição dos sinais provenientes dos cabos sob testes. 


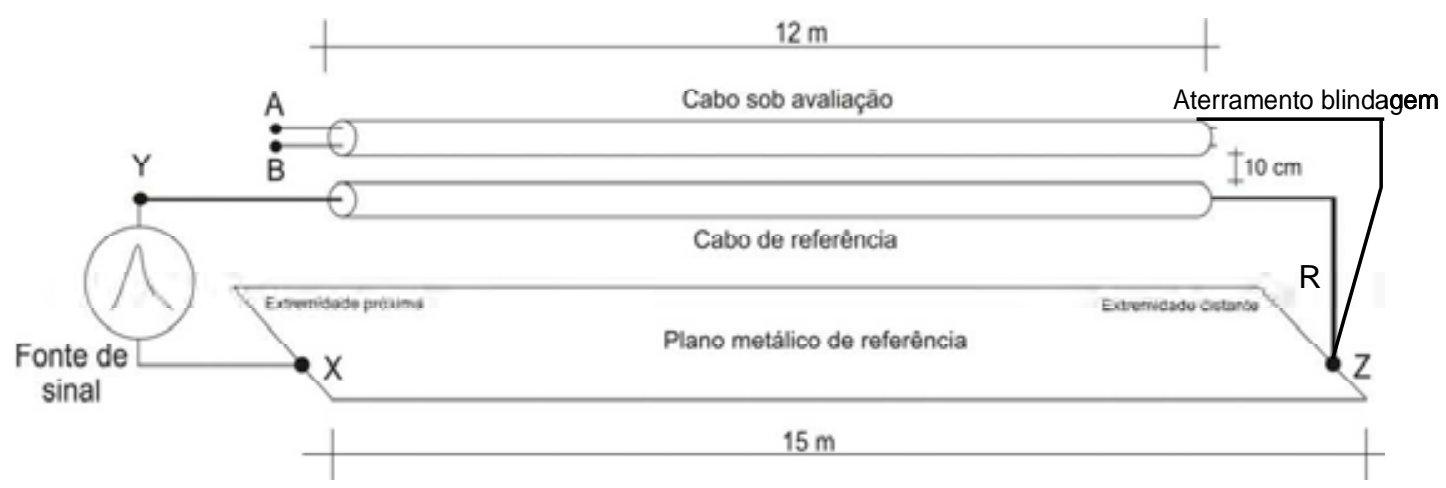

Figura 3.26 Diagrama simplificado do arranjo de ensaios

\subsubsection{Ensaios Laboratoriais Realizados}

Para a verificação das características da suscetibilidade eletromagnética de cada tipo de cabo utilizado para supervisão, proteção, comunicação e controle em subestações, foram reproduzidos em laboratório diferentes tipos de eventos eletromagnéticos, a que estão submetidos tais cabos em seu ambiente de operação. Os ensaios realizados compreendem três tipos de eventos:

a) Transitórios elétricos rápidos resultantes de cargas indutivas em baixa tensão segundo a norma (IEC-61000-4-4, 1995), com forma de onda 5/50ns e repetição de 2,5kHz;

b) Transitórios de surto atmosférico, segundo a norma (IEC-61000-4-5, 1995) - impulso combinado (tensão com forma de onda de 1,2/50us e corrente com forma de onda de 8/20us);

c) Campo magnético na frequência de $60 \mathrm{~Hz}$, que consiste em avaliar a resultante da corrente nesta frequência em regime permanente.

Para cada um dos eventos realizados, executou-se uma série de ensaios, visando avaliar a blindagem dos cabos nas diversas condições. Os cabos sob teste foram avaliados sob as seguintes condições:

a) Sem aterramento;

b) Aterrado na extremidade mais próxima do ponto de aplicação do sinal $(\mathbf{X})$;

c) Aterrado na extremidade mais afastada do ponto de aplicação do sinal $(\mathbf{Z})$;

d) Aterrado nas duas extremidades $(\mathbf{X}, \mathbf{Z})$. 
A Tabela 3.3 ilustra os ensaios realizados em cada uma das amostras de cabos que são utilizados em subestações.

Tabela 3.3 Ensaios realizados para diversos tipos de aterramentos

\begin{tabular}{|c|c|c|c|c|c|c|c|c|c|c|c|c|}
\hline \multirow{2}{*}{$\begin{array}{c}\text { Amostras } \\
\text { Condição } \\
\text { da } \\
\text { Blindagem }\end{array}$} & \multicolumn{4}{|c|}{$\begin{array}{c}\text { Impulso } \\
\text { Combinado }\end{array}$} & \multicolumn{4}{|c|}{$\begin{array}{c}\text { Transitório } \\
\text { Elétrico Rápido }\end{array}$} & \multicolumn{4}{|c|}{$\begin{array}{c}\text { Campo Magnético } \\
\text { na Frequência de } \\
60 \mathrm{~Hz}\end{array}$} \\
\hline & (a) & (b) & (c) & (d) & (a) & (b) & (c) & (d) & (a) & (b) & (c) & (d) \\
\hline 10 & $\mathrm{X}$ & & & & $\mathrm{X}$ & & & & $X$ & & & \\
\hline 17 & $X$ & & & & $\mathrm{X}$ & & & & $X$ & & & \\
\hline 12 & $\mathrm{X}$ & $\mathrm{X}$ & $\mathrm{X}$ & $X$ & $\mathrm{X}$ & $\mathrm{X}$ & $\mathrm{X}$ & $\mathrm{X}$ & $X$ & $\mathrm{X}$ & $\mathrm{X}$ & $X$ \\
\hline 13 & $\mathrm{X}$ & $\mathrm{X}$ & $\mathrm{X}$ & $X$ & $\mathrm{X}$ & $\mathrm{X}$ & $\mathrm{X}$ & $\mathrm{X}$ & $X$ & $\mathrm{X}$ & $\mathrm{X}$ & $\mathrm{X}$ \\
\hline 14 & $\mathrm{X}$ & $\mathrm{X}$ & $\mathrm{X}$ & $X$ & $\mathrm{X}$ & $\mathrm{X}$ & $\mathrm{X}$ & $\mathrm{X}$ & $X$ & $\mathrm{X}$ & $\mathrm{X}$ & $\mathrm{X}$ \\
\hline 18 & $X$ & $\mathrm{X}$ & $X$ & $X$ & $X$ & $\mathrm{X}$ & $X$ & $X$ & $X$ & $X$ & $X$ & $X$ \\
\hline
\end{tabular}

Além dos ensaios terem sido realizados para as mais diversas formas de aterramento, foram considerados, também, diversos níveis (picos/frentes de onda) para a aplicação das formas de onda normalizadas em cada um dos eventos. A Tabela 3.4 ilustra os níveis considerados para a análise da suscetibilidade eletromagnética. Considerando os diversos níveis de tensão e os diversos tipos de aterramento, foram realizados um total de 446 ensaios.

Tabela 3.4 Ensaios realizados para diversos níveis de sinal

\begin{tabular}{|l|c|c|c|}
\hline \multicolumn{1}{|c|}{ Eventos } & $\mathbf{2 5 0 V}$ & $\mathbf{5 0 0 V}$ & $\mathbf{1 k V}$ \\
\hline Impulso Combinado & $\mathrm{X}$ & $\mathrm{X}$ & $\mathrm{X}$ \\
\hline Transitório Elétrico Rápido & $\mathrm{X}$ & $\mathrm{X}$ & \\
\hline Campo Magnético na Frequência de 60Hz & \multicolumn{4}{|c|}{ Corrente elétrica de 100A } \\
\hline
\end{tabular}




\subsubsection{Ensaios de Impulso Combinado}

Este transitório aplicado visa simular as ondas impulsivas provocadas por descargas atmosféricas. Na Figura 3.27 está representado o esquema de ligação deste ensaio.

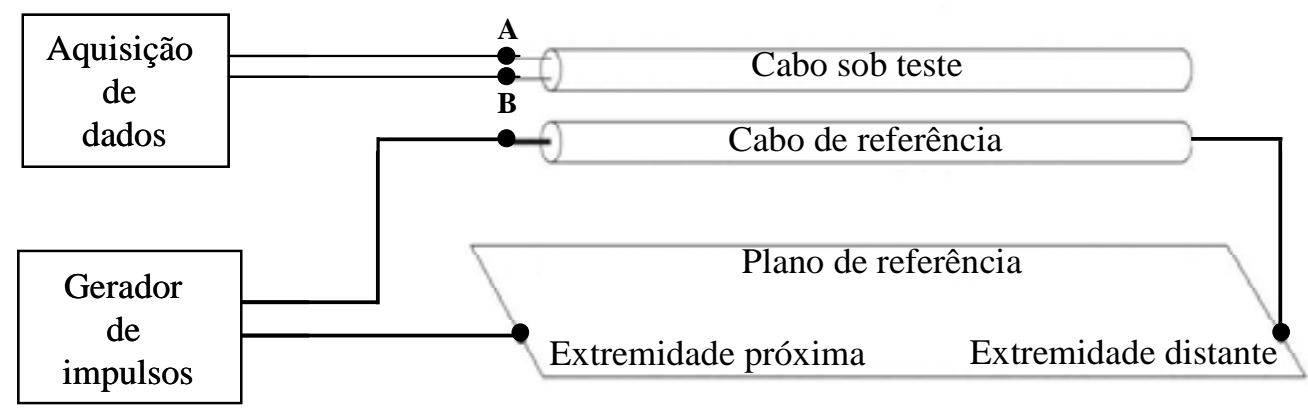

Figura 3.27 Diagrama de ligação dos ensaios de impulso combinado

Os impulsos aplicados possuem forma de onda $1,2 / 50 \mu$ s para tensão e $8 / 20 \mu$ s para corrente. Foram aplicados impulsos com tensão de 250V, 500V e 1000V. Na Figura 3.28 apresenta-se a forma de onda de tensão (cor amarela - canal 1) e corrente (cor azul - canal 2) resultantes deste ensaio.

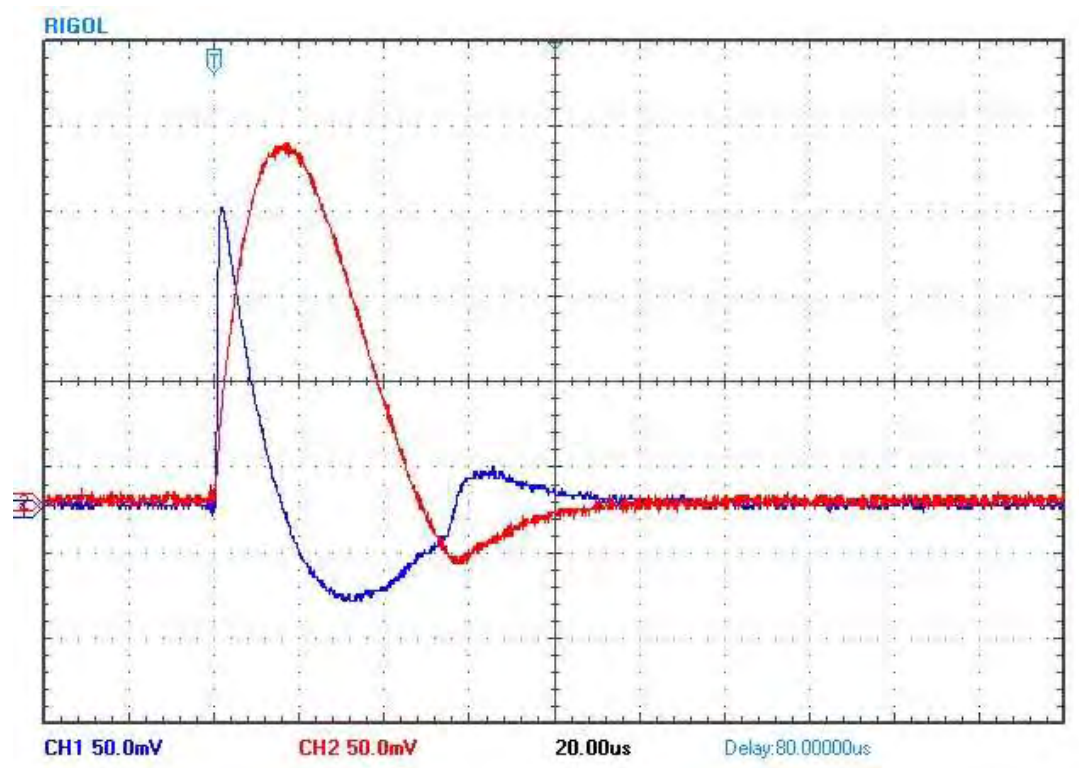

Figura 3.28 Impulsos de tensão (canal 1 - 50mV/div) e corrente (canal 2 - 50mV/div) 


\subsubsection{Ensaios de Transitório Elétrico Rápido}

Este tipo de fenômeno eletromagnético é resultante do chaveamento eletromecânico de correntes elétricas indutivas, como motores e solenóides. É um ruído caracterizado por rajadas de sinais de alta frequência e espaçados por certo intervalo de tempo. Para a reprodução do fenômeno, foi utilizado um gerador de transitórios elétricos rápidos, em conformidade com a norma técnica (IEC 61000-4-4, 1995). Neste caso, a terminação do cabo foi aterrada ao plano de referência, através de uma carga resistiva de $50 \Omega$. Na Figura 3.29 está representado o esquema de ligação deste ensaio. Para a realização dos ensaios, foram aplicados transitórios elétricos rápidos com valor de tensão de crista de 250V e 500V. A Figura 3.30 apresenta a forma de onda de tensão aplicada no cabo de referência.

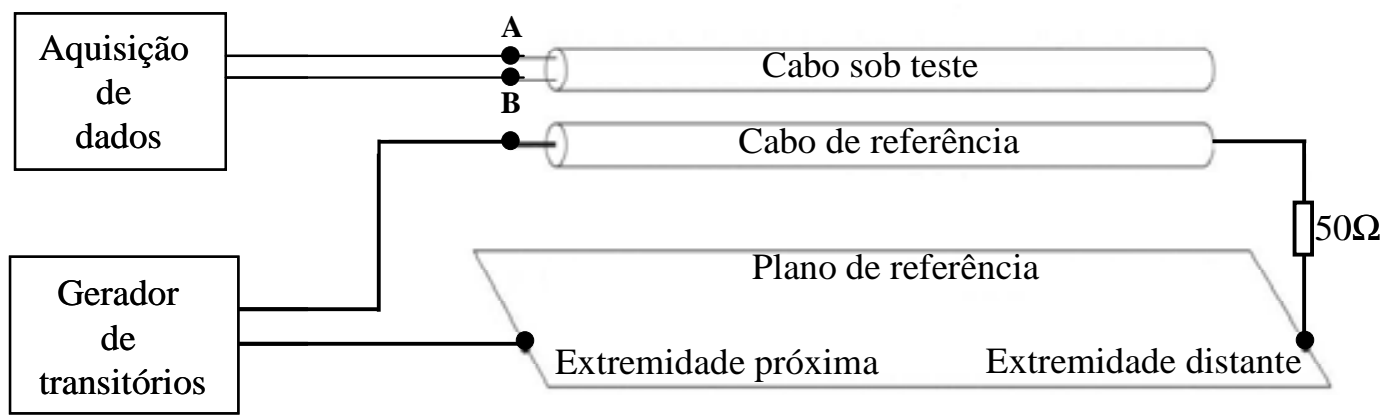

Figura 3.29 Diagrama de ligação dos ensaios de transitório elétrico rápido

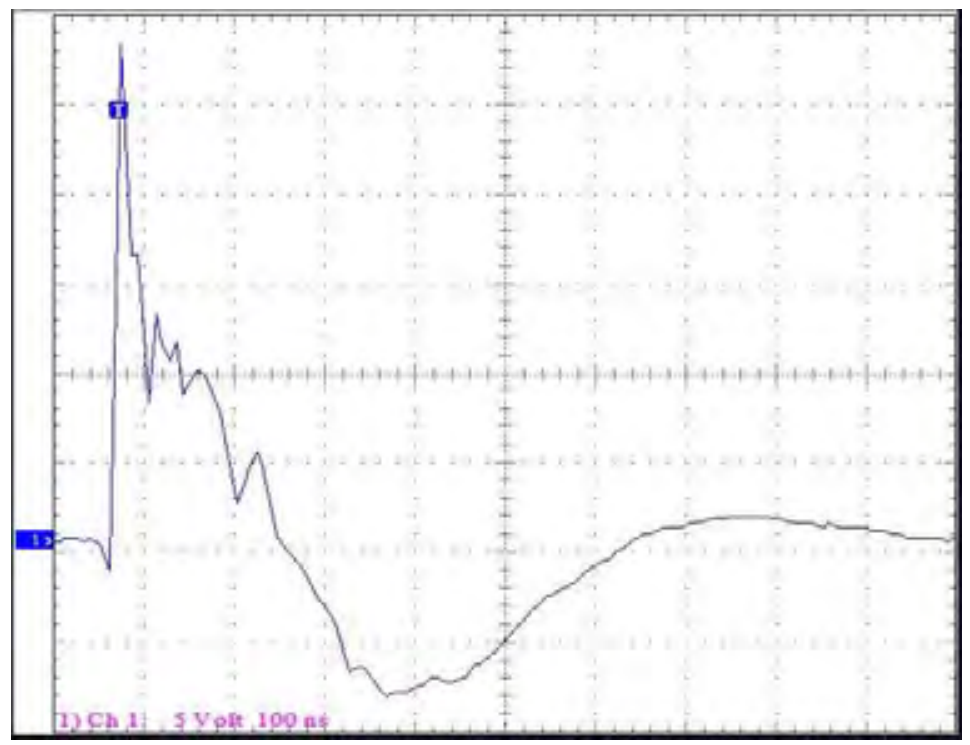

Figura 3.30 Transitório elétrico rápido aplicado (50V/div) 


\subsubsection{Ensaios de Campo Magnético Resultante da Corrente na Frequência de $60 \mathrm{~Hz}$}

Este tipo de fenômeno eletromagnético é resultante do campo magnético da corrente na frequência de $60 \mathrm{~Hz}$ em regime permanente. Para tal, foi aplicada uma corrente de 100A RMS por meio de um transformador, com baixa impedância de saída e capacidade máxima de corrente de saída de 500A. Na Figura 3.31 está representado o diagrama de ligação deste ensaio.

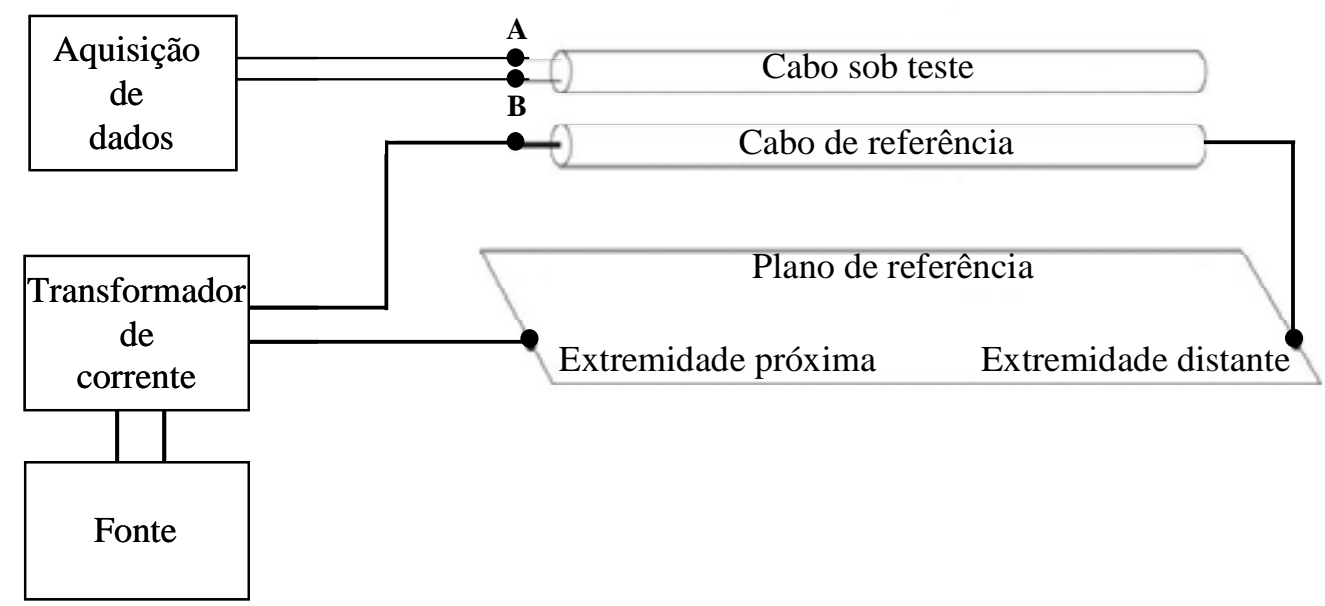

Figura 3.31 Diagrama de ligação dos ensaios de campo magnético na frequência de $60 \mathrm{~Hz}$

\subsubsection{Técnica de Medição da Tensão Induzida}

A medição da tensão induzida nos cabos em análise foi realizada através de osciloscópios digitais, com taxa de aquisição de dados compatível com o evento eletromagnético simulado. No caso dos impulsos combinados e de corrente na frequência de $60 \mathrm{~Hz}$, foi utilizado um osciloscópio com largura de banda de $200 \mathrm{MHz}$ e taxa de amostragem de 1GS/s. Para a coleta de dados relativos à aplicação de transitórios elétricos rápidos, foi utilizado um osciloscópio com taxa de amostragem de 5GS/s e largura de banda de $1 \mathrm{GHz}$. Ambos foram ligados aos pontos A e B do cabo em análise, conforme indicado na Figuras 3.27, 3.29 e 3.31. A referência utilizada para as medições foi o plano metálico (plano de referência). 
Em cabos com apenas um condutor interno foi utilizada apenas uma ponta de prova de medição, e em cabos com diversos condutores internos, dois destes foram selecionados para as medições. Para a seleção desses condutores foram feitas experiências com a medição em diferentes condutores e não tendo sido notada diferença nos resultados encontrados, a escolha de tais condutores foi aleatória.

A medição individual de cada um dos canais do osciloscópio apresenta a tensão de modo comum induzida nos condutores do cabo em análise. A diferença entre as tensões medidas em cada um dos canais representa a tensão de modo diferencial entre os condutores (subtração do canal 1 em relação ao canal 2).

\subsubsection{Amostra dos Cabos Ensaiados}

Para a realização dos ensaios, utilizou-se os cabos comumente empregados nas subestações de $440 \mathrm{kV}$ da CTEEP. Esses cabos foram selecionados levando-se em consideração cada um dos sistemas da subestação e os mais encontrados na maior parte da planta. As amostras de cabos utilizados nos ensaios realizados podem ser vistos no item 3.1 .

\subsubsection{Simulação de Transitórios conforme a Norma CEI EN6100-4-4}

A norma européia (CEI EN6100-4-4, 1995) define um tipo de onda específica para transientes e sugere um circuito gerador de transiente próprio para tal fim. De acordo com esta norma, o diagrama do circuito do gerador de transientes é mostrado na Figura 3.32.

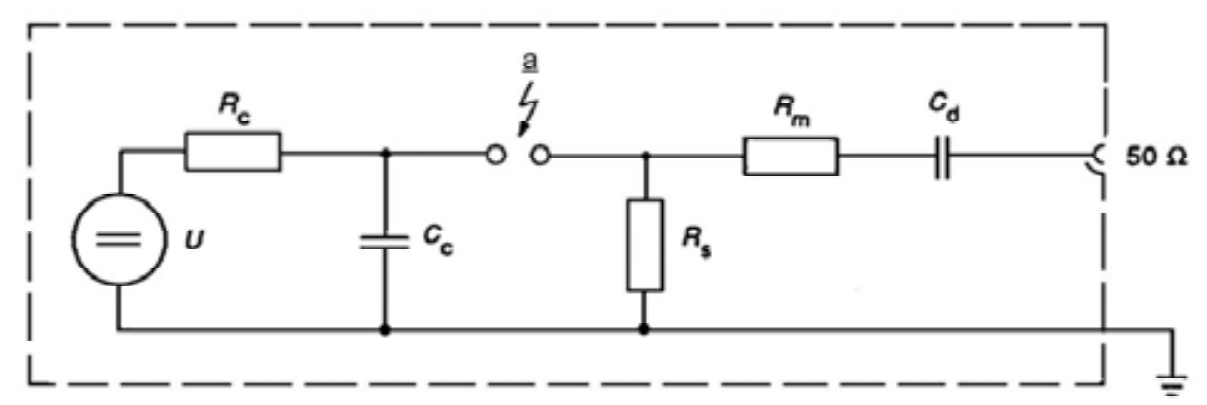

Figura 3.32 Diagrama do circuito de teste 
Os elementos do circuito gerador de transientes são:

- Fonte de alta tensão $(U)$;

- Resistor de carga $\left(R_{\mathrm{c}}\right)$;

- Capacitor armazenador de energia $\left(C_{\mathrm{c}}\right)$;

- Spark gap (a);

- Resistor para formar a duração do impulso $\left(R_{\mathrm{m}}\right)$;

- Resistor como impedância $\left(R_{\mathrm{S}}\right)$;

- Capacitor para remover o nível CC $\left(C_{\mathrm{d}}\right)$.

A Figura 3.33 representa a forma de onda de um pulso em uma carga de $50 \Omega$, gerada pelo circuito recomendado pela norma (CEI EN6100-4-4, 1995).

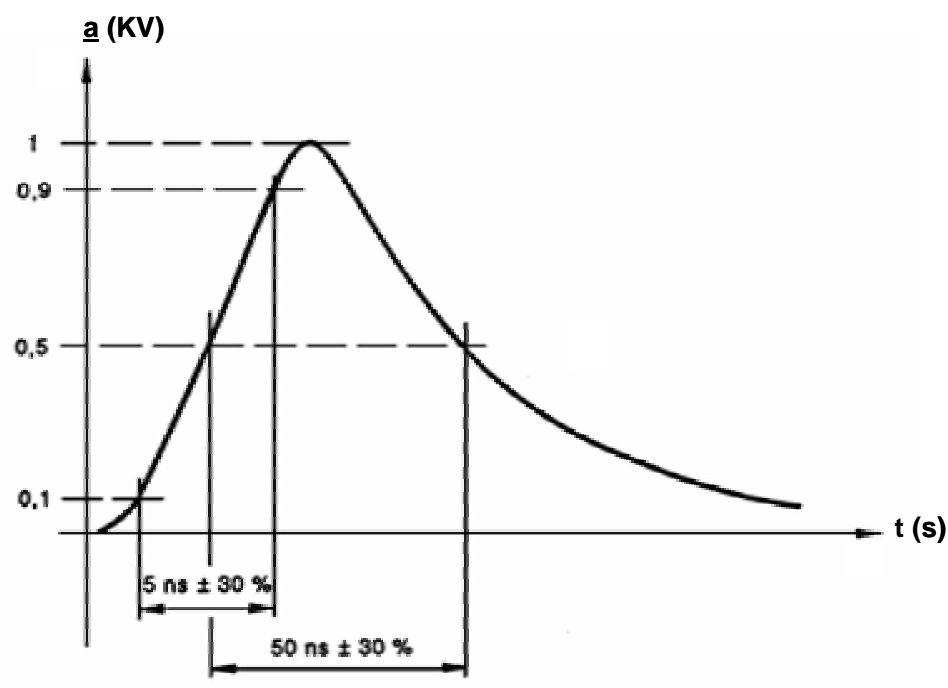

Figura 3.33 Forma de onda de um pulso

O circuito utilizado no Matlab/Simulink para geração dos transientes é mostrado na Figura 3.34. 


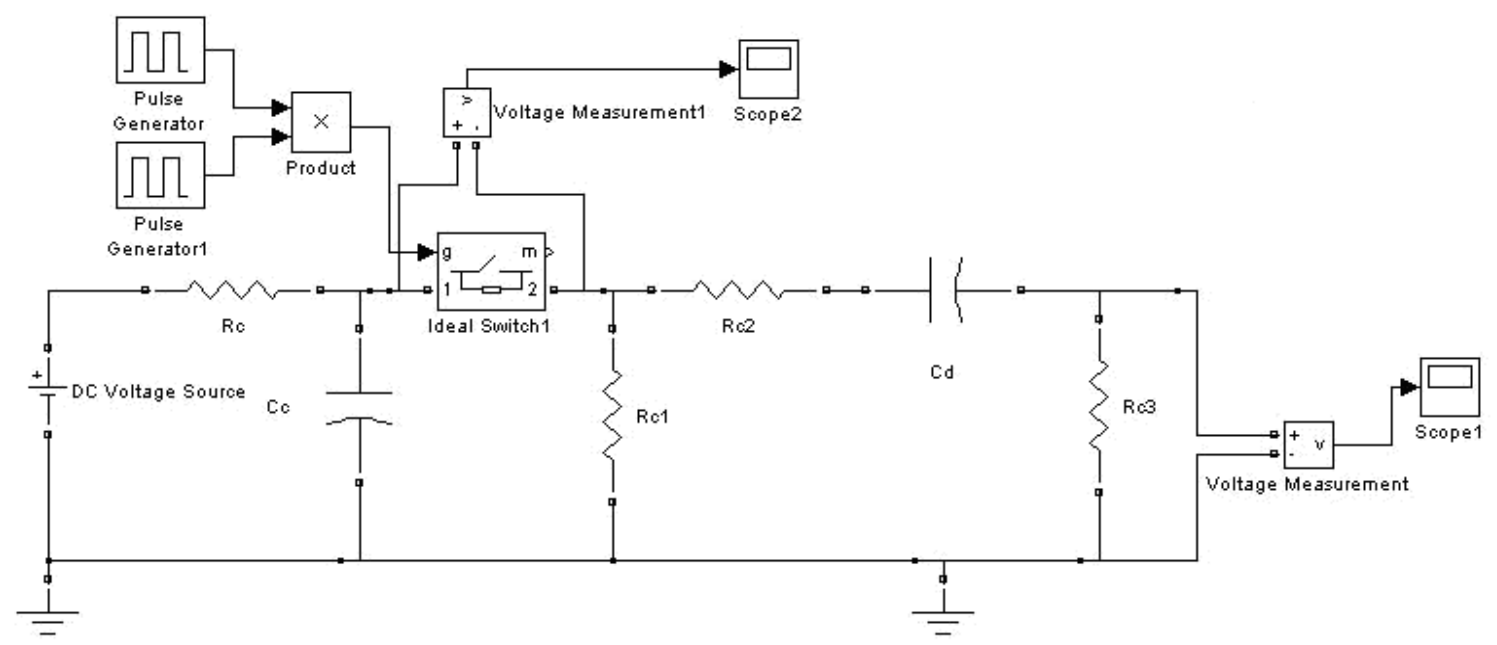

Figura 3.34 Circuito utilizado na simulação de transitórios

O bloco "Pulse Generator" produz pulsos em um período de $0,1 \mathrm{~ms}$ e amplitude de $1 \mathrm{~V}$. O bloco "Pulse Generator1" produz pulsos em um período de 0,1ms. O produto dos resultados destas duas fontes determina o sinal aplicado à chave ideal ("Ideal Switch1"). Os valores dos componentes discretos são indicados na Tabela 3.5

Tabela 3.5 Valores dos componentes discretos

\begin{tabular}{|c|c|c|}
\hline Componente & Descrição & Valor \\
\hline$D C$ Voltage Source & Fonte de alta tensão & $2 \mathrm{kV}$ \\
\hline$R c$ & Carga & $1 \Omega$ \\
\hline$R c 1$ & Impedância & $100 \mathrm{k} \Omega$ \\
\hline$R c 2$ & Duração do impulso & $0,5 \Omega$ \\
\hline$R c 3$ & Carga & $50 \Omega$ \\
\hline$C c$ & Remover o nível $C C$ & $10 \mathrm{nF}$ \\
\hline
\end{tabular}


O resultado da simulação para apenas um pulso do circuito da Figura 3.34 pode ser observado na Figura 3.35.

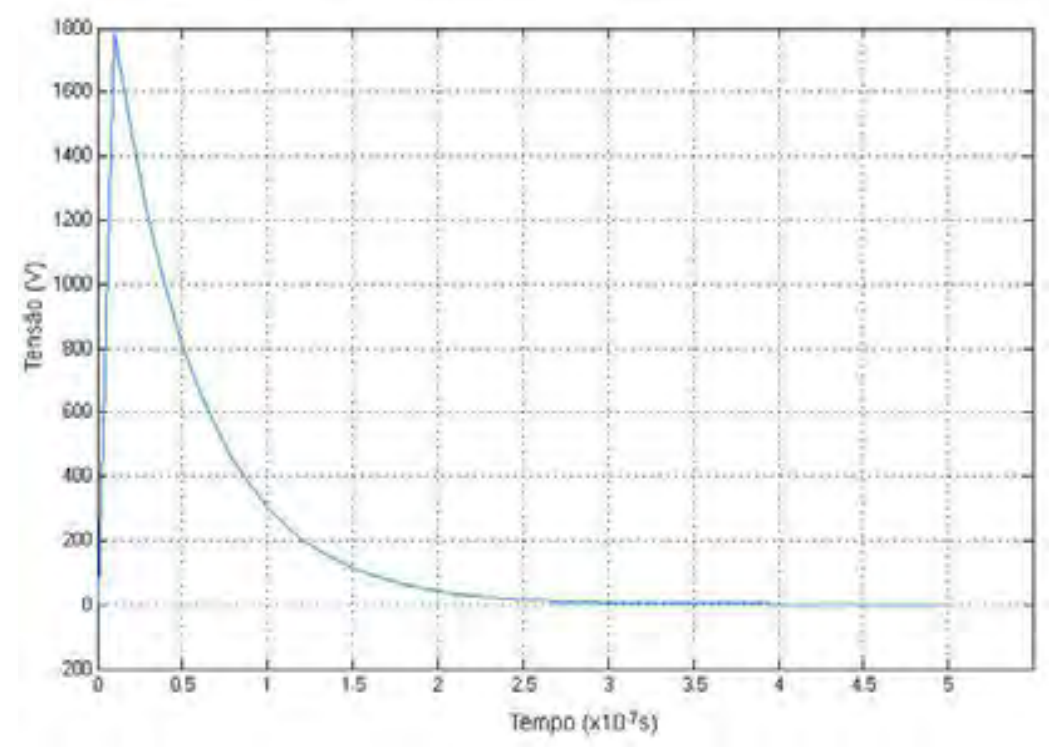

Figura 3.35 Resultado da simulação do circuito para um pulso

Nota-se que os resultados obtidos nesta simulação foram semelhantes ao descritos na norma. O gráfico da Figura 3.36 mostra o espectro de frequência do sinal de saída do circuito para um pulso. Pode-se observar que existem componentes harmônicas até $100 \mathrm{MHz}$ (foi considerado como frequência fundamental 20MHz).

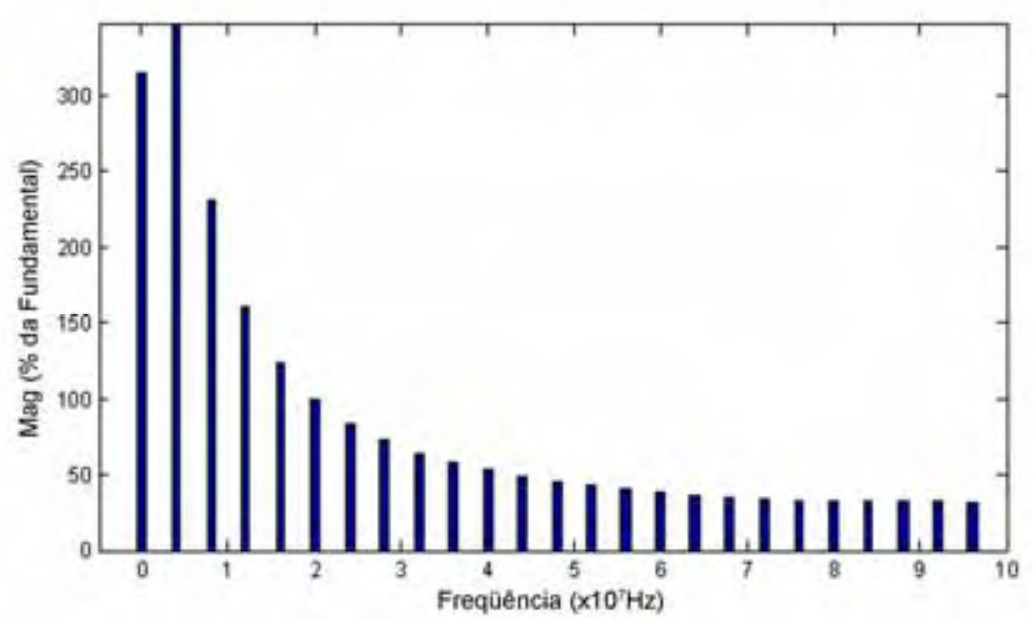

Figura 3.36 Espectro de frequência do pulso gerado 


\subsubsection{Processamento dos Sinais}

Após a realização dos ensaios laboratoriais, tornou-se necessário o processamento dos sinais, visando avaliar e comparar os níveis encontrados nos cabos sob testes, nos diversos eventos simulados. Para tal, foi realizada uma série de etapas de processamento em cada uma dos ensaios, visando selecionar e identificar as informações espectrais contidas no sinal. As fases de análise dos resultados foram:

a) Ajustes, adequação de níveis e separação dos sinais para o processamento;

b) Seleção de uma janela gráfica de pontos onde se obteve o maior ou menor valor de tensão/corrente no cabo sob testes;

c) Extração desta janela e impressão do gráfico para posterior análise;

d) Aplicação da Transformada Discreta da Fourier (DFT) com resolução máxima para a obtenção dos espectros de amplitude dos sinais coletados;

e) Separação da análise espectral em dois níveis: análise em baixa frequência e alta frequência;

f) Impressão gráfica de análise espectral em baixa e alta frequência. 


\section{Capítulo 4}

\section{Análise dos Resultados e Comentários}

Este capítulo consiste da apresentação dos ensaios realizados, das comparações e das análises dos cabos ensaiados à luz da suscetibilidade eletromagnética.

\subsection{Implementação Computacional dos Parâmetros Primitivos para os Modelos de Cabos Paralelos e Coaxiais}

A simulação foi implementada no programa Matlab e para isso foi desenvolvido um programa em Excel chamado de "InicializaSimCabo", que calcula os valores das indutâncias, capacitâncias e resistências do circuito para cada frequiência. O programa inicializa a simulação no Simulink, baseado nos valores primitivos determinados nos testes e nas dimensões dos cabos. Para simplificar o processo foi criado também, um programa chamado "SimLoteCabo", que solicita o nome do cabo, abre o arquivo ".xls" correspondente, chama o programa "InicializaSimCabo" para cada frequência, armazena os resultados da simulação em um vetor e mostra os gráficos da resposta do cabo em função da frequência.

Os valores de indutâncias de acoplamento entre os condutores, blindagens e estruturas, de capacitâncias próprias dos condutores e das blindagens e estruturas foram calculadas de acordo com as explicações descritas no Capítulo 3.

\subsection{Adequação dos Modelos às Condições dos Ensaios Laboratoriais}

Os cabos blindados com múltiplos condutores podem ser estudados como cabo paralelo, se for de interesse conhecer a interferência de um sinal de um condutor interno em outro. Se o interesse for analisar a interferência de um sinal proveniente de um condutor externo em um condutor interno do cabo, o modelo do cabo coaxial é usado nesta situação. 
Para as amostras 12, 13, 14 e 18 foram utilizados o modelo de simulação de cabos coaxiais, em função desses cabos apresentarem características mais próximas a esse tipo. Um dos fatores determinantes para a escolha deste modelo é a presença da blindagem nos condutores. Para as amostras 10 e 17 foram utilizados o modelo de simulação de cabos paralelos. A ausência de blindagem e a presença de vários condutores no mesmo cabo foram fatores determinantes para essa escolha deste modelo.

As simulações realizadas a partir da etapa de implementação computacional, descrita anteriormente, proporcionaram a geração das curvas de interferências eletromagnéticas dos cabos estudados. As figuras 4.1 a 4.6 mostram conjuntamente os resultados das simulações e dos ensaios laboratoriais para facilitar a análise. Os dois gráficos superiores referem-se aos resultados da simulação (impulso combinado (500V, sem aterramento)) e os inferiores aos resultados do ensaio laboratorial (impulso combinado (500V, sem aterramento)), conforme descrito no Capítulo 3. 

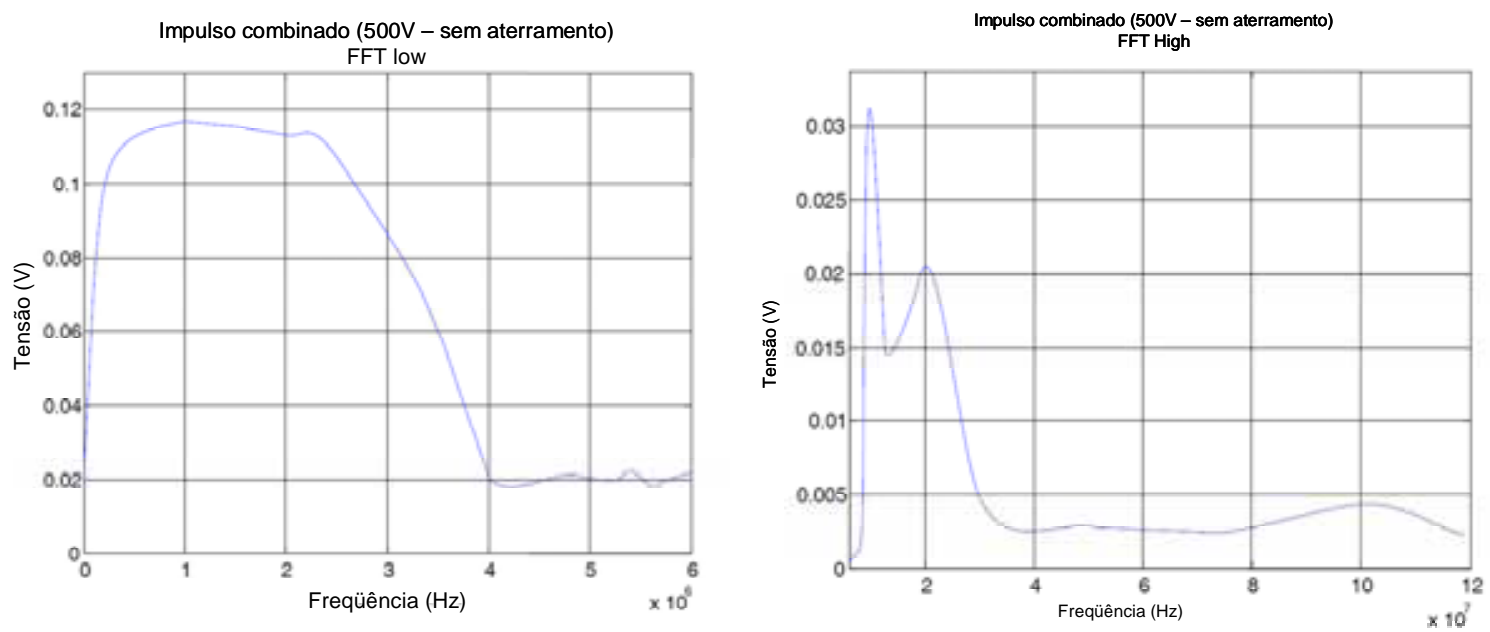

(a)
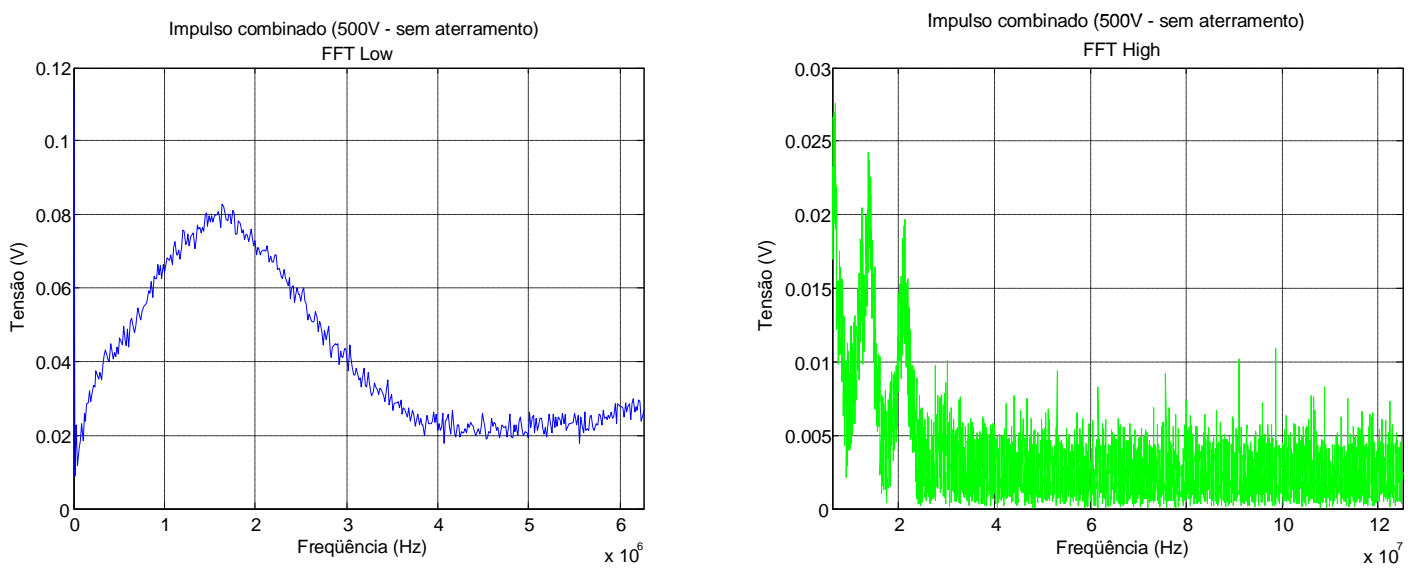

(b)

Figura 4.1 (a) Simulação; (b) Ensaio - amostra 10

$\mathrm{Na}$ análise da simulação (a), para frequências menores que $6 \mathrm{MHz}$, a mesma mostra um rápido pico e depois um decaimento do sinal a medida que se aumenta a frequência. No ensaio realizado (b) há um comportamento crescente do sinal para frequências até $1,6 \mathrm{MHz}$ aproximadamente e após isso ocorre um decréscimo da amplitude gerada. Para frequências maiores que $6 \mathrm{MHz}$ a simulação corresponde bem ao ensaio, decrescendo e ficando constante até o final da faixa. O ensaio obtido comporta-se de forma análoga ao simulado. 
Uma análise mais detalhada dos resultados dos dados da Figura 4.1, resultou na Tabela 4.1

Tabela 4.1 Amostra 10

\begin{tabular}{|c|c|c|}
\hline Frequência $(\mathbf{M H z})$ & Simulação $(\mathbf{m V})$ & Ensaio $(\mathbf{m V})$ \\
\hline $\mathbf{0 , 5}$ & 80 & 42 \\
\hline $\mathbf{1}$ & 99 & 66 \\
\hline $\mathbf{1 , 6}$ & 90 & 80 \\
\hline $\mathbf{3}$ & 82 & 42 \\
\hline $\mathbf{4 , 5}$ & 20 & 28 \\
\hline $\mathbf{6}$ & 22 & 29 \\
\hline $\mathbf{8}$ & 33 & 18 \\
\hline $\mathbf{1 0}$ & 30 & 24 \\
\hline $\mathbf{1 2}$ & 27 & 24 \\
\hline
\end{tabular}



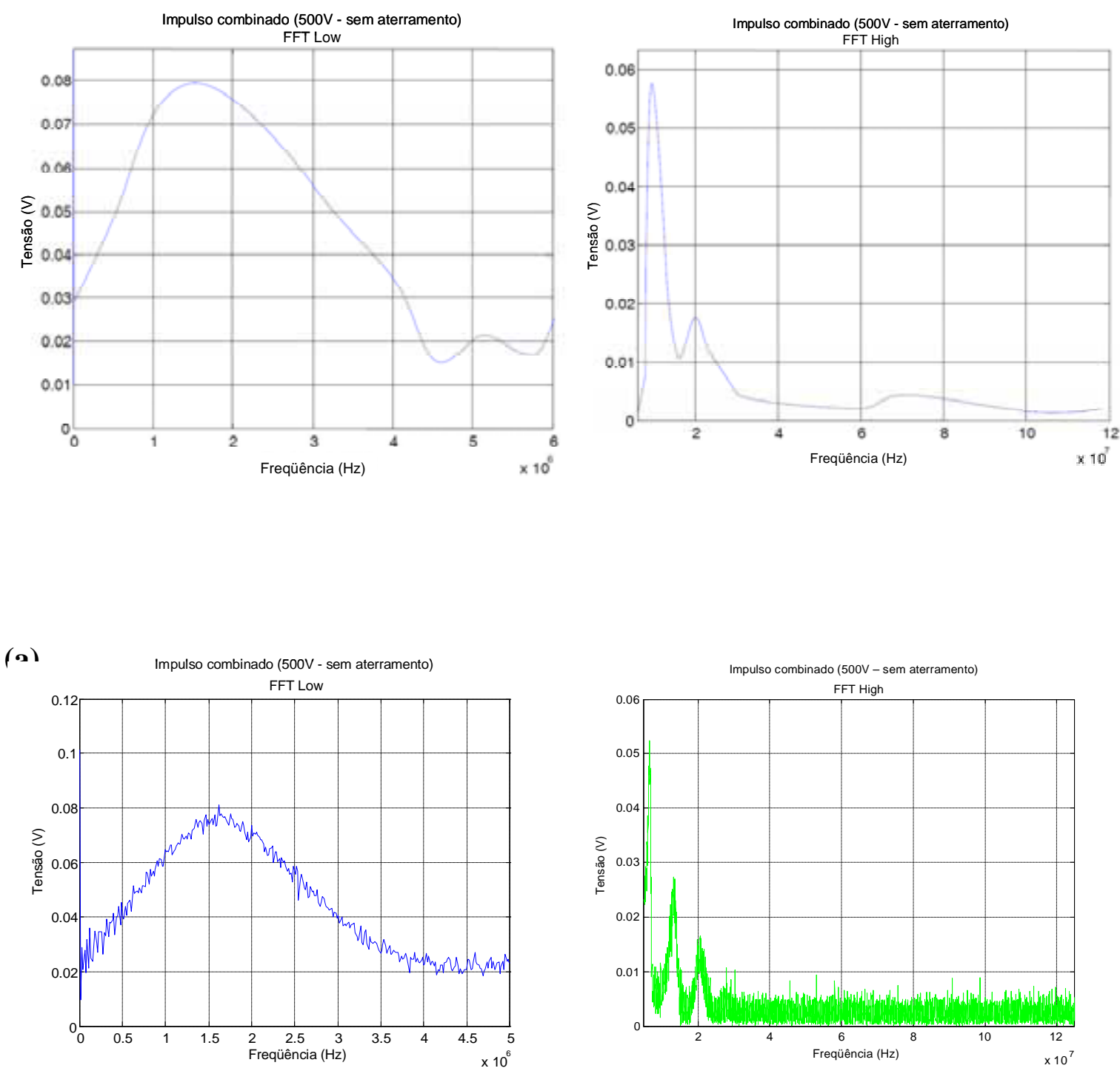

(b)

Figura 4.2 (a) Simulação; (b) Ensaio - amostra 17

Com frequência abaixo de $6 \mathrm{MHz}$, a simulação (a) apresenta um pico inicial com alta amplitude, decrescendo o sinal à medida que se aumenta a frequência. No ensaio realizado (b) o pico de sinal é bem mais singelo e fica em torno de $1,6 \mathrm{MHz}$, decrescendo posteriormente. Para frequências superiores a $6 \mathrm{MHz}$, a simulação apresenta-se de maneira 
mais eficaz e seu pico localiza-se praticamente na mesma faixa de frequência que a do ensaio e posteriormente o sinal mantém-se praticamente constante. $\mathrm{O}$ ensaio obtido comporta-se de forma análoga ao simulado.

Uma análise mais detalhada dos resultados dos dados da Figura 4.2, resultou na Tabela 4.2

Tabela 4.2 Amostra 17

\begin{tabular}{|c|c|c|}
\hline Frequência (MHz) & Simulação $(\mathbf{m V})$ & Ensaio $(\mathbf{m V})$ \\
\hline $\mathbf{0 , 5}$ & 50 & 45 \\
\hline $\mathbf{1}$ & 72 & 60 \\
\hline $\mathbf{1 , 6}$ & 79 & 77 \\
\hline $\mathbf{3}$ & 56 & 40 \\
\hline $\mathbf{4 , 5}$ & 16 & 25 \\
\hline $\mathbf{6}$ & 58 & 30 \\
\hline $\mathbf{8}$ & 50 & 13 \\
\hline $\mathbf{1 0}$ & 33 & 28 \\
\hline $\mathbf{1 2}$ & 15 & 20 \\
\hline
\end{tabular}



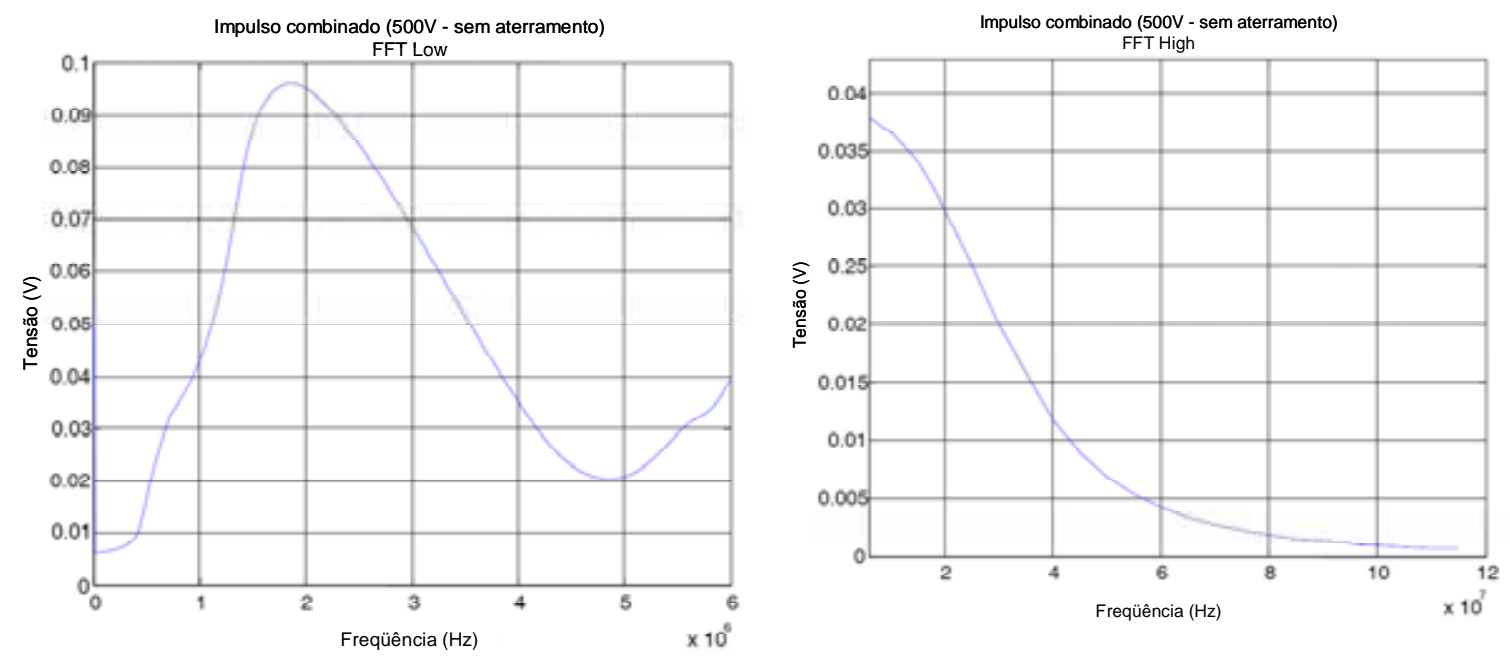

(a)
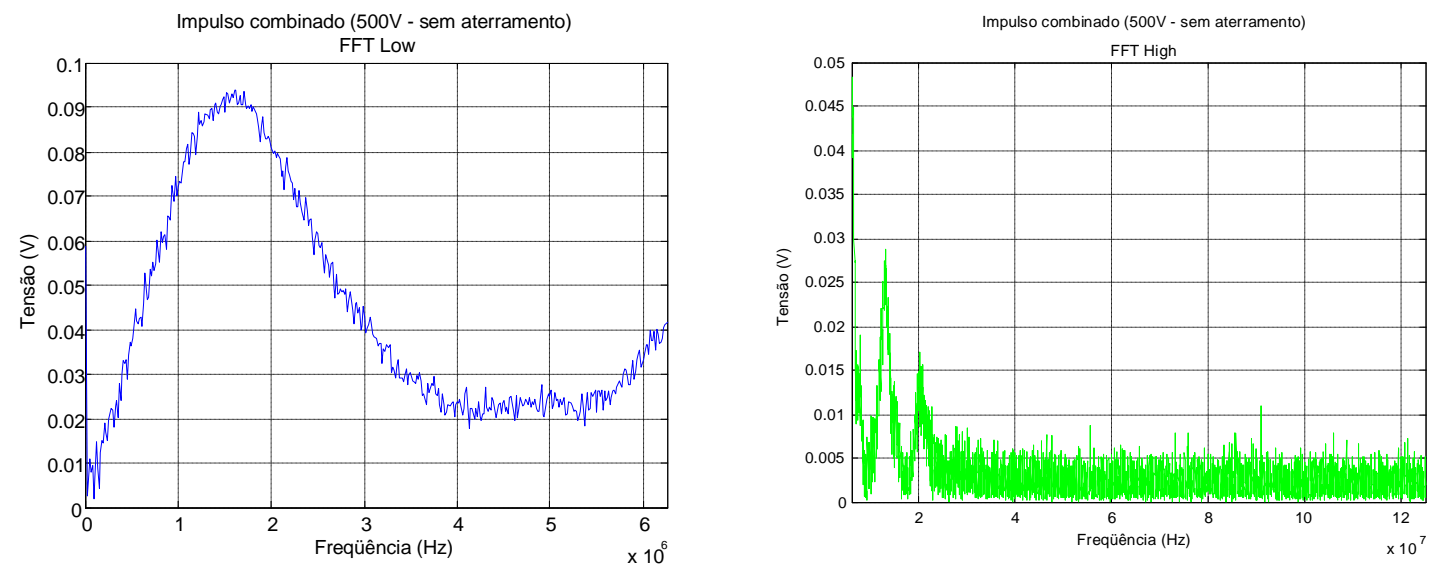

(b)

Figura 4.3 (a) Simulação; (b) Ensaio - amostra 12

Para frequências abaixo de $6 \mathrm{MHz}$, a simulação (a) conseguiu reproduzir parcialmente o que de fato ocorreu no ensaio realizado (b). Para frequências acima de $10 \mathrm{MHz}$, a simulação apresentou uma amplitude alta do sinal e havendo posteriormente um decréscimo. A imprecisão da simulação ocorre, pois o tipo do cabo analisado não se adequou completamente ao modelo de simulação aplicado. 
Uma análise mais detalhada dos resultados dos dados da Figura 4.3, resultou na Tabela 4.3.

Tabela 4.3 Amostra 12

\begin{tabular}{|c|c|c|}
\hline Frequência $(\mathbf{M H z})$ & Simulação $(\mathbf{m V})$ & Ensaio $(\mathbf{m V})$ \\
\hline $\mathbf{0 , 5}$ & 20 & 35 \\
\hline $\mathbf{1}$ & 43 & 70 \\
\hline $\mathbf{1 , 8}$ & 96 & 90 \\
\hline $\mathbf{3}$ & 68 & 45 \\
\hline $\mathbf{4 , 5}$ & 23 & 24 \\
\hline $\mathbf{6}$ & 40 & 36 \\
\hline $\mathbf{8}$ & 36 & 15 \\
\hline $\mathbf{1 0}$ & 35 & 27 \\
\hline $\mathbf{1 2}$ & 34 & 15 \\
\hline
\end{tabular}



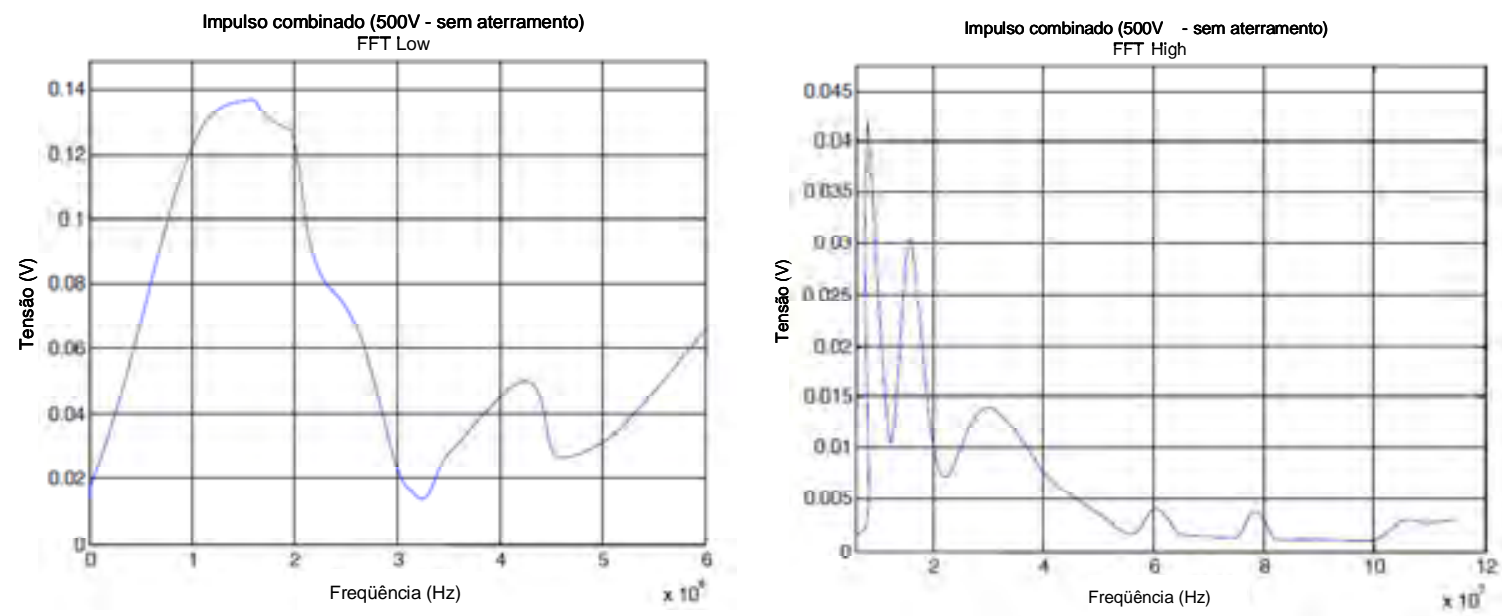

(a)
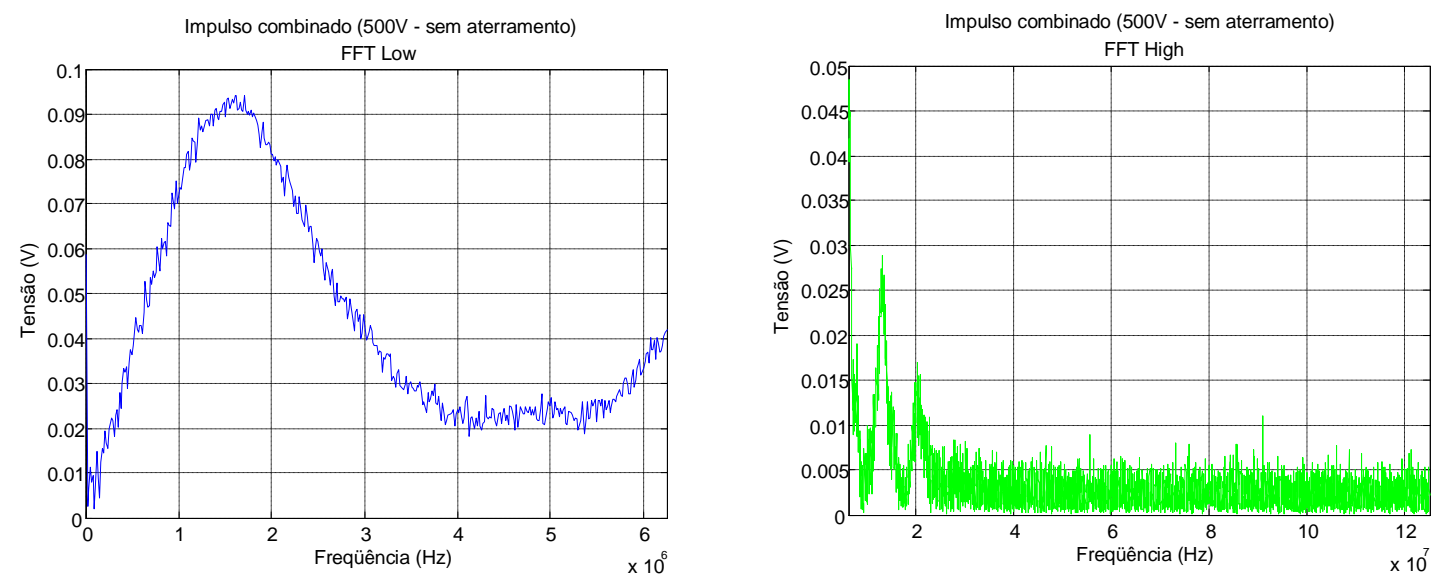

(b)

Figura 4.4 (a) Simulação; (b) Ensaio - amostra 13

Na simulação (a) para frequências até $6 \mathrm{MHz}$, o sinal decresce muito rapidamente perante a comparação do ensaio realizado (b) e tem seu ponto de máximo em $1,6 \mathrm{MHz}$. Para a simulação com valores de frequências acima de $10 \mathrm{MHz}$ o decrescimento do sinal dá-se posteriormente a $40 \mathrm{MHz}$ e diminui de maneira gradativa. No ensaio realizado, para frequências entre aproximadamente $10 \mathrm{MHz}$ e $20 \mathrm{MHz}$, o sinal oscila, decrescendo até o final da faixa onde o mesmo fica quase constante. Para este caso o modelo apresentou uma eficácia razoável. 
Uma análise mais detalhada dos resultados dos dados da Figura 4.4, resultou na Tabela 4.4.

Tabela 4.4 Amostra 13

\begin{tabular}{|c|c|c|}
\hline Frequência $(\mathbf{M H z})$ & Simulação $(\mathbf{m V})$ & Ensaio $(\mathbf{m V})$ \\
\hline $\mathbf{0 , 5}$ & 70 & 42 \\
\hline $\mathbf{1 , 6}$ & 135 & 94 \\
\hline $\mathbf{2}$ & 125 & 84 \\
\hline $\mathbf{3}$ & 25 & 45 \\
\hline $\mathbf{4 , 5}$ & 30 & 25 \\
\hline $\mathbf{6}$ & 65 & 38 \\
\hline $\mathbf{8}$ & 37 & 13 \\
\hline $\mathbf{1 0}$ & 35 & 27 \\
\hline $\mathbf{1 2}$ & 34 & 15 \\
\hline
\end{tabular}



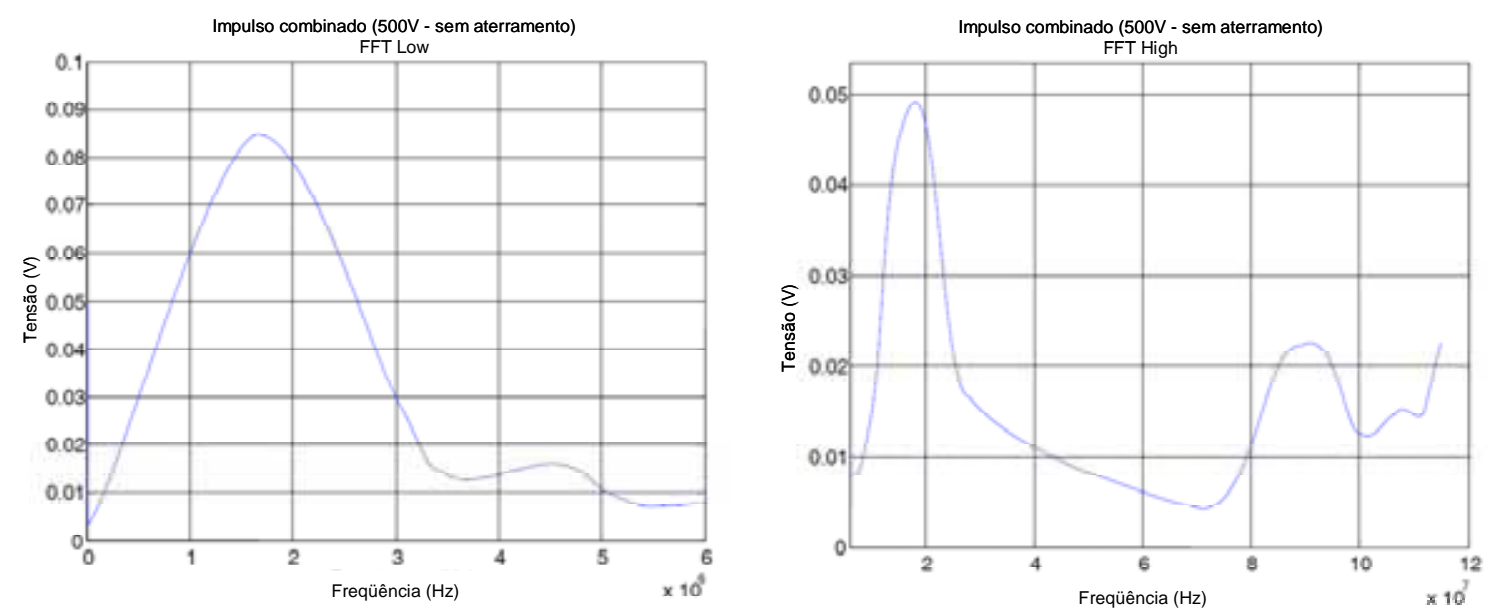

(a)
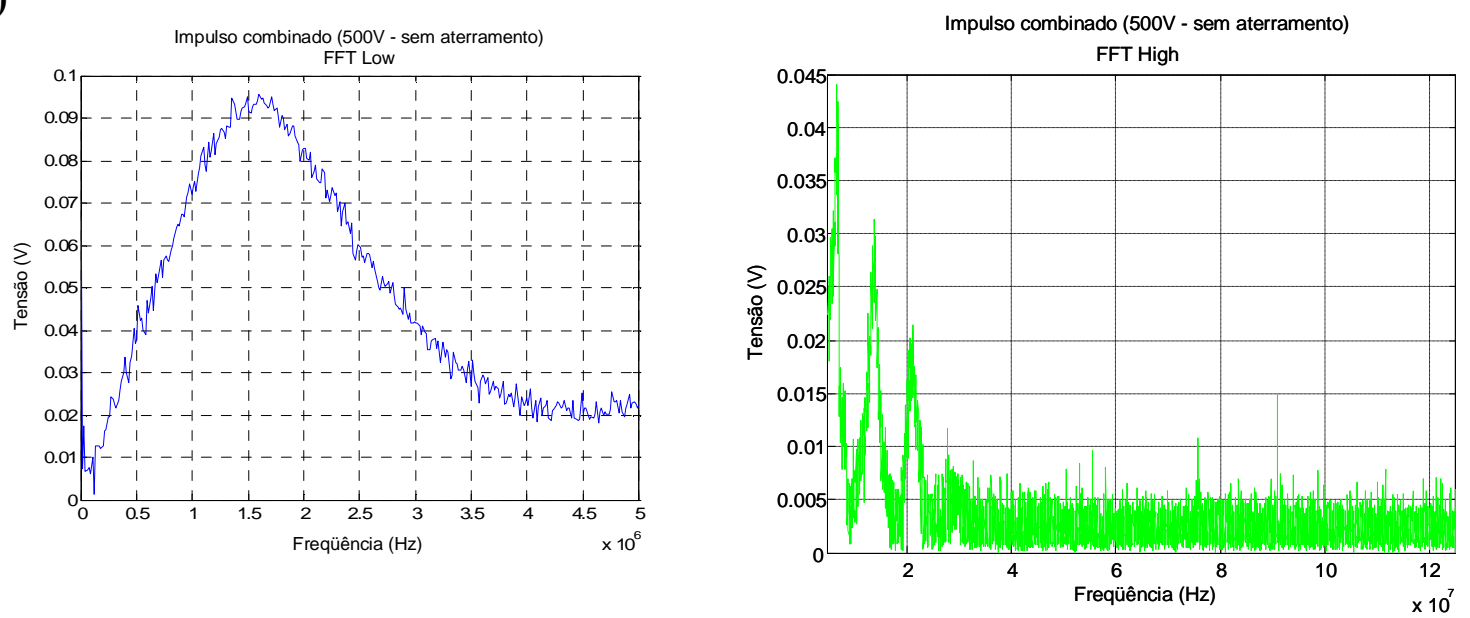

(b)

Figura 4.5 (a) Simulação; (b) Ensaio - amostra 14

No gráfico simulado (a), para valores de frequências abaixo de $6 \mathrm{MHz}$, tem-se um decrescimento do sinal de maneira repentina em $0,2 \mathrm{MHz}$, crescendo discretamente depois. No ensaio realizado (b), observa-se um comportamento não tão próximo do simulado. Inicialmente, há um decrescimento repentino, como no simulado, porém, a partir dai existe 
um crescimento considerável do sinal, atingindo um pico em $1,6 \mathrm{MHz}$ e decaindo posteriormente. Para frequência acima de $6 \mathrm{MHz}$, o ensaio possui picos de oscilações do sinal e depois permanece constante até o final da faixa. Para este caso o modelo apresentou uma eficácia razoável.

Uma análise mais detalhada dos resultados dos dados da Figura 4.5, resultou na Tabela 4.5.

Tabela 4.5 Amostra 14

\begin{tabular}{|c|c|c|}
\hline Frequência (MHz) & Simulação $(\mathbf{m V})$ & Ensaio $(\mathbf{m V})$ \\
\hline $\mathbf{0 , 5}$ & 30 & 40 \\
\hline $\mathbf{1}$ & 60 & 70 \\
\hline $\mathbf{1 , 6}$ & 85 & 95 \\
\hline $\mathbf{3}$ & 30 & 41 \\
\hline $\mathbf{4 , 5}$ & 16 & 25 \\
\hline $\mathbf{6}$ & 7 & 5 \\
\hline $\mathbf{8}$ & 20 & 13 \\
\hline $\mathbf{1 0}$ & 35 & 25 \\
\hline $\mathbf{1 2}$ & 43 & 30 \\
\hline
\end{tabular}



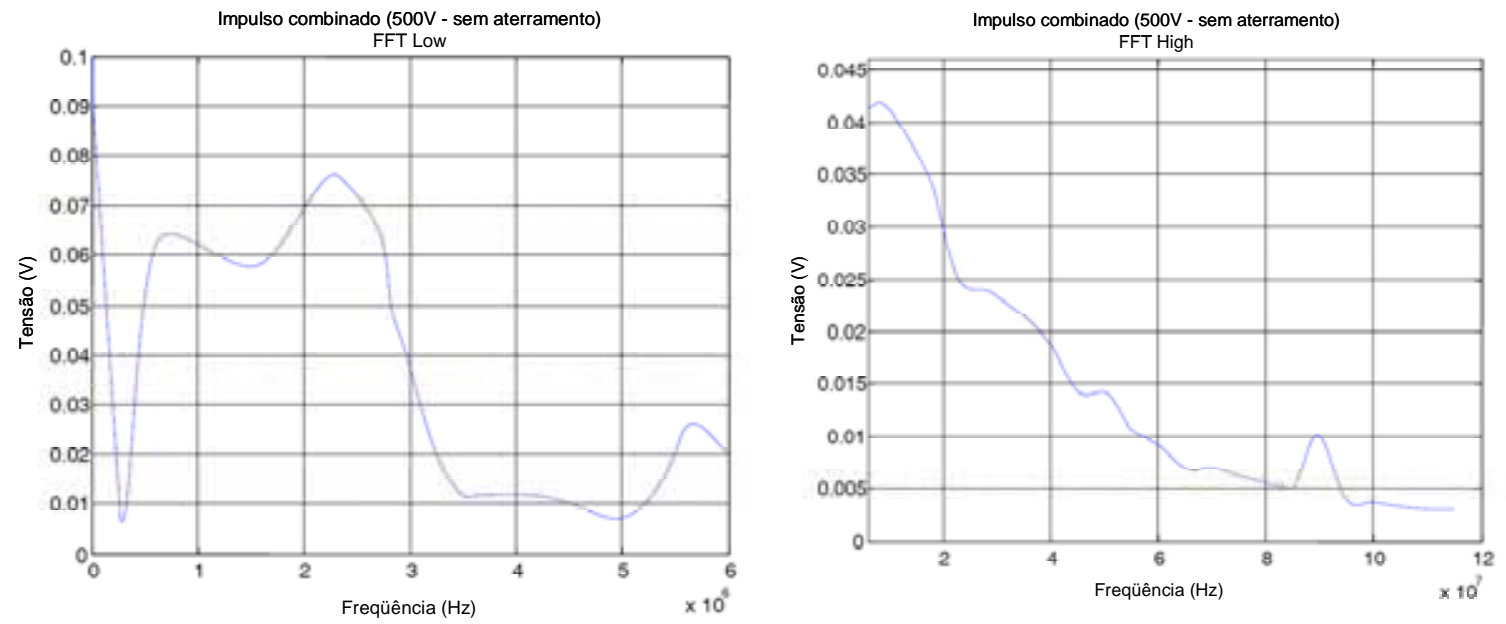

(a)
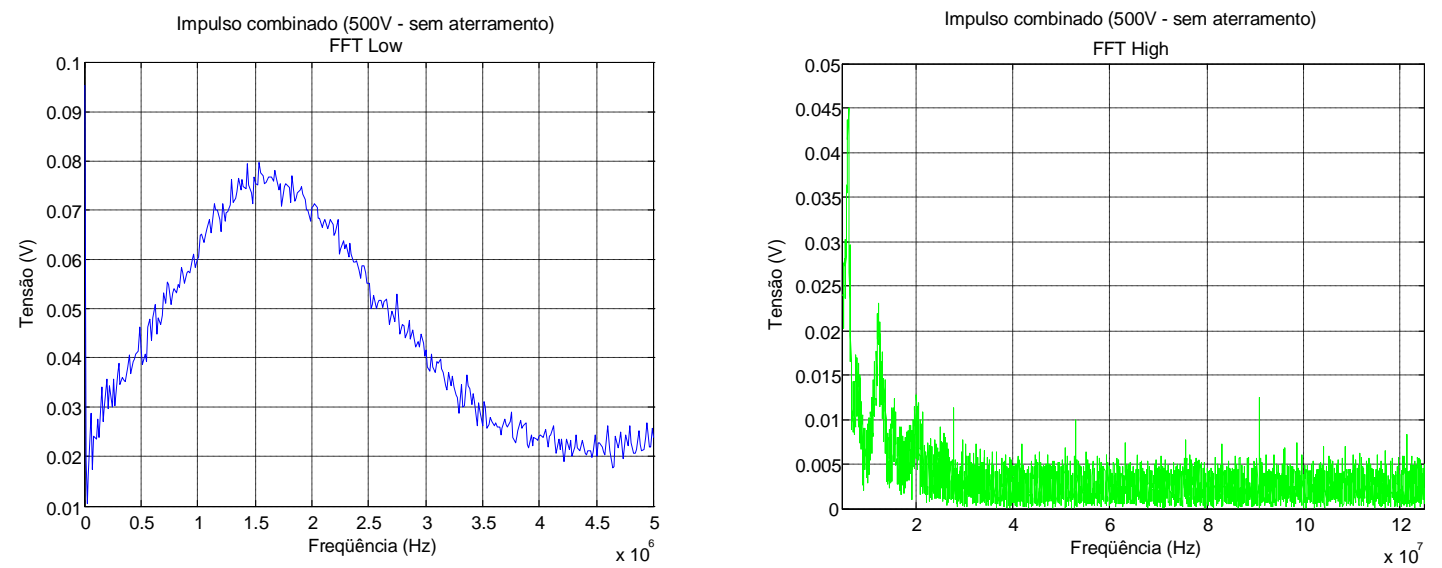

(b)

Figura 4.6 (a) Simulação; (b) Ensaio - amostra 18

Para valores até $6 \mathrm{MHz}$, o gráfico simulado (a) apresenta um decaimento em $0,5 \mathrm{MHz}$ e um crescimento à partir dessa frequência. No ensaio realizado (b) pode-se analisar um decaimento em $0,2 \mathrm{MHz}$, valor de frequência muito próximo ao simulado e posteriormente o sinal volta a crescer atingindo o pico em 1,6MHz. Para a análise da simulação a partir de $10 \mathrm{MHz}$, o sinal tende a cair gradativamente. Essa tendência foi evidenciada no ensaio realizado para frequências a partir de $10 \mathrm{MHz}$, porém, a frequência em que o sinal fica 
constante está na faixa de 30MHz. A imprecisão da simulação ocorre em alguns pontos, pois o tipo do cabo analisado não se adequou completamente ao modelo de simulação aplicado.

Uma análise mais detalhada dos resultados dos dados da Figura 4.6, resultou na Tabela 4.6.

Tabela 4.6 Amostra 18

\begin{tabular}{|c|c|c|}
\hline Frequência $(\mathbf{M H z})$ & Simulação $(\mathbf{m V})$ & Ensaio $(\mathbf{m V})$ \\
\hline $\mathbf{0 , 5}$ & 55 & 46 \\
\hline $\mathbf{1}$ & 62 & 64 \\
\hline $\mathbf{2}$ & 70 & 72 \\
\hline $\mathbf{3}$ & 36 & 41 \\
\hline $\mathbf{4 , 5}$ & 10 & 23 \\
\hline $\mathbf{6}$ & 41 & 30 \\
\hline $\mathbf{8}$ & 40 & 15 \\
\hline $\mathbf{1 0}$ & 39 & 23 \\
\hline $\mathbf{1 2}$ & 37 & 17 \\
\hline
\end{tabular}

\subsubsection{Análise dos Resultados do Ajuste dos Modelos às Condições dos Ensaios Laboratoriais}

Embora os gráficos da simulação e dos ensaios tenham apresentados alguns pontos não concordantes, é possível notar que há uma relação em todos os gráficos para todas as amostras. Pode-se observar que para algumas amostras, o modelo não convergiu totalmente, ou em outros, o modelo se adaptou quase que completamente. Isto é explicado pela grande variedade de cabos ensaiados, pela complexidade de construção de alguns desses cabos e pelo fato de que o modelo proposto por (DARNEY, 1977) precisa de melhorais para atender aos cabos coaxiais mais complexos. 
Uma análise criteriosa foi executada considerando ponto a ponto em toda a faixa de frequência x amplitude, tanto para a simulação, quanto para os ensaios laboratoriais. Assim, as simulações representam o comportamento das interferências eletromagnéticas nos cabos, que foram constatadas nos ensaios laboratoriais. Portanto, para os ensaios laboratoriais, da maneira como foram idealizados, mostrados no Capítulo 3, são confirmados pelo modelo proposto por (DARNEY, 1997) e adaptado para este trabalho. Esta confirmação é importante, pois não existem normas específicas para ensaios de interferências eletromagnéticas em cabos e este trabalho foi baseado em pesquisa desenvolvida por (ARDJOMAND et al., 2005), e adaptado para tal.

\subsection{Resultados e Comparações dos Cabos Analisados}

Com objetivo de avaliar a eficiência da blindagem dos cabos ensaiados, utilizou-se a avaliação entre ensaios com blindagem não aterrada e com blindagem aterrada no ponto mais próximo da fonte de interferência. Desta forma, a comparação foi realizada para o pior caso (blindagem sem aterramento), e o melhor caso (blindagem aterrada no ponto mais próximo), conforme mostrado no item 3.10.2, proporcionando resultados que expressam a proteção estabelecida pela blindagem de um cabo.

Para o processamento digital dos sinais para avaliação da eficiência da blindagem, foram utilizados os sinais armazenados nos ensaios laboratoriais que envolveram: Transitório Elétrico Rápido, Campo Magnético Resultante da Corrente na Frequência de $60 \mathrm{~Hz}$ e Impulso Combinado que foram produzidos no Capítulo 3. Esses dados foram devidamente tratados, com normalizações de escalas, amplitudes, fases, análises de off-set e FFT para os cabos coaxiais com a blindagem aterrada e blindagem não aterrada.

Para o valor da atenuação (\%) foi utilizada a relação tensão do sinal não aterrado (blindagem) / tensão do sinal aterrado (blindagem) em toda a extensão do espectro analisado $(12 \mathrm{MHz})$, calculando a porcentagem em relação à tensão do sinal não aterrado. Em seguida efetuou-se uma média aritmética destes pontos para obter um valor médio em toda a faixa de frequência analisada. 
O valor da atenuação $(\mathrm{dB})$ foi calculado usando a expressão:

$$
20 \log _{10} \frac{\text { Tensãosematerramento }}{\text { Tensãocomaterramento }}
$$

Em seguida efetuou-se uma média aritmética destes pontos para obter um valor médio em toda a faixa analisada (12MHz).

Para a realização desta avaliação foram utilizados somente cabos com blindagens (amostras 12, 13, 14 e 18), pois esta etapa consistiu na comparação por meio dos efeitos causados em cabos blindados aterrados e cabos blindados não aterrados, produzindo um valor que expressa a atenuação do sinal que relaciona os dois métodos de instalação, conforme mostrado no Capítulo 3. Os gráficos obtidos são expressos pelas Figuras 4.7 a 4.28 . 


\section{Amostra 12}

Ensaio de Transitório Elétrico Rápido

Burst 500V

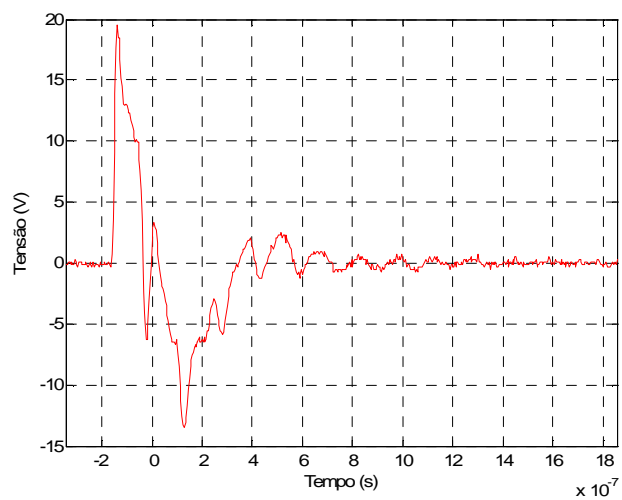

Figura 4.7 Tensão sem aterramento

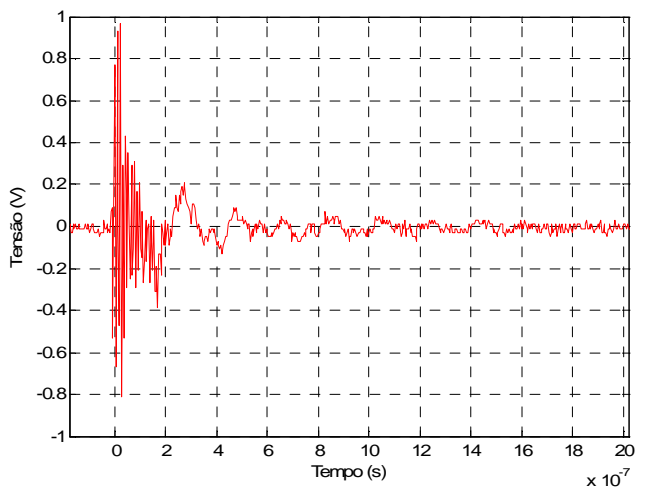

Figura 4.8 Tensão com aterramento (extremidade mais próxima)
Amostra 12

Ensaios de Campo na Frequência de $60 \mathrm{~Hz}$

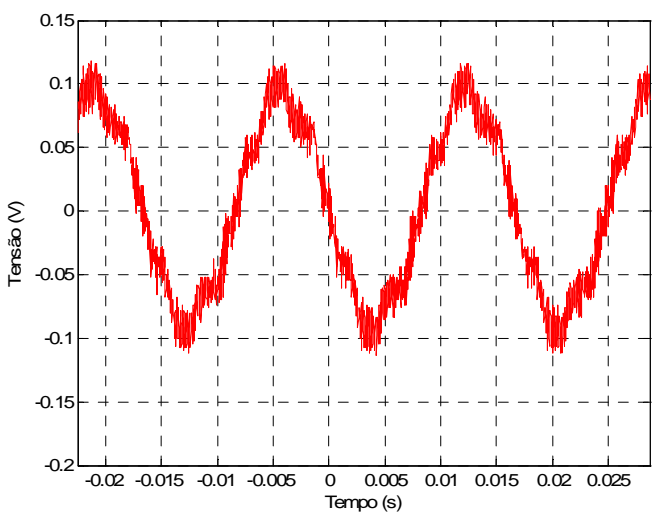

Figura 4.9 Tensão sem aterramento

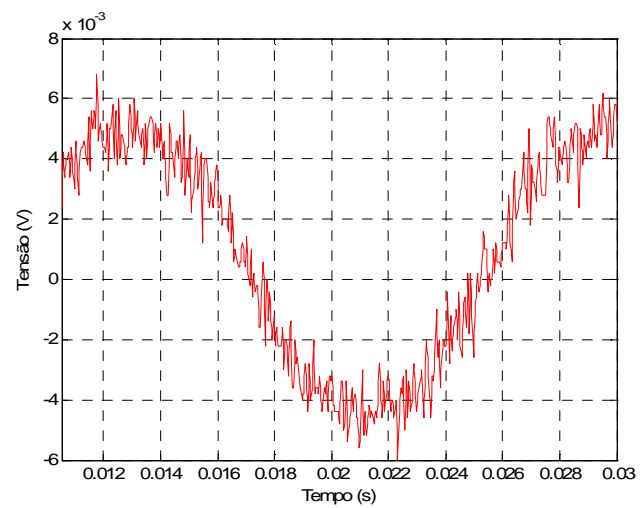

Figura 4.10 Tensão com aterramento (extremidade mais próxima) 


\section{Amostra 12}

Ensaio de Impulso Combinado $1 \mathrm{kv}$

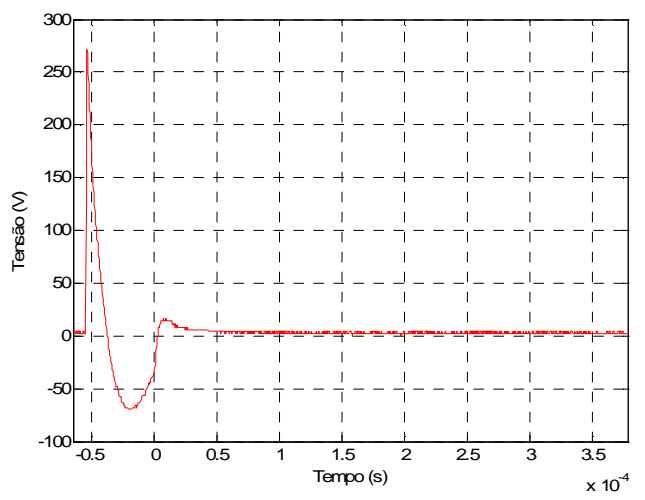

Figura 4.11 Tensão sem aterramento

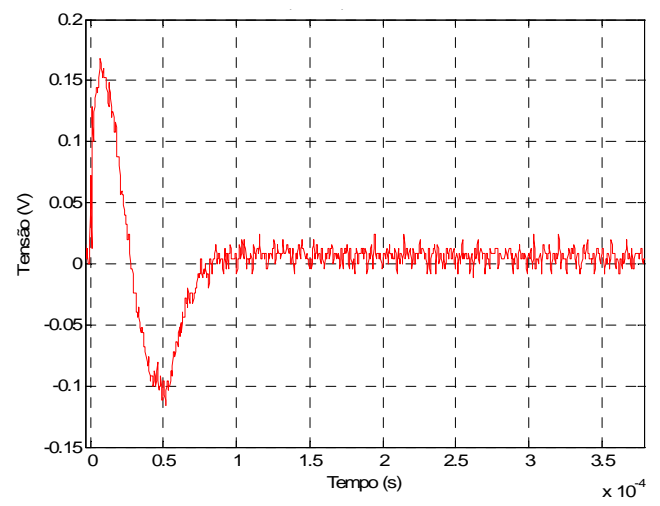

Figura 4.12 Tensão com aterramento (extremidade mais próxima)
Amostra 13*

Ensaio de Transitório Elétrico Rápido

Burst 500V

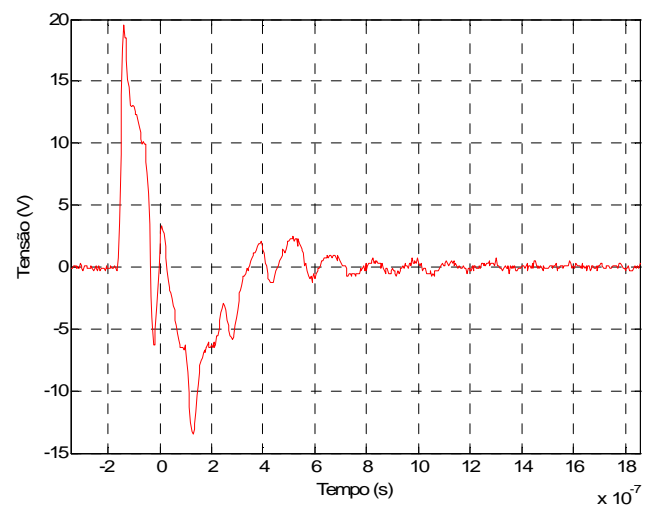

Figura 4.13 Tensão sem aterramento

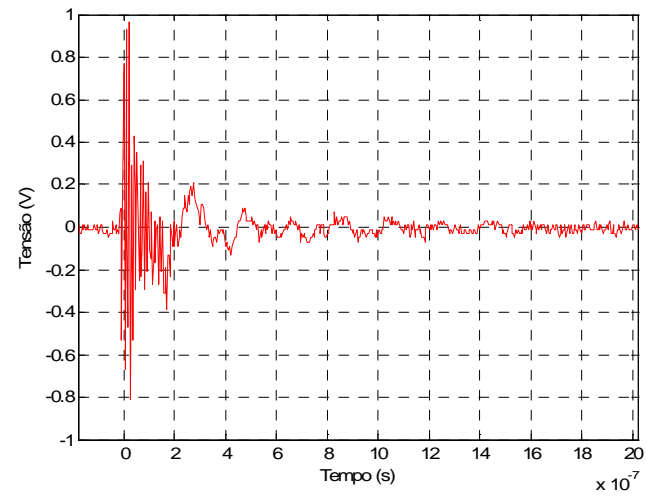

Figura 4.14 Tensão com aterramento (extremidade mais próxima) 
Amostra 13*

Ensaio de Impulso Combinado $1 \mathrm{kV}$

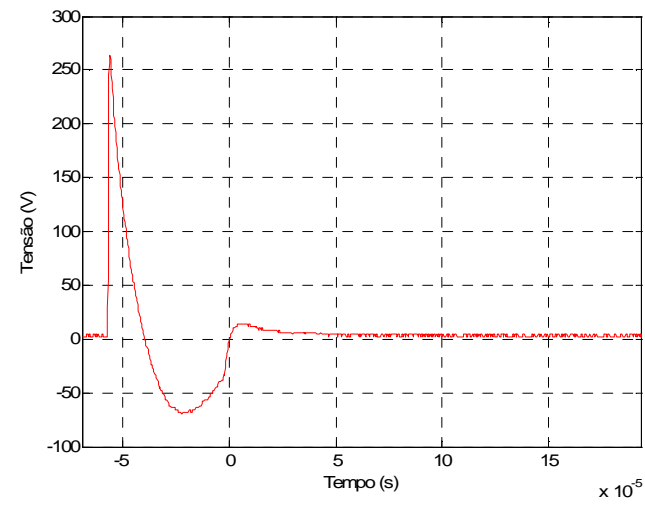

Figura 4.15 Tensão sem aterramento

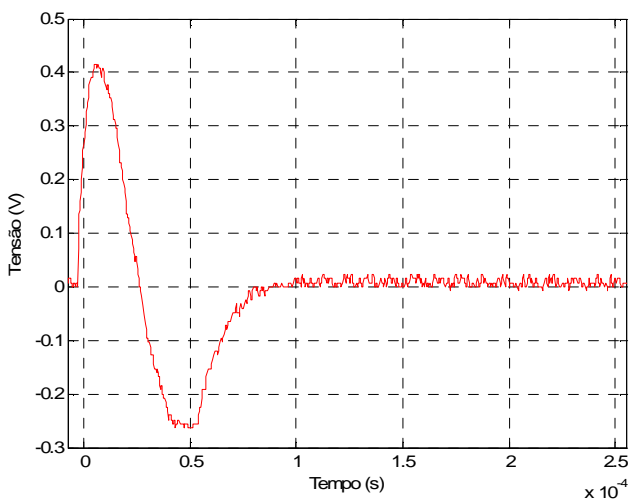

Figura 4.16 Tensão com aterramento (extremidade mais próxima)
Amostra 14

Ensaio de Transitório Elétrico Rápido

Burst 500V

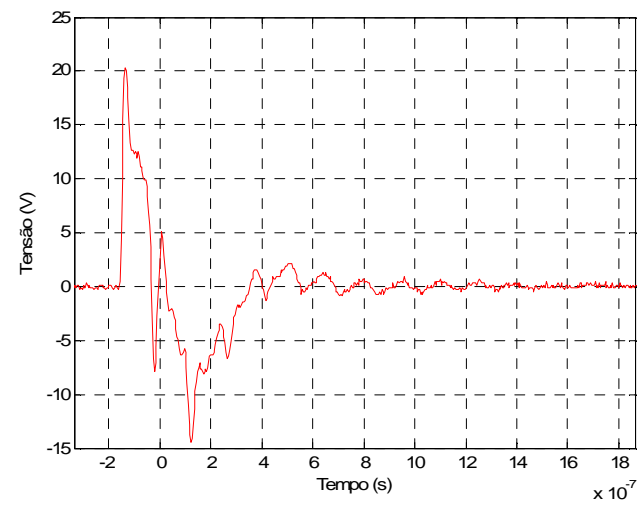

Figura 4.17 Tensão sem aterramento

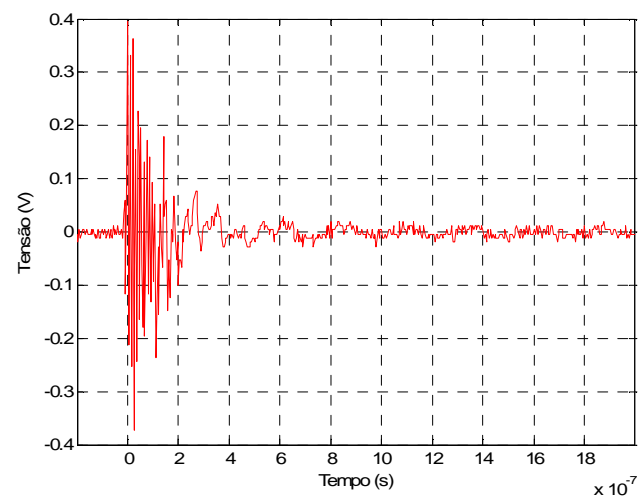

Figura 4.18 Tensão com aterramento (extremidade mais próxima)

* A amostra 13 não possui dados para campo na frequência de $60 \mathrm{~Hz}$. 
Amostra 14

Ensaios de Campo na Frequência de

$60 \mathrm{~Hz}$

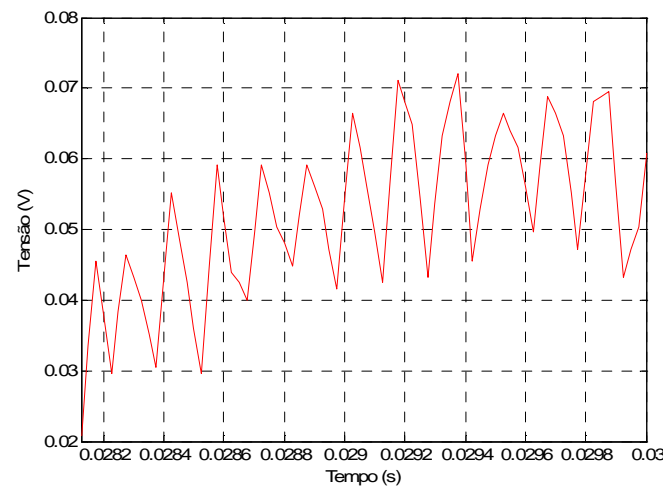

Figura 4.19 Tensão sem aterramento

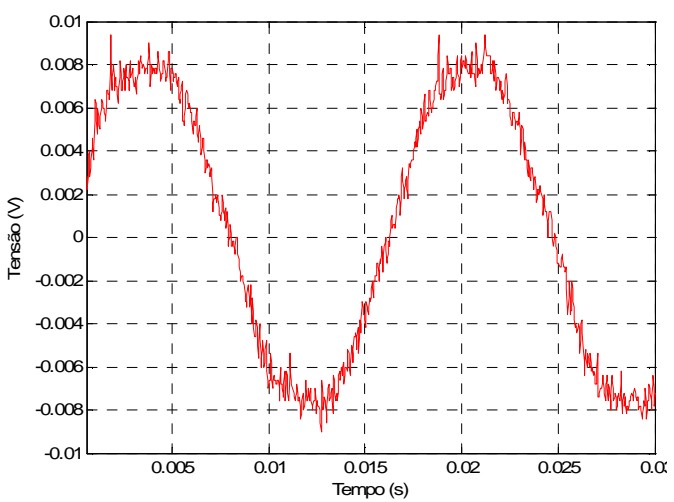

Figura 4.20 Tensão com aterramento (extremidade mais próxima)
Amostra 14

Ensaio de Impulso Combinado $1 \mathrm{kV}$

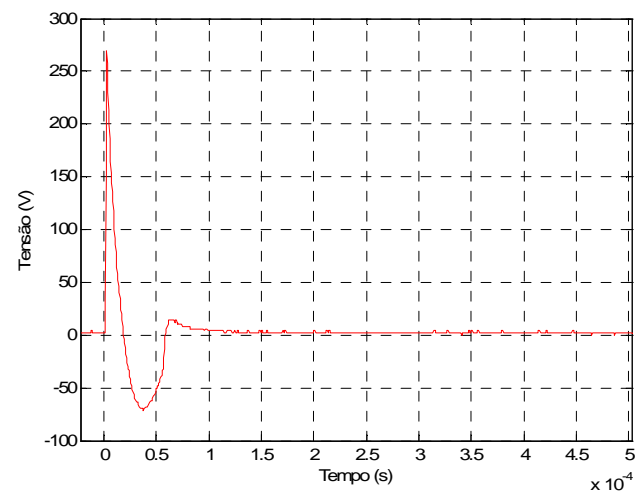

Figura 4.21 Tensão sem aterramento

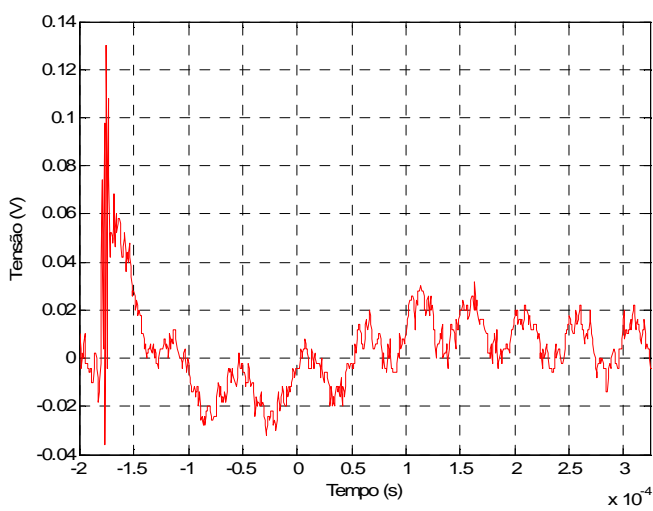

Figura 4.22 Tensão com aterramento (extremidade mais próxima) 


\section{Amostra 18}

\section{Ensaio de Transitório Elétrico Rápido}

Burst 500V

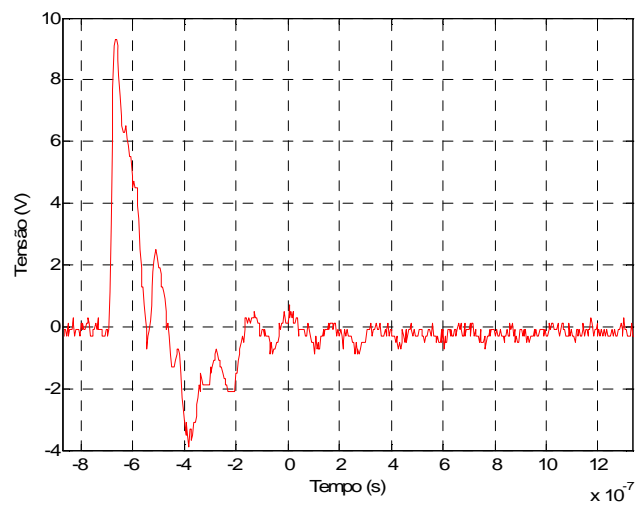

Figura 4.23 Tensão sem aterramento

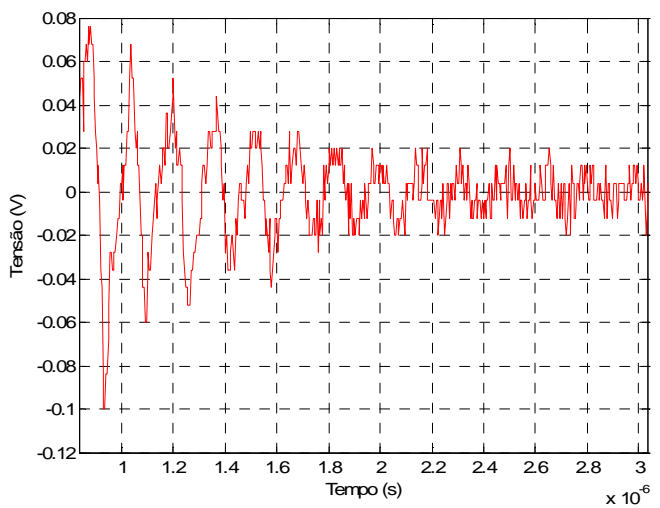

Figura 4.24 Tensão com aterramento (extremidade mais próxima)
Amostra 18

Ensaios de Campo na Frequência de $60 \mathrm{~Hz}$

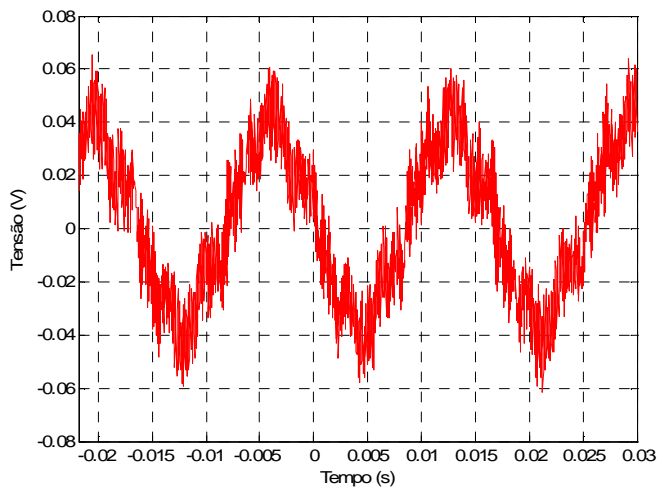

Figura 4.25 Tensão sem aterramento

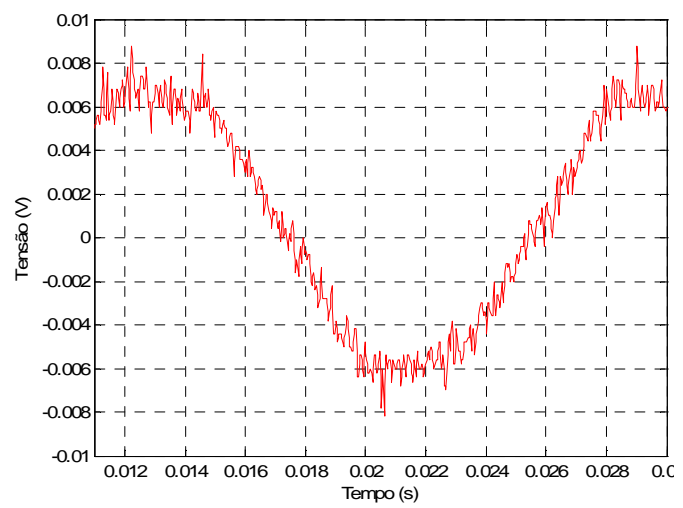

Figura 4.26 Tensão com aterramento (extremidade mais próxima) 


\section{Amostra 18**}

Ensaio de Impulso Combinado 500V

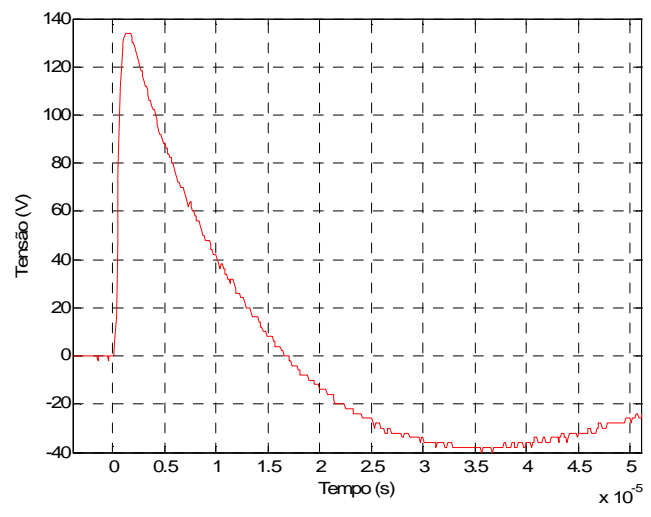

Figura 4.27 Tensão sem aterramento

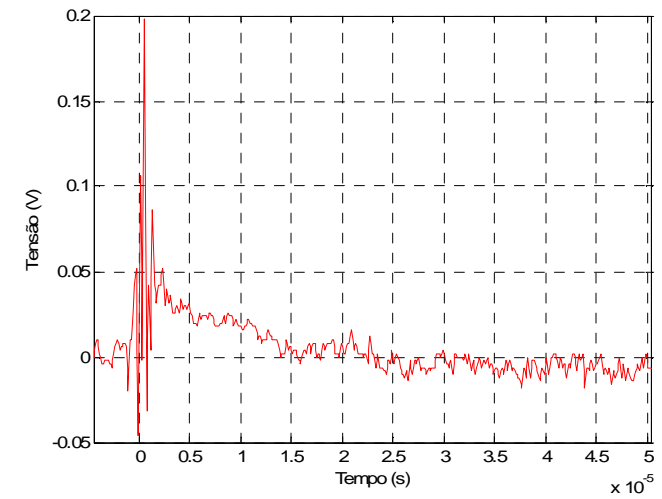

Figura 4.28 Tensão com aterramento (extremidade mais próxima)

**A amostra 18 possui apenas impulso combinado para $500 \mathrm{~V}$. 


\subsection{Análise dos Resultados dos Ensaios}

Uma análise mais detalhada dos resultados dos dados apresentados anteriormente resultou na Tabela 4.7 .

Tabela 4.7 Análise dos resultados gráficos

\begin{tabular}{|c|c|c|}
\hline $\begin{array}{c}\text { Amostra de } \\
\text { Cabos com } \\
\text { Blindagem }\end{array}$ & Tipos de Interferências & Atenuação \\
\hline \multirow{3}{*}{12} & Transitório elétrico rápido-Burst & $\begin{array}{c}95,33 \% \\
-26,61 \mathrm{~dB}\end{array}$ \\
\hline & Campo na frequência de $60 \mathrm{~Hz}$ & $\begin{array}{c}4,81 \% \\
-0,43 \mathrm{~dB}\end{array}$ \\
\hline & Impulso combinado & $\begin{array}{c}97,72 \% \\
-32,84 \mathrm{~dB}\end{array}$ \\
\hline \multirow{3}{*}{13} & Transitório elétrico rápido-Burst & $\begin{array}{c}95,33 \% \\
-26,61 \mathrm{~dB}\end{array}$ \\
\hline & Campo na frequência de $60 \mathrm{~Hz}$ & - \\
\hline & Impulso combinado & $\begin{array}{c}97,24 \% \\
-31,18 \mathrm{~dB}\end{array}$ \\
\hline \multirow{3}{*}{14} & Transitório elétrico rápido-Burst & $\begin{array}{c}95,20 \% \\
-26,38 \mathrm{~dB}\end{array}$ \\
\hline & Campo na frequência de $60 \mathrm{~Hz}$ & $\begin{array}{c}5,81 \% \\
-0,52 \mathrm{~dB}\end{array}$ \\
\hline & Impulso combinado & $\begin{array}{c}92,19 \% \\
-22,15 \mathrm{~dB}\end{array}$ \\
\hline \multirow{3}{*}{18} & Transitório elétrico rápido-Burst & $\begin{array}{c}99,90 \% \\
-60,00 \mathrm{~dB}\end{array}$ \\
\hline & Campo na frequência de $60 \mathrm{~Hz}$ & $\begin{array}{c}9,03 \% \\
-0,82 \mathrm{~dB}\end{array}$ \\
\hline & Impulso combinado & $\begin{array}{r}34,21 \% \\
-3,64 \mathrm{~dB}\end{array}$ \\
\hline
\end{tabular}




\subsection{Recomendações de Utilização dos Cabos Ensaiados}

Neste item serão propostas as possibilidades de utilização dos cabos ensaiados, propostas estas baseadas nos resultados obtidos.

- Amostra 10 - Cabo com vinte condutores de cobre isolados e sem blindagem.

Comentários: Este cabo é utilizado para comandos e controles, principalmente em subestações e deve ser instalado em local seco. Como é um cabo sem blindagem, a sua utilização deve-se restringir as situações sem interferências. Se usado de outra forma, esse cabo deve estar no interior de uma blindagem, do tipo eletroduto ou eletrocalha. Sua utilização fica restrita a sistemas de alimentação de equipamentos remotos dentro da subestação. Também pode ser utilizado para a aquisição de dados secundários, que não interfiram na operação da subestação, em um eventual surto de tensão.

- Amostra 17 - Cabo para rede de computadores - categoria 5 UTP.

Comentários: Este cabo é utilizado para rede de computadores, portanto, deve ser instalado no interior de eletroduto que servirá como blindagem. Para utilizá-lo sem a blindagem externa, deve-se tomar o cuidado de não instalá-lo próximo à parede externa dos edifícios e sempre na parte interna dos mesmos. Para ser utilizado no pátio das subestações, deve-se tomar muito cuidado, pois normalmente não se instalam dispositivos contra surtos de tensão junto aos equipamentos que utilizam este tipo de cabo. A instalação em eletrocalhas pode ser realizada, porém os níveis de emissão gerados por outros cabos nesta eletrocalha poderão comprometer o desempenho do mesmo, que será utilizado na transmissão de dados entre pontos distintos.

- Amostra 12 - Cabo com 20 condutores e blindagem de malha.

Comentários: Este cabo é normalmente utilizado em comando e controle e pode também ser utilizado em supervisão, proteção, sinalização e teleproteção. $\mathrm{O}$ mesmo não deve ser utilizado imerso em água nem diretamente enterrado no solo e raramente é utilizado em telecomunicações e informática. 
O cabo conta com o acréscimo de uma blindagem do tipo malha de cobre estanhada e este suplemento permite que o mesmo seja instalado em ambiente de subestação de forma segura, pois os níveis de interferências de alta frequência e ao impulso combinado são em média 96\% menores em comparação ao mesmo cabo sem blindagem.

- Amostra 13 - Cabo com 6 condutores e blindagem de fita.

Comentários: Este cabo é normalmente utilizado em comando e controle e pode também ser utilizado em supervisão, proteção, sinalização e teleproteção. Esse condutor não deve ser utilizado imerso em água nem diretamente enterrado no solo e raramente é utilizado em telecomunicações e informática.

Este condutor tem blindagem contínua do tipo fita de cobre e proporciona grande atenuação aos transitórios elétricos rápidos e ao impulso combinado. Portanto, o cabo é adequado ao uso em subestações, nas aplicações em que requerem a coleta de dados para a tomada de decisões do sistema.

- Amostra 14 - Cabo Telefônico com 100 pares blindado CI para uso interno.

Comentários: Este cabo é normalmente utilizado em sistemas de telecomunicações, supervisão e informática, em ambiente interno e seco. Não é um cabo para ser utilizado no pátio das subestações, pois não suporta campos magnéticos na frequência de $60 \mathrm{~Hz}$. Pode ser usado para sinalização, porém em baixa tensão $(50 \mathrm{~V})$ e em corrente continua.

- Amostra 18 - Cabo para rede de computadores - categoria 5 F/UTP.

Comentários: Este cabo é utilizado para rede de computadores e como possui blindagem pode ser utilizado em canaletas de PVC. Deve-se tomar o cuidado de não instalá-lo próximo à parede externa dos edifícios e sempre na parte interna dos mesmos. Este cabo para ser utilizado no pátio da subestação deve ser feito com muito cuidado, pois normalmente não se instala dispositivo contra surtos de tensão junto aos equipamentos que utilizam este tipo de cabo. Apresentam excelente eficiência $(99,9 \%)$ na atenuação de 
transitórios elétricos rápidos e boa eficiência na atenuação de impulso combinado. Essas características elétricas permitem que este cabo seja instalado em eletrocalhas externas, porém, como o mesmo não apresenta resistência mecânica apropriada, não sendo comumente utilizado externamente.

\subsection{Resumo das Recomendações de Instalação}

\subsubsection{Cabos sem Blindagem}

Os cabos sem blindagem estão sujeitos a toda e qualquer interferência eletromagnética, portanto, devem ser utilizados nos pátios das subestações com bastante reserva. Normalmente devem estar acondicionados em eletrodutos, eletrocalhas, que ofereçam uma blindagem parcial. Esses eletrodutos ou eletrocalhas devem estar aterrados, somente assim, fornecem uma blindagem mais eficiente. A Tabela 4.8 apresenta o resumo das recomendações técnicas para instalação e utilização de cabos sem blindagens, segundo os dados obtidos nos ensaios e na experiência do autor no setor energético. 
Tabela 4.8 Resumo das recomendações para utilização de cabos sem blindagem

\begin{tabular}{|c|c|c|}
\hline Amostra & Tipo de Cabo & Comentários \\
\hline 10 & $\begin{array}{l}\text { Cabo com } 20 \text { condutores } \\
\text { isolados sem blindagem }\end{array}$ & $\begin{array}{l}\text { 1 - Este cabo é normalmente utilizado na área } \\
\text { de comando e controle. Pode também ser } \\
\text { utilizado nos sistemas de supervisão, } \\
\text { proteção, sinalização e teleproteção. } \\
\text { Raramente é utilizado em telecomunicações e } \\
\text { informática. O cabo é muito utilizado no } \\
\text { interior de eletrodutos e canaletas, porém } \\
\text { nunca imerso em água. }\end{array}$ \\
\hline 17 & $\begin{array}{l}\text { Cabo para Rede de } \\
\text { Computadores } \\
\text { categoria } 5 \text { UPT }\end{array}$ & $\begin{array}{l}1 \text { - Este cabo é normalmente utilizado para } \\
\text { redes internas de computadores. O mesmo } \\
\text { não aceita umidade e pode ser utilizado em } \\
\text { telecomunicações, principalmente para } \\
\text { ligações dos ramais das centrais telefônicas. }\end{array}$ \\
\hline
\end{tabular}

\subsubsection{Cabos com Blindagem}

Os cabos com blindagem atendem melhor aos quesitos necessários para que sejam instalados no interior de uma subestação, mesmo assim, requerem cuidados especiais no aterramento das blindagens: dos cabos e dos eletrodutos ou eletrocalhas. A Tabela 4.9 apresenta um resumo das recomendações técnicas para instalação e utilização de cabos com blindagens, segundo os dados obtidos nos ensaios e na experiência do autor no setor energético. 
Tabela 4.9 Resumo das recomendações para utilização de cabos com blindagem

\begin{tabular}{|c|c|c|}
\hline Amostra & Tipo de Cabo & Comentários \\
\hline 12 & $\begin{array}{l}\text { Cabo com } 20 \text { condutores } \\
\text { e blindagem de malha }\end{array}$ & $\begin{array}{l}1 \text { - Este cabo é normalmente utilizado em } \\
\text { comando e controle. Pode também ser } \\
\text { utilizado em supervisão, proteção, sinalização } \\
\text { e teleproteção. Raramente é utilizado em } \\
\text { telecomunicações e informática; } \\
2 \text { - Susceptibilidade a campos magnéticos; } \\
3 \text { - Excelente imunidade à transitórios } \\
\text { elétricos rápidos (chaveamentos elétricos) e a } \\
\text { campos eletromagnéticos. }\end{array}$ \\
\hline 13 & $\begin{array}{l}\text { Cabo com } 6 \text { condutores e } \\
\text { blindagem de fita }\end{array}$ & $\begin{array}{l}\text { 1 - Cabo normalmente utilizado em comando } \\
\text { e controle. Pode também ser utilizado em } \\
\text { supervisão, proteção, sinalização e } \\
\text { teleproteção. Raramente é utilizado em } \\
\text { telecomunicações e informática. Esse } \\
\text { condutor não deve ser utilizado imerso em } \\
\text { água, nem diretamente enterrado no solo; } \\
2 \text { - Susceptibilidade à campos magnéticos; } \\
3 \text { - Excelente imunidade à transitórios } \\
\text { elétricos rápidos (chaveamentos elétricos) e a } \\
\text { campos eletromagnéticos. }\end{array}$ \\
\hline 14 & $\begin{array}{l}\text { Cabo Telefônico } 100 \\
\text { pares blindado CI }\end{array}$ & $\begin{array}{l}\text { 1 - Este cabo é normalmente utilizado em } \\
\text { sistemas de telecomunicações, em ambiente } \\
\text { interno e seco. O mesmo não deve ser } \\
\text { utilizado, mesmo no interior de eletrodutos, } \\
\text { enterrado no solo. O cabo pode ser utilizado } \\
\text { para a área de supervisão, informática e } \\
\text { sinalização, porém de preferência em baixa } \\
\text { tensão (até 50V - corrente contínua); } \\
2 \text { - O cabo é suscetível à campos magnéticos; } \\
3 \text { - Este cabo tem alta imunidade a } \\
\text { transitórios elétricos rápidos (chaveamentos } \\
\text { elétricos) e à campos eletromagnéticos. }\end{array}$ \\
\hline 18 & $\begin{array}{l}\text { Cabo de Rede de } \\
\text { Computadores - } \\
\text { categoria } 5 \text { F/UTP }\end{array}$ & $\begin{array}{l}1 \text { - Este cabo é normalmente utilizado para } \\
\text { redes internas de computadores e não aceita } \\
\text { umidade. O mesmo pode ser utilizado em } \\
\text { telecomunicações, principalmente para } \\
\text { ligações dos ramais das centrais telefônicas; } \\
2 \text { - O cabo é suscetível a campos magnéticos } \\
\text { e campos eletromagnéticos; } \\
3 \text { - O cabo tem alta imunidade a transitórios } \\
\text { elétricos rápidos (chaveamentos elétricos). }\end{array}$ \\
\hline
\end{tabular}




\section{Capítulo 5}

\section{Conclusões e Trabalhos Futuros}

\subsection{Conclusões Gerais}

A realização deste projeto de pesquisa possibilitou a análise preditiva do comportamento da imunidade eletromagnética dos cabos utilizados em subestações de alta tensão nas finalidades de supervisão, proteção, comunicação e controle. O resultando conduziu a uma análise da interferência eletromagnética para cada cabo, nas aplicações que se obtém o melhor desempenho da blindagem. Isto pode ser verificado analisando os dados apresentados no Capítulo 4 - Análise dos Resultados e Comentários, onde foi possível avaliar para cada cabo a aplicação que obtém o melhor desempenho da blindagem, de acordo com a sua aplicação em uma subestação de alta tensão.

O método para obtenção dos parâmetros de interferências por meio de ensaios laboratoriais mostrou-se altamente eficiente, auxiliando na etapa de análise de dados que resultou na caracterização de atenuação de sinais propagados do meio e refratados nos cabos. A modelagem e circuitos equivalentes para compatibilidade eletromagnética proposto por (DARNEY, 1977) e mostrado no Capítulo 3, permitiu a confirmação dos ensaios laboratoriais. Embora este modelo não tivesse aderência em todas as amostras de cabos ensaiados, o mesmo permitiu que os ensaios laboratoriais fossem realizados da forma que foi mostrado no Capítulo 3. Este modelo precisa de melhorias para atender aos cabos coaxiais mais complexos.

Como resultado foi possível a realização da análise de suscetibilidade e imunidade eletromagnética aos campos elétrico e magnético incidentes, culminando nas Tabelas $4.2 \mathrm{e}$ 4.3. Nota-se que tiveram bom desempenho em concordância com os ensaios realizados em laboratório, o cabo 10 (sem blindagem), e os cabos 14 e 18 (com blindagem), sendo, portanto os mais indicados para o uso em subestações. 
Os resultados obtidos neste trabalho auxiliarão os engenheiros das empresas de energia elétrica, a escolher e aplicar os cabos metálicos mais adequados, bem como, o tipo de blindagem que possa eliminar as interferências eletromagnéticas indesejáveis, que afetam os equipamentos eletrônicos dos sistemas de supervisão, comunicação, proteção, comando e controle. Tal análise auxiliará na redução dos efeitos eletromagnéticos indesejados nos sistemas responsáveis pela operação da subestação e, desta forma, melhores índices de qualidade de fornecimento de energia elétrica serão alcançados, por fim, ter-se-á um aumento da confiabilidade do sistema elétrico transmissor.

\subsection{Trabalhos Futuros}

Embora este trabalho tenha abordado o tema de compatibilidade eletromagnética em cabos utilizados em subestações de alta tensão, vale ressaltar que o assunto é bastante extenso e complexo. Desta forma, como trabalhos futuros sugere-se a realização de medições de EMI diretamente nos cabos de controle e comunicação instalados nos pátios das subestações e um estudo da influência dos sistemas (malhas) de aterramento na susceptibilidade eletromagnética desses cabos. 


\section{Referências Bibliográficas}

ARDJOMAND, L. M.; SILVA, N. M.; QUOIRIN, N. S. R.; ARAUJO, R. L.. Blindagem shielding mesh. In: XVIII SNPTEE - SEMINÁRIO NACIONAL DE PRODUÇÃO E TRANSMISSÃO DE ENERGIA ELÉTRICA, 2005, Curitiba. Blindagem shielding mesh. Curitiba: Cigre-Brasil. CD-ROM.

BARRACK, C. S.; SIEW, W. H.; PRYOR, B. M.. The measurement of fast transient electromagnetic interference within power system substations. In: 6TH INTERNATIONAL CONFERENCE DEVELOPMENTS POWER SYSTEM PROTECTION, 1997, EUA. The measurement of fast transient electromagnetic interference within power system substations. EUA: Inst. Elect. Eng. Conf. Publ., 1977. p. $270-273$.

CASTRO, F. C. C.; FRANCO, P. R. G.. Antenas. Departamento de Engenharia Elétrica, PUCRS. Disponível em: <http://www.ee.pucrs.br/ decastro/download.html>. Acesso em: 18 nov. 2009.

CHRISTOPOULOS, C.. Principles and techniques of electromagnetic compatibility. Nottingham, Inglaterra: CRC Press, 1995.

DARNEY, I.. CIRCUIT MODELING FOR ELECTROMAGNETIC COMPATIBILITY. EUA: Electronics \& Communication Engineering Journal, ago. 1997.

DIMCHEV, V.; HANDJISKI, B.; GAVROVSKI, C.; GRCEV, C.. Comparison of electromagnetic fields produced from overhead power transmission lines to distribution lines. In: EMC'98 Roma, 1998, Roma. Comparison of electromagnetic fields produced from overhead power transmission lines to distribution lines. Roma: Proceeding of International Symposium on Electromagnetic Compatibility, 1998. p. 133-138. 
EDMINISTER, J, A.. Theory and problems of electromagnetic. EUA: McGraw Hill, 1993.

GOESDBLOED, J.. Electromagnetic compatibility: Section 4.3: Capacitive crosstalk; Section 4.4: Inductive crosstalk. EUA: Prentice Hall, 1990.

GOODRICH, D. B.; WARFORD, J. S.. COMPUTER AIDED MAGNETIC FIELD CALCULATIONS FOR NONLINEAR SHIELDING MATERIALS. EUA: IEEE Transactions on Magnetics, 1973.

GREENWOOD, A.. Electrical transients in power systems. Nova York: John Wiley \& Sons, 1992.

GRIJP, M. H. B.; BORN, C.. ELECTROMAGNETIC COMPATIBILITY IN OPEN AIR SUBSTATIONS. EUA: IEEE Transactions on Magnetics, 1996.

HE, J.; BICHENG, M.; ZOU, J.; CHEN, S.. ELECTROMAGNETIC INTERFERENCE IN CONTROL CABLES OF SUBSTATION CAUSED BY SHORT CIRCUIT FAULT. EUA: IEEE Publication 0-7803-7459-2/02, 2002.

HERRING, J. L. Developments in the transmission line modeling method for electromagnetic compatibility studies. Tese (Doutorado), University of Nottingham, Nottingham, 1993.

KOUYOUMDJIAN, A.. A compatibilidade eletromagnética. São Paulo: Editora Artliber, 1998.

LEE, K. S. H.; BAUM, C.. APPLICATION OF MODAL ANALYSIS TO BRAIDED SHIELDED CABLES. EUA: IEEE Trans. on Electromagnetic Compatibility, 1975.

MARIN, P. S.. Cabeamento estruturado, desvendando cada passo do projeto à instalação. São Paulo: Editora Erica, 2008. 
NEKHOUL, B.. SHIELDING CHARACTERIZATION OF THE ELECTROMAGNETIC ENVIRONMENT OF AN ELECTRIC POWER NETWORK. EUA: IEEE Transactions on Magnetics, 2003.

PAVIÉ, A.; STIH, Z.. The Influence of cables on the electromagnetic fields around the power system substation. In: IEEE MELECON, 2004, Dubrovnik, Croatia. The Influence of cables on the electromagnetic fields around the power system substation. Croatia: IEEE Melcom publ., 2004.

RAO, M. M.; THOMAS, M. J.; SINGH, B. P.. Computational of EMI fields in a high voltage gas insulated substation during switching operations. In: IEEE INTERNATIONAL SYMPOSIUM ELECTROMAGNETIC COMPATIBILITY, 2003, EUA. Computational of EMI fields in a high voltage gas insulated substation during switching operations. EUA: Proc.IEEE Publ., 2003. p. 743-748.

SANCHES, D.. Interferência eletromagnética. Rio de Janeiro: Editora Interciência, 2003.

SKITEK,G. G.; MARSHALL, S. V.. Electromagnetic concepts and application. EUA: Prentice Hall, 1982.

SUGANYA, S.. Electromagnetic compatibility - definition and need. India: Robert Bosch, 2004.

THOMAS, D. E.; WIGGINS, C. M.; SALAS, T. M.; NICCKEL, F. S.; WRIGHT, S. E.. INDUCED TRANSIENTS IN SUBSTATION CABLES: MEASUREMENTS AND MODELS. EUA: IEEE Transactions on Power Delivery, out.1994.

WHITE, D. R. J.. A handbook series on electromagnetic interference and compatibility - EMI control methods and techniques, Volume II. Germantown, Maryland: Don White Consultants, 1973. 
WHITE, D. R. J.. A handbook series on electromagnetic interference and compatibility - EMI control methods and techniques, Volume III. Germantown, Maryland: Don White Consultants, 1973.

WHITE, D. R. J.. A handbook on electromagnetic shielding - materials and performance. Gainesville, Virginia: Don White Consultants, 1980.

WIGGINS, C. M.; THOMAS, D. E.; NICKEL, F. S.; WRIGHT, S. E.; SALAS, T. M.. TRANSIENT ELECTROMAGNETIC INTERFERENCE IN SUBSTATION. EUA: IEEE Transactions on Power Delivery, Vol. 9, out. 1994.

ANSI C63.14-1998. American National Standard Dictionary for Technologies of Electromagnetic Compatibility (EMC), Electromagnetic Pulse (EMP), and Electrostatic Discharge (ESD).

IEC 61000-4-4-1995. Electromagnetic Compatibility (EMC) - Part 4-4: Testing and Measurement Techniques - Electrical fast transient/burst immunity test.

IEC 61000-4-5-1995. Electromagnetic Compatibility (EMC) - Part 4-5: Testing and Measurement Techniques - Surge immunity test.

IEC 61312-1. Protection against lightning electromagnetic impulses, Part 1 - General principles, Ed. 1995.

EIA/TIA 568-1991. Electronic Industries Association / Telecommunications Industry Association, Commercial Building Telecommunications Wiring Standard.

NBR10484-1988. Cabo telefônico CCE-APL isolado com polietileno ou polipropileno, protegido por capa APL, Especificação Técnica.

NBR10488-2001 Cabo telefônico com condutores estanhados, isolados com termoplástico e com núcleo protegido por capa APL, Especificação Técnica. 
NBR10497-1991. Cabo telefônico CCE isolado com polietileno ou propileno, com revestimento interno de polietileno ou copolímero, blindado com fita de cobre e revestimento externo de polietileno ou copolímero, Especificação Técnica.

NBR10500-1988. Cabo telefônico CTP-APL-GE isolado com polietileno ou polipropileno protegido por capa APL, Especificação Técnica.

NBR10501-2001. Cabo telefônico blindado para redes internas, Especificação Técnica.

NBR11880-2000. Cabo telefônico isolado com termoplástico expandido, núcleo preenchido com geléia e protegido por capa APL, Especificação Técnica.

NBR14607-2000. Cabo telefônico isolado com termoplástico expandido e núcleo protegido por capa APL, Especificação Técnica.

NBR9124-1999. Cabo telefônico isolado com termoplástico e núcleo protegido por capa APL, Especificação Técnica.

NBR9886-2005. Cabo telefônico interno CCI, Especificação Técnica.

Catálogo Divisão Cabos Pirelli. Fios e Cabos para Telefonia e Telecomunicações, 1980.

Catálogo Prysmian Cables \& Systems. Fios e Cabos para Telefonia e Telecomunicações, 2008. 